UNIVERSIDADE DE SÃO PAULO

FACULDADE DE FILOSOFIA, CIÊNCIAS E LETRAS DE RIBEIRÃO PRETO PROGRAMA DE PÓS-GRADUAÇÃO EM PSICOBIOLOGIA

DEPARTAMENTO DE PSICOLOGIA

\author{
PATRÍCIA CONSOLO
}

PERCURSOS DE DISTÂNCIAS E ORIENTAÇÕES ESPACIAIS AO CAMINHAR COM VISÃO OCLUIIDA EM CAMPO ABERTO

Versão Corrigida

Ribeirão Preto 


\title{
PATRICIA CONSOLO
}

\section{PERCURSOS DE DISTÂNCIAS E ORIENTAÇÕES ESPACIAIS AO CAMINHAR COM VISÃO OCLUIIDA EM CAMPO ABERTO}

\author{
Tese apresentada à Faculdade de Filosofia, \\ Ciências e Letras de Ribeirão Preto - USP, como \\ parte das exigências para a obtenção do título de \\ Doutor em Ciências.
}

Área de Concentração: Psicobiologia.

Orientador: Prof.Dr. Sérgio Sheiji Fukusima

Ribeirão Preto 
AUTORIZO A DIVULGAÇÃO TOTAL OU PARCIAL DA PRESENTE OBRA, POR QUALQUER MEIO CONVENCIONAL OU ELETRÔNICO, DESDE QUE CITADA A FONTE.

Ficha catalográfica

Consolo, Patrícia

Percursos de distâncias e orientações espaciais ao caminhar com visão ocluída em campo aberto. Ribeirão Preto, 2015.

79p.: il.; $30 \mathrm{~cm}$

Tese apresentada à Faculdade de Filosofia, Ciências e Letras de Ribeirão Preto/USP- Departamento de Psicologia. Área: Psicobiologia.

Orientador: Prof. Dr. Sérgio Sheiji Fukusima

1. Percepção espacial 2. Distância egocêntrica 3. Espaço vista 
FOLHA DE APROVAÇÃO

Nome: Patrícia Consolo

Título: Percursos de distâncias e orientações espaciais ao caminhar com visão ocluída em campo aberto.

Tese apresentada à Faculdade de Filosofia, Ciências e Letras de Ribeirão Preto - USP, como parte das exigências para a obtenção do título de Doutor em Ciências. Área: Psicobiologia.

Aprovado em:

Banca examinadora

Prof. Dr. Sérgio Sheiji Fukusima (orientador)

Instituição: FFCLRP - Universidade de São Paulo. Assinatura:

Prof. Dr.

Instituição

Assinatura

Prof. Dr.

Instituição

Assinatura

Prof. Dr.

Instituição

Assinatura

Prof. Dr.

Instituição Assinatura 
Para meus filhos Humberto, Isadora e Isabella. 


\section{AGRADECIMENTOS}

Ao meu orientador e professor Sérgio Sheiji Fukusima pela recepção, apoio e atenção ao longo desta pós-graduação.

Aos professores do programa pelas valorosas contribuições.

À amiga Renata Vicentini pela disponibilidade em escutar e dar orientações às dúvidas surgidas durante o doutorado e por ter tido sempre uma palavra de incentivo nos momentos de maior desalento.

À amiga Amélia pelas revisões dos textos e pelo inestimável suporte ao longo deste período.

Aos colegas do Laboratório de Psicofísica e Percepção: Rui, Bruno, Leonardo, Lina, Cris, Luciana, Nelson, Lívia, Elisa, Arthur e Gabriel pela amizade e troca de experiências.

Ao técnico Igor, pela competência e ajuda nos quesitos relativos à informática.

A Regina Teles, Denise, Inês, Fabiana e César pela atenção e disposição no atendimento de minhas solicitações.

Ao meu filho e amigo Humberto pela ajuda incontestável nos quesitos relativos à matemática e contribuições para o aperfeiçoamento desta tarefa.

Aos meus pais, Lamartini e Sari (in memoriam), pela força e apoio que me proporcionaram ao longo desta jornada.

Ao Centro Universitário Moura Lacerda pela sessão do espaço experimental para a realização do estudo. 
Ao engenheiro Jonas Ribeiro e aos técnicos da Santiago e Cintra- GeoTecnologias pelo treinamento e auxilio no uso do receptor GPS.

À amiga Tania que permaneceu ao meu lado em todos os momentos e fez parte dessa minha formação.

A CAPES pela concessão da bolsa para a realização do Doutorado. 


\section{RESUMO}

Consolo, P. Percursos de distâncias e orientações espaciais ao caminhar com visão ocluída em campo aberto. 2015. 79f. Tese (Doutorado). Faculdade de Filosofia, Ciências e Letras de Ribeirão Preto, Universidade de São Paulo, São Paulo, 2015.

Embora a estimação de distância tenha sido extensivamente estudada, a habilidade de humanos julgarem distâncias maiores do que $30 \mathrm{~m}$ tem sido pouco investigada. O objetivo deste trabalho foi avaliar o desempenho de voluntários em tarefas envolvendo o julgamento de distância e de orientação espacial pelo indicativo de resposta do caminhar com a visão ocluída em distâncias de 30,00; 41,60; 57,69 e 80,00 metros, em um ambiente amplo e natural. Para tanto, trinta e cinco voluntários de ambos os sexos, com idades ente 18 e 35 anos foram divididos aleatoriamente em três tarefas experimentais. A primeira tarefa consistiu em caminhar diretamente a um alvo, com a visão ocluída, após vê-lo brevemente. A segunda tarefa consistiu em caminhar vidente até um alvo, e subsequentemente realizar um giro de $180^{\circ}$ e retornar sozinho, com a visão ocluída, à origem do percurso. A terceira tarefa foi similar à segunda, mas com uma diferença, o participante caminhou por distâncias com a visão ocluída, pelo guiar de um condutor, e ao final da caminhada subsequentemente, girou e retornou sozinho à origem do percurso. Em todas as tarefas experimentais, a distância caminhada (em metros) e o tempo (em segundos) de cada trajetória na fase de resposta, foram coletados e registrados utilizando um receptor de Sistema de Posição Global (GPS). Após a medição do movimento, os dados extraídos do GPS foram pós-processados e as coordenadas de todas as grandezas físicas de cada sujeito foram calculadas, a saber, a distância percorrida (metros), a velocidade (metros por segundo), o desvio angular (graus), e para o caso da trajetória circular, a velocidade angular média (radianos por segundo) e o raio da trajetória circular teórica (metros). Independente da tarefa, a observação das trajetórias produzidas pelos participantes demonstrou que os desvios de direção apresentavam padrões geométricos bem definidos (reta, circular, reta-circular, reta-reta e alternada), e os padrões reta e circular foram os mais frequentes. Em todas as tarefas, a análise das distâncias caminhadas mostrou uma tendência à subconstância perceptiva por conta do valor do expoente psicofísico abaixo de 1,0. Entretanto, esta tendência foi mais acentuada na resposta de retornar a um ponto de origem após deslocamento com os participantes sob completa privação visual sem prévisualização do alvo. Nossos resultados sugerem que os padrões das trajetórias e a acurácia das distâncias produzidas dependem da amplitude da distância, do ambiente experimental onde as distâncias foram estimadas e da disponibilidade de indícios perceptuais presentes na tarefa experimental.

Palavras chaves: percepção espacial; distância egocêntrica; espaço vista 


\begin{abstract}
Consolo, P. Routes of distances and spatial orientation in blindfolded humans walking in an open-field. 2015. 79f. Doctorate's thesis. Faculdade de Filosofia, Ciências e Letras de Ribeirão Preto, Universidade de São Paulo, São Paulo.

Although distance estimation has been extensively studied, the human ability to judge distances greater than $30.00 \mathrm{~m}$ has been understudied. The objective of this work was to evaluate and analyze the performance of volunteers in tasks involving the judgment of distance and spatial orientation by the response of walking with occluded vision 30.00, 41.60, 57.69 and 80.00-meter distances. For this purpose, thirty-five volunteers of both genders, aged between 18 and 35 years were invited to participate in three experimental tasks in a natural and open field. For this purpose, thirty-five volunteers aged between 18 and 35 years of both genders were invited to participate in three experimental tasks in a natural and open field. The first task consisted of walking blindfolded directly towards a target, after seeing it briefly. The second task consisted in sighted walking until the target, and after that he or she rotated $180^{\circ}$ and returned alone with the blinded vision to the origin of the trajectory. Finally the third task was similar to the second, but with the difference that the subject walked with the occluded vision in a straight lines distances, led by the experimenter, and subsequently, to turn and returning to the origin of the route alone. In all experimental tasks, the walked distance (in meters) and the time (in seconds) of each trajectory over the distance phase were collected and registered using a Global System Position receiver (GPS). After the measurement of the movement, the data obtained from the GPS were processed, the coordinators of the movement were determined, and the physical quantities of each subject were calculated, namely the walked distance (meters), the velocity (meters per seconds), the angular deviance (degrees), and only for the circular trajectory, the mean angular velocity (radians per seconds) and the mean radius of the theoretical circular trajectory (meters). The observation of the trajectories demonstrated that the direction deviances showed well-defined geometrical patterns (straight, circular, straight-circular, straight-straight and alternate), and the straight and circular patterns were the most frequent ones. Our results suggest that both trajectory patterns and the accuracy of the participant's walked distances depend on the amplitude of the distance, the experimental environment in which distances were estimated, and the availability of perceptual evidence of distance present in the experimental task.
\end{abstract}

Keywords: spatial perception; egocentric distance; vista space 


\section{LISTA DE ILUSTRAÇÕES}

Figura 1. Representação esquemática dos procedimentos das três tarefas de produção de distâncias pelo indicativo de resposta do caminhar com a visão ocluída: (A) produção de distâncias a um alvo visualmente percebido (V) Fase de estímulo: o participante observa diretamente a sua frente, um alvo posicionando a uma determinada distância. Fase de resposta: o participante é solicitado a caminhar vendado até o local onde ele julga que o alvo está localizado. (B) reprodução de distâncias caminhada sob condições visuais (Lv). Fase de estímulo: o participante caminha vidente até um alvo, diretamente posicionado a sua frente, a uma determinada distância. Fase de resposta: ao alcançar o alvo, o participante é vendado, realiza um giro de corpo de $180^{\circ}$, e retornar ao ponto de origem $(\mathrm{O})$, tentando reproduzir a distância percorrida na fase de estímulo. (C) reprodução de distância caminhada não visual (L). Fase de estímulo: o participante é conduzido pelo guiar do pesquisador em linha reta (segurando seu antebraço) do ponto de origem por uma determinada distância. Fase de resposta: ao final da caminhada, o participante realiza um giro de corpo de $180^{\circ}$, e retorna ao ponto de origem (O), tentando reproduzir a distância percorrida na fase de estímulo.

Figura 2. Interpretação geométrica do desvio angular.

Figura 3. Trajetórias realizadas pelos participantes dentro da área experimental, durante o caminhar não visual ao alvo de $30,00 \mathrm{~m}$ na tarefa $\mathrm{V}$.

Figura 4. Trajetórias realizadas pelos participantes dentro da área experimental, durante o caminhar não visual ao alvo de 41,60 m na tarefa $\mathrm{V}$.

Figura 5. Trajetórias realizadas pelos participantes dentro da área experimental, durante o caminhar não visual ao alvo de $57,69 \mathrm{~m}$ na tarefa $\mathrm{V}$.

Figura 6. Trajetórias realizadas pelos participantes dentro da área experimental, durante o caminhar não visual ao alvo de $80,00 \mathrm{~m}$ na tarefa $\mathrm{V}$.

Figura 7. Trajetórias realizadas pelos participantes dentro da área experimental, durante o caminhar não visual no retorno à origem para a distância de $30 \mathrm{~m}$ na tarefa Lv.

Figura 8. Trajetórias realizadas pelos participantes dentro da área experimental, durante o caminhar não visual no retorno à origem para a distância de $41,60 \mathrm{~m}$ na tarefa $\mathrm{Lv}$.

Figura 9. Trajetórias realizadas pelos participantes dentro da área experimental, durante o caminhar não visual no retorno à origem para a distância de 57,69m na tarefa Lv. 
Figura 10. Trajetórias realizadas pelos participantes dentro da área experimental, durante o caminhar não visual no retorno à origem para a distância de $80 \mathrm{~m}$ na tarefa $\mathrm{Lv}$

Figura 11. Trajetórias realizadas pelos participantes dentro da área experimental, durante o caminhar não visual no retorno à origem para a distância de $30 \mathrm{~m}$ na tarefa $\mathrm{L}$

Figura 12. Trajetórias realizadas pelos participantes dentro da área experimental, durante o caminhar não visual no retorno à origem para a distância de $41,60 \mathrm{~m}$ na tarefa $\mathrm{L}$

Figura 13. Trajetórias realizadas pelos participantes dentro da área experimental, durante o caminhar não visual no retorno à origem para a distância de $57,69 \mathrm{~m}$ na tarefa $\mathrm{L}$

Figura 14. Trajetórias realizadas pelos participantes dentro da área experimental, durante o caminhar não visual no retorno à origem para a distância de $80 \mathrm{~m}$ na tarefa $\mathrm{L}$

Figura 15. Exemplo das trajetórias observadas e suas diferentes classificações. No sistema de referência das tarefas $\mathrm{V}, \mathrm{LV}$ e $\mathrm{L}$, a direção horizontal é paralela às traves do campo e a direção vertical é perpendicular a elas. A origem está localizada na marca do pênalti.

Figura 16. Pontuação dos desvios de orientação. Os resultados são expressos em termos de taxa de desvios para todos os participantes da tarefa $\mathrm{V}$.

Figura 17. Pontuação dos desvios de orientação. Os resultados são expressos em termos de taxa de desvios para todos os participantes da tarefa Lv..........

Figura 18. Pontuação dos desvios de orientação. Os resultados são expressos em termos de taxa de desvios para todos os participantes da tarefa $\mathrm{L}$

Figura 19. Exemplo do comportamento observado da velocidade angular (m/s) com relação ao tempo para um dos sujeitos no experimento $\mathrm{V}$

Figura 20. Médias das distâncias caminhadas e respectivos desvios-padrão dos participantes do estudo em função das distâncias físicas de 30,00; 41,60; 57,69 e 80,00 m para a tarefa V, tarefa Lv e tarefa L (em valores absolutos). A linha diagonal indica acurácia perfeita 


\section{LISTA DE TABELAS}

Tabela 1. Padrões das trajetórias da Tarefa V. Porcentagem (\%) das trajetórias observadas (reta, reta-circular, circular, alternada, e reta-reta) em função das distâncias de apresentação do alvo de 30,00; 41,60; 57,69 e $80,00 \mathrm{~m}$.

Tabela 2. Padrões das trajetórias da Tarefa Lv. Porcentagem (\%) das trajetórias observadas (reta, reta-circular, circular, alternada, e reta-reta) em função das distâncias de apresentação do alvo de 30,00; 41,60; 57,69 e $80,00 \mathrm{~m}$

Tabela 3. Padrões das trajetórias da Tarefa L. Porcentagem (\%) das trajetórias observadas (reta, reta-circular, circular, alternada, e reta-reta) em função das distâncias de 30,00; 41,60; 57,69 e 80,00 m.

Tabela 4. Valores médios e respectivos desvios-padrão $( \pm \mathrm{dp})$ do deslocamento $(m)$, da distância percorrida $(m)$, velocidade $\left(v_{m}\right)$, desvio angular $\left(\alpha_{m}\right)$, velocidade angular $\left(\dot{\psi}_{m}\right)$, e raio $\left(R_{m}\right)$ das trajetórias circulares dos participantes da tarefa $\mathrm{V}$, em função das distâncias de apresentação do alvo de 30,00; 41,60; 57,69 e 80,00 metros.

Tabela 5. Valores médios e respectivos desvios-padrão $( \pm \mathrm{dp})$ do deslocamento(m), da distância percorrida $(m)$, velocidade $\left(v_{m}\right)$, desvio angular $\left(\alpha_{\mathrm{m}}\right)$, velocidade angular $\left(\dot{\psi}_{\mathrm{m}}\right)$, e raio $\left(\mathrm{R}_{\mathrm{m}}\right)$ das trajetórias circulares dos participantes da tarefa $\mathrm{Lv}$, em função das distâncias de apresentação do alvo de 30,00; 41,60; 57,69 e 80,00 metros.

Tabela 6. Valores médios e respectivos desvios-padrão ( \pm dp) do deslocamento $(\mathrm{m})$, da distância percorrida $(\mathrm{m})$, velocidade $\left(\mathrm{v}_{\mathrm{m}}\right)$, desvio angular $\left(\alpha_{\mathrm{m}}\right)$, velocidade angular $\left(\dot{\psi}_{\mathrm{m}}\right)$, e raio $\left(\mathrm{R}_{\mathrm{m}}\right)$ das trajetórias circulares dos participantes da tarefa $\mathrm{L}$, em função das distâncias de 30,00; 41,60; 57,69 e 80,00 metros.

Tabela 7. Teste $\mathrm{t}$ de Student para amostras emparelhadas para comparação entre as médias da velocidade do caminhar entre a condição experimental e controle para as tarefas: (A) produção de distâncias a um alvo visualmente percebido, (B) reprodução de distâncias caminhada sob condições visuais, e, (C) reprodução de distâncias após o caminhar não visual em função das distâncias testadas $(30,00$; 41,$60 ; 57,69$ e 80,00 metros). 
Tabela 8. Erro médio de $\mu$ entre as coordenadas do ponto da trajetória circular teórico e um ponto da trajetória real e o desvio padrão correspondente significa $\sigma$ como uma função das distancias de 30,00; 41,60; 57,69 e $80,00 \mathrm{~m}$.

Tabela 9. Valores médios e respectivos desvios-padrão (dp) do deslocamento(m); da distância percorrida $(m)$, da velocidade $\left(\mathbf{v}_{\mathbf{m}}\right)$ e do desvio angular $\left(\boldsymbol{\alpha}_{\mathbf{m}}\right)$ das trajetórias reta, reta-circular, reta-reta e alternada dos participantes da tarefa $\mathrm{V}$ em função das distâncias de apresentação do alvo de 30,$00 ; 41,60 ; 57,69$ e 80,00 metros.

Tabela 10. Valores médios e respectivos desvios-padrão (dp) do deslocamento(m); da distância percorrida $(m)$, da velocidade $\left(\mathbf{v}_{\mathbf{m}}\right)$ e do desvio angular $\left(\boldsymbol{\alpha}_{\mathbf{m}}\right)$ das trajetórias reta, reta-circular, reta-reta e alternada dos participantes da tarefa Lv em função das distâncias de 30,$00 ; 41,60 ; 57,69$ e 80,00 metros.

Tabela 11. Valores médios e respectivos desvios-padrão (dp) do deslocamento(m); da distância percorrida $(\mathrm{m})$, da velocidade $\left(\mathbf{v}_{\mathbf{m}}\right)$ e do desvio angular $\left(\boldsymbol{\alpha}_{\mathbf{m}}\right)$ das trajetórias reta, reta-circular, reta-reta e alternada dos participantes da tarefa L em função das distâncias de 30,$00 ; 41,60 ; 57,69$ e 80,00 metros.

Tabela 12. Teste $t$ de Student para amostras emparelhadas para comparação entre as médias da velocidade do caminhar entre a condição experimental e controle para as tarefas: (A) produção de distâncias a um alvo visualmente percebido, (B) reprodução de distâncias após o caminhar sob condições visuais a tarefa de reprodução de distâncias após o caminhar não visual, e, (C) reprodução de distâncias após o caminhar não visual em função das distâncias testadas $(30,00 ; 41,60$; 57,69 e 80,00 metros).

Tabela 13. Valores médios e respectivos desvios-padrão $( \pm d p)$ do expoente (n), constante escalar $(\mathrm{k})$ e coeficiente de determinação $\left(\mathrm{r}^{2}\right)$ para os participantes nas tarefas $\mathrm{V}, \mathrm{LV}$ e $\mathrm{L}$

Tabela 14. Valores médios e respectivos desvios-padrão ( \pm dp) para o erro relativo dos julgamentos de distância (distância percorrida) em função das distâncias físicas de 30,00; 41,60; 57,69 e 80,00 metros nas tarefas experimentais $\mathrm{V}, \mathrm{Lv}$ e $\mathrm{L}$ 


\section{SUMÁRIO}

\section{INTRODUÇÃO}

1.1. Tarefas utilizadas para avaliar a contribuição de indícios visuais e não visuais na estimação de distância.

1.1.1 A informação visual em ambientes em que o observador permanece em uma posição estática em relação ao que está sendo observado.

1.1.2 A informação não visual em relação à distância percorrida

1.1.3 Tarefas de ação visualmente dirigida.

1.1.4 Tarefas para avaliar as contribuições do fluxo óptico.

1.2. A orientação espacial e o comportamento de veering.

1.3. O espaço de ação e o espaço vista.

2. MÉTODO.

2.1. Participantes

2.2. Espaço Experimental

2.3. Materiais.

2.4. Procedimento.

2.5. Registro do Movimento

2.6. Transformação das coordenadas

3. RESULTADOS: DESVIOS DE ORIENTAÇÃO.

3.1. Análise estatística.

3.2. Análise dos padrões das trajetórias.

3.3. Preferência lateral

3.4.Análise da Trajetória Circular.

3.5 Análise das trajetórias reta, reta-circular, alternada e reta-reta.

3.6. Discussão

3.6.1 Frequências dos padrões das trajetórias e o desempenho na tarefa de caminhada...

3.6.2. Velocidade angular e o padrão das trajetórias. 


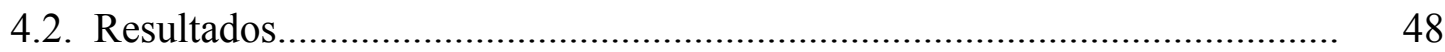

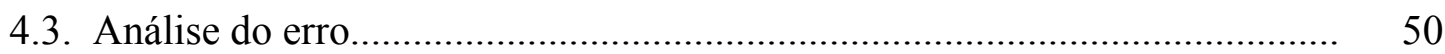

4.4. Discussão....................................................................................... 51

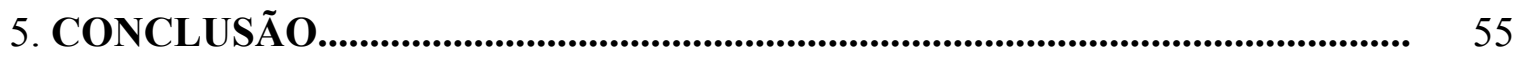

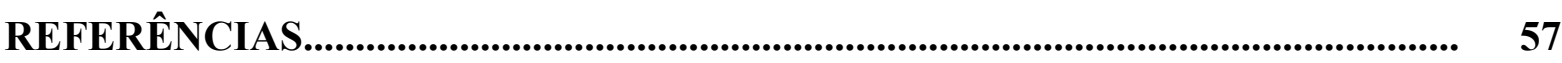

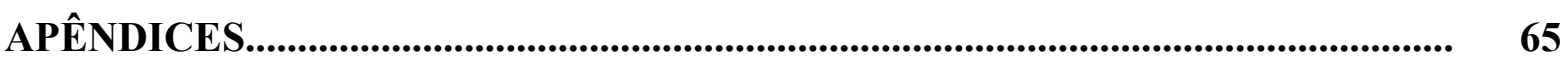

APÊNDICE A - Instruções das Tarefas Experimentais.............................................. 65

APÊNDICE B - Modelo matemático para trajetórias circulares................................... 68

APÊNDICE C - Artigo apresentado no exame de qualificação e publicado na revista Psychology \& Neuroscience................................................................................. 69

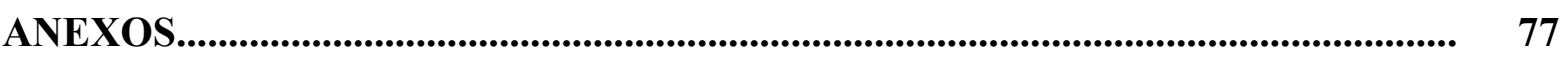

ANEXO A - Aprovação do Comitê de Ética em Pesquisa da FFCLRP-USP............... 77

ANEXO B - Inventário de Dominância Lateral de Edinburgh...................................... 78

ANEXO C - Questionário de preferência lateral podal................................................ 79 


\section{INTRODUÇÃO}

A navegação espacial é o processo de determinar e manter uma trajetória de um lugar a outro (Gallistel, 1990). A habilidade de navegar com precisão no ambiente depende de representações neurais de localização e direção, bem como do monitoramento contínuo da distância percorrida. É bem conhecido que as informações visuais externas (alotéticas) controlam predominantemente essas representações, no entanto os indícios gerados pelo próprio movimento (idiotéticos) podem assumir o controle quando pistas visuais familiares não estão disponíveis no ambiente ao observador (Yoder \& Taube, 2014).

$\mathrm{Na}$ literatura a distância egocêntrica, a distância de um observador a um objeto, é diferenciada da distância exocêntrica, a distância entre dois objetos, ou partes de um objeto. A informação de distância egocêntrica pode ser fornecida por uma variedade de indícios visuais estáticos e dinâmicos. Os indícios visuais estáticos podem incluir a acomodação, a convergência, a disparidade binocular, o tamanho relativo e o tamanho familiar. Outros indícios são dados pelo movimento, ou seja, derivam do movimento de textura ou de fluxo óptico quando o observador se move no espaço. Estes indícios são dados pela forma com que a textura muda em função do tempo, ou quando o observador, ou o mundo, se move. Quando as texturas se comprimem, cobrem menos área e aumentam em densidade, e os objetos associados a elas distanciam-se mais (Da-Silva, Aznar-Casanova, Pinto-Ribeiro Filho, \& Santillán, 2006).

Nas tarefas cotidianas o cérebro integra diversos indícios visuais a cerca da geometria tridimensional dos objetos para gerar comandos motores apropriados. Pesquisas perceptuais recentes demonstram que os observadores humanos fazem julgamentos em relação ao tamanho, a forma e a orientação de um objeto de modo próximo ao estatisticamente ideal (Hillis, Watt, Landy, \& Banks, 2004; Saunders \& Knill, 2001).

A informação de distância também se encontra disponível por meio de indícios não visuais, que são gerados internamente como consequência do próprio movimento do corpo no espaço (Mittlestadt \& Mittlestadt, 2001). Esta fonte de informação, frequentemente citada como informação idiotética, é fornecida por indicadores proprioceptivos (articulações, músculos, tendões), sinais eferentes motores e pela informação do sistema vestibular gerada como resultado de mudanças na velocidade dos movimentos lineares e rotacionais (Glausauer, Amorim, Viaud-Delmon, \& Berthoz, 2002). 
Apesar da percepção da distância possuir alguns componentes observáveis, tais como o movimento de vergência ocular, a maioria dos processos é interna ao observador, e não podem ser diretamente observados ou medidos. Por conseguinte, para determinar quão bem os seres humanos podem perceber a distância egocêntrica, um grande número de métodos de mensuração tem sido desenvolvido. Sumariamente, existem três categorias de tais métodos: as estimativas verbais, o emparelhamento perceptual e as ações visualmente dirigidas (Renner, Velichkovsky, \& Helmert, 2013).

Ademais, os pesquisadores desta temática usam tarefas que envolvem duas fases, ou seja, uma fase de estímulo e outra de resposta. Comumente os métodos utilizados para avaliar a contribuição de indícios específicos de distância envolvem a manipulação das condições visuais ou de outro sistema de percepção em cada uma destas fases. A informação de distância em cada fase poderia incluir a informação visual estática entre o observador e um alvo e/ou a informação obtida pelo próprio movimento durante a distância caminhada (Sun, Campos, Young, Chan, \& Ellard, 2004).

\subsection{Tarefas utilizadas para avaliar a contribuição de indícios visuais e não visuais na estimação de distância}

\subsubsection{A informação visual em ambientes em que o observador permanece numa posição estática em relação ao que esta sendo observado.}

Inúmeros estudos sobre percepção de distância utilizam uma perspectiva estática para a medição dos sistemas sensoriais. As investigações nesta área abrangem tanto estudos realizados em laboratório envolvendo a manipulação da disponibilidade de indícios visuais (Gogel, 1990), como em ambientes naturais com indícios completos de distância (Da-Silva, 1985). Por exemplo, os métodos envolvendo dimensões escalares, tais como: estimação de magnitude, produção de magnitude e fracionamento têm demonstrado que a percepção de distância é linearmente relacionada à distância física. Além disso, a acurácia perceptiva nos julgamentos parece depender do paradigma psicofísico utilizado e a amplitude das distâncias testadas (Da-Silva, 1985). 


\subsubsection{A informação não visual em relação à distância percorrida}

Mais recentemente, o interesse das pesquisas tem focado na contribuição da informação sensorial não visual nos julgamentos de distância para testar a coerência e a importância dos sistemas perceptivos que complementam a função visual. Por exemplo, uma abordagem frequente requer que os participantes vendados caminhem por uma determinada distância e, em seguida, reproduzam a distância percorrida ao novamente caminharem vendados (Bigel \& Ellard, 2000; Klatzky et al., 1990; Mittelstaed \& Mittelstaed, 2001). Estudos similares conduzidos em laboratório analisaram aspectos específicos da informação não visual por seletivamente manipular indícios particulares. Por exemplo, estudos anteriores demonstraram que a distância aprendida através da informação vestibular gerada através do movimento passivo foi acuradamente reproduzida quando os participantes foram solicitados a responder usando os mesmos indícios vestibulares (Berthoz, Israël, Georges-François, Grasso, \& Tsuzuku, 1995; Harris, Jenkin \& Zikovitz, 2000; Israël, Grasso, Georges-Francois, Tsuzuku, \& Berthoz, 1997). É importante ressaltar que em alguns desses estudos os movimentos dos participantes foram completamente passivos (Harris, Jenkin, \& Zikovitz, 2000) enquanto que em outros os participantes controlaram o próprio movimento sem produzir os movimentos das pernas, ou seja, através de um joystick (Berthoz et al.,1995; Israël et al., 1997).

\subsubsection{Tarefas de ação visualmente dirigida}

Uma das mais influentes abordagens usadas para examinar a habilidade de humanos para processar a informação de distância é a tarefa envolvendo o caminhar visualmente dirigido. O caminhar sem-visão (i.e. o caminhar com a visão-oclusa) em direção a um objeto é um exemplo típico deste comportamento. Nesta tarefa, o participante vê um alvo dentro do seu ambiente imediato. Quando pronto, ele é instruído a colocar uma venda sobre os olhos, e em seguida caminhar às cegas diretamente à localização previamente visualizada. A resposta ou a distância caminhada é usada como um indicador da distância inicialmente percebida do alvo e reflete sua percepção da localização do alvo. A distância caminhada é comparada com a distância real ou física para determinar a acurácia global do desempenho (Da-Silva et al., 2006). 
Os resultados dos experimentos envolvendo o caminhar visualmente dirigido têm mostrado desempenho acurado dos participantes para distâncias de até 25 metros (Loomis \& Philbeck, 2008). No entanto, existe uma tendência dos indivíduos para subestimar a magnitude da distância, ou seja, encerrarem o deslocamento antes do ponto final com o aumento da distância do alvo (Andre \& Rogers, 2006; Fukusima, Loomis, \& Da-Silva, 1997). Supõe-se que, durante a tarefa, os participantes inicialmente codifiquem sua posição em relação ao alvo por avaliar os indícios de distância visuais estáticos e, subsequentemente, usem esta representação para executar apropriadamente a resposta motora escalonada. Durante a locomoção tanto a informação eferente como a proprioceptiva, são usadas para monitorar a distância enquanto esta é percorrida. Ao mesmo tempo esses indícios também são usados para atualizar a representação interna da localização do alvo (Rieser, Ashmead, Taylor, \& Youngquist, 1990). Geralmente os erros produzidos nesta tarefa poderiam ter origem no processamento da informação visual, no processamento da informação motora e/ou no processo de calibração visomotora.

\subsubsection{Tarefas para avaliar as contribuições do fluxo óptico}

$\mathrm{Na}$ tarefa descrita anteriormente, os participantes são solicitados a caminhar uma distância na ausência da informação visual. Tal tarefa é um valioso instrumento para isolar a contribuição produzida pela informação idiotética para o processo da coordenação visomotora (Sun, Campos, Young, Chan, \& Ellard, 2004). No entanto, esta tarefa é diferente do caminhar natural, no qual a informação do fluxo óptico é normalmente disponibilizada em combinação com a informação visual estática e a informação idiotética.

Nas ultimas décadas, numerosos estudos investigaram o papel do fluxo óptico no movimento visual, no controle da postura e na locomoção (Gibson, 1950; Lappe, 2000; Warren \& Wertheim, 1990). Estas pesquisas empregaram testes que envolvem a estimulação visual do movimento sem os correspondentes indícios locomotores, consequentemente avaliando o fluxo óptico em separado.

Durante a navegação pelo ambiente, o fluxo óptico pode especificar a velocidade e a magnitude do movimento como um todo (Larish \& Flach, 1990). Bremmer e Lappe (1999) demonstraram em estudos que indivíduos saudáveis, quando apresentados unicamente com a informação do fluxo óptico simulado em computador, foram capazes de reproduzir e discriminar as distâncias percorridas. 
Todavia, a integração entre os indícios não visuais e o fluxo óptico tem sido pouco explorada. Essas investigações incluíram tarefas envolvendo a reprodução de um deslocamento angular (Lambrey, Viaud-Delmon \& Berthoz, 2002), a manutenção da velocidade durante o caminhar em uma esteira ergométrica (Varraine, Bonnard,\& Pailhous, 2002) e as tarefas de integração caminho envolvendo o processamento da distância caminhada e da direção no retorno à origem (Klatzky et al., 1998). Escassos estudos têm examinado diretamente o papel do fluxo óptico na navegação em humanos, quando a correspondente informação não visual é concomitantemente disponível, particularmente no que diz respeito à locomoção em ambientes naturais (Rieser; Pick, Ashmead, \& Garing, 1995).

\subsection{A orientação espacial e o comportamento de veering}

Para uma pessoa normal, sob condições visuais, caminhar em linha reta de um lugar para outro em um ambiente comum é uma tarefa fácil. Este ambiente comum deve oferecer, de maneira satisfatória, fontes externas de referências visuais para auxiliar o indivíduo a caminhar em linha reta. Entretanto, quando o ambiente carece de fontes de referência como, por exemplo, em um deserto ou uma floresta, ou, fontes externas de informação visual e auditiva externas não estão disponíveis para o sujeito, ele se perde e tende a andar em círculos, ou, geralmente, caminha de forma não linear, ainda que ele pretenda seguir em linha reta (Souman, Frissen, Sreenivasa, \& Ernst, 2009). Nesse contexto, tal tendência de desviar-se de um caminho pretendido durante a locomoção é denominada veering (Kallie, Schrater, \& Legge, 2007).

O comportamento de veering ainda não foi bem compreendido pelos pesquisadores e têm gerado diferentes explicações. Questões relacionadas a esses desvios de orientação têm atraído a atenção de cientistas ao longo dos últimos 100 anos, particularmente no que diz respeito à sua origem (Guldbberg, 1897; Howard \&Templeton, 1966; Mach, 1885; Schaeffer, 1928; Scientific American, 1893). Por exemplo, a origem dessa tendência direcional ao caminhar é diversamente atribuída a um mecanismo inato em espiral (Guldbberg, 1897; Schaeffer, 1928), a assimetrias biomecânicas nos membros inferiores (Boyadjian, Marin, \& Danion, 1999), e a assimetrias sensoriais e motoras, em especial a lateralidade manual e podal (Day \& Vickie, 1999; Scharine \& McBeath, 2002). Proposições adicionais realizadas por outros autores sugerem que tanto o desenvolvimento assimétrico pré-natal do sistema vestibular, decorrente da posição fetal (Previc \& Saucedo, 1992), quanto à assimetria hemisférica do sistema dopaminérgico (Mohr, Landis, Bracha, Fathi, \& Brugger, 2003; Mohr, 
Brugger, Bracha, Landis, \& Viaud-Delmon, 2004; Mohr \& Lievesley, 2007), também poderiam ser a causa desta tendência direcional.

Por outro lado, Bestaven, Guillaud, \& Cazalets (2012) sugerem que os desvios de orientação não estão relacionados à assimetria postural ou dominância funcional, e sim a reações corporais dos sujeitos à informação vestibular. Ocorre que, na ausência da informação visual, os humanos são capazes de caminhar em uma linha reta em distâncias curtas $(\leq 20$ metros), utilizando os seus indícios corporais, tais como a informação vestibular e proprioceptiva, para perceber a direção de seu caminhar (Souman, Frissen, Sreenivasa, \& Ernst, 1999; Rieser, Ashmead, Taylor, \&, Youngquist, 1990). Entretanto, ao serem solicitados a caminharem às cegas por distancias mais longas, esses indícios internos corporais tornam-se inconfiáveis, e a manutenção e o controle da direção do caminhar pode ser perturbado pela acumulação de ruído sensorial (Cheung, Zhang, S., Stricker, \& Srinivasan, 2007; Cheung, Stricker, \& Srinivasan, 2008).

\subsection{O espaço de ação e o espaço em perspectiva}

O espaço ao redor do observador pode ser dividido com base nos princípios da percepção e da ação humana. Vários modelos têm sido propostos (Grüsser, 1983; Cutting \& Vishton, 1995; Previc, 1998), os quais distinguem um espaço de comportamentos imediatos ao redor do ser humano e um espaço mais amplo. Por exemplo, Cutting e Vishton (1995) dividiram o espaço perceptual em três regiões egocêntricas. A primeira área é denominada de espaço peripessoal ou manipulatório (dentro do alcance dos braços, limitado a $2 \mathrm{~m}$ ). Nesse espaço, os humanos executam a maioria de suas interações mais próximas e, por conseguinte, a percepção de profundidade é altamente refinada devido à sua importância na vida cotidiana. De 2 a 30 metros, abrange um segundo espaço, ou seja, o espaço de ação. Neste espaço, os indivíduos podem interagir com razoável acurácia com outros objetos, como por exemplo, jogar uma bola para acertar um alvo. Entretanto, no espaço de ação existem menos indícios visuais de profundidade disponíveis, consequentemente a acurácia perceptual é menor do que no espaço peripessoal. Além de 30 metros, é denominado de espaço em perspectiva (ou vista), uma área na qual os objetos assemelham-se a estimativas planas e achatadas, e as distâncias tornam-se empobrecidas em comparação aos espaços mais próximos ao corpo.

De maneira semelhante, Previc $(1990,1998)$ propôs uma divisão do campo visual dos humanos em espaço peripessoal (imediatamente ao redor do observador), correspondendo ao campo visual inferior, onde seriam realizadas ações como o alcance e a manipulação de 
objetos, e espaço extra-pessoal (localizado a uma maior distância do observador), correspondendo ao campo visual superior, com a função de localização e reconhecimento de objetos e faces, navegação, orientação espacial e gravitacional. Também relacionou esses conceitos com a divisão neuroanatômica dorsal e ventral das vias visuais centrais. O sistema visual dorsal processaria as informações dadas pelo espaço peripessoal, enquanto que o sistema visual ventral estaria relacionado ao campo visual superior e ao espaço extra-pessoal. Segundo ele, esta relação representaria a característica ecológica mais fundamental de nosso mundo tridimensional, estabelecida quando os mamíferos elevaram o foco de visão do solo para longe. Nos primatas de postura ereta, os olhos alcançaram posição elevada em relação aos membros superiores usados para alcançar e agarrar.

Estas classificações são especialmente úteis, pois sugerem que a precisão perceptualmotora é impactada pelo aumento do espaço físico. Portanto, pode-se supor que a percepção de distância varia em função da distância de observação.

Nas últimas décadas, o espaço peripessoal tem sido extensivamente estudado (por exemplo, Gogel, 1964; Loomis, Da-Silva, Fujita, \& Fukusima, 1992). Salvo algumas exceções e bem documentadas pequenas distorções, as estimativas de distância no espaço peripessoal são notavelmente acuradas (Daum \& Heicht, 2009). Dentro do espaço de ação, as distâncias maiores que $8 \mathrm{~m}$ de observação, podem ser caracterizadas pela subestimação do volume do espaço, um fenômeno denominado compressão da representação do espaço ou compressão do espaço percebido. Os indícios de distância que fortemente operam no espaço peripessoal e no espaço de ação perdem sua robustez à medida que as distâncias físicas aumentam (Da-Silva et al.,2006).

A subestimação da distância egocêntrica no espaço de ação depende consideravelmente do método e verifica-se que os diferentes procedimentos utilizados para julgar distância produzem algumas variações nos resultados destes experimentos. Os métodos de estimativa verbal tendem a serem menos precisos do que os métodos baseados em ações motoras. O estudo de Andre e Rogers (2006) comprova este aspecto, no qual as estimativas de distâncias geradas em uma tarefa de caminhar visualmente dirigido foram significativamente mais acuradas do que as tarefas que envolviam julgamentos verbais para alvos posicionados a distâncias de até $27 \mathrm{~m}$. Outros métodos, como caminhar a um alvo por triangulação, tipicamente produzem significativa subestimação das respostas de distância (em torno de $50 \%$ ), sobretudo quando esses experimentos são realizados em ambientes virtuais (Thompson et al., 2004).

De acordo com as pesquisas relacionadas até aqui, dentro do espaço de ação, o aumento das distâncias gera uma compressão gradual dos julgamentos. Todavia, em experimentos realizados dentro do espaço em perspectiva ou vista, esta compressão espacial não está bem fundamentada. Alguns pesquisadores examinaram esse tema através de métodos 
de estimativas verbais de distâncias (Bee, 1991; Fine \& Kobrick 1983; Daum \& Hecht, 2009), e foram realizados principalmente no contexto da investigação militar e conduzidos em grandes áreas planas e abertas. Em geral, os resultados desses estudos apontam para uma anisotropia entre o espaço de ação e o espaço em perspectiva. As regiões mais próximas do observador (de até $75 \mathrm{~m}$ ) parecem comportar-se como no espaço de ação, enquanto que as distâncias maiores do que 75 m foram superestimadas. Assim sendo, as grandes distâncias não poderiam ser tratadas no mesmo quadro teórico pertinente ao espaço de ação (Daum \& Hecht, 2009).

Mas os resultados da pesquisa de Bergmann e colaboradores (2010) não seguiram na mesma direção. Eles solicitaram aos sujeitos o registro das estimativas a alvos posicionados entre 20 a $262 \mathrm{~m}$ por meio de julgamentos verbais e locomotores. Foi observado, que os julgamentos verbais permaneceram linearmente escalonados ao longo de toda amplitude de distâncias, e os julgamentos locomotores ficaram aquém das distâncias testes superiores a $100 \mathrm{~m}$. E, contrariamente aos resultados obtidos nos experimentos de Daum e Hecht (2009), observou-se que em ambas as condições experimentais as distâncias maiores que $100 \mathrm{~m}$ foram subestimadas. Pode ser que as diferenças nos resultados deste estudo e dos anteriores sejam devidas às diferenças na metodologia empregada.

Embora seja observado o emprego de distâncias maiores que $30 \mathrm{~m}$ em investigações envolvendo a acurácia perceptiva do comportamento espacial em ambientes reais e naturais, a literatura sobre o assunto demonstra que este tema tem sido pouco explorado. Estas investigações têm focado somente nas variáveis ópticas e oculomotoras que se relacionam com as propriedades do terreno, em ambientes em que o observador permanece numa posição fixa em relação ao que está sendo observado. Existem poucos estudos sobre a representação mental na estimação de distância dentro do espaço em perspectiva durante a locomoção e, menos ainda, durante o caminhar sem a informação visual.

Deste modo, no presente estudo foram conduzidas três tarefas experimentais para investigar os julgamentos de distâncias e a orientação espacial em distâncias entre 30,00 e 80,00 metros, em um ambiente amplo e natural. A primeira tarefa consistiu em caminhar diretamente a um alvo, com a visão ocluída, após vê-lo brevemente. A segunda tarefa consistiu em caminhar vidente até um alvo, e subsequentemente realizar um giro de $180^{\circ}$ e retornar sozinho, com a visão ocluída, à origem do percurso. A terceira tarefa foi similar à segunda, mas com uma diferença, o participante caminhou por distâncias com a visão ocluída, pelo guiar de um condutor, e ao final da caminhada subsequentemente, girou e retornou sozinho à origem do percurso. Em todas as tarefas experimentais, a distância caminhada (em metros) e o tempo (em segundos) de cada trajetória na fase de resposta, foram coletados e registrados utilizando um receptor de Sistema de Posição Global (GPS). 


\section{MÉTODO}

\subsection{Participantes}

Trinta e cinco voluntários, de ambos os sexos (23 mulheres; 12 homens), com idades entre 18 e 35 anos participaram desse estudo. Os sujeitos foram recrutados e divididos aleatoriamente em três tarefas experimentais: (i) tarefa de produção de distâncias a um alvo visualmente percebido $(\mathrm{n}=12)$;(ii) tarefa de reprodução de distâncias após o caminhar não visual (n=12);(iii); e, a tarefa reprodução de distâncias após o caminhar não visual (n=11). Todos assinaram um Termo de Consentimento Livre e Esclarecido, aprovado pelo Comitê de Ética em Pesquisa da Faculdade de Filosofia Ciências e Letras de Ribeirão Preto da Universidade de São Paulo (FCLRP-USP) (Anexo A), conforme as normas vigentes no Brasil referente a experimentos com humanos. Esse consentimento foi feito após os participantes terem se adequado aos seguintes critérios de inclusão: independência na locomoção; visão normal ou corrigida através do uso de lentes corretivas; inexistência de patologias que pudessem impedir a mobilidade e a execução da tarefa experimental. Versões adaptadas e traduzidas do Inventário de Dominância Manual de Edimburgo (Oldfield, 1971) (Anexo B) e, do questionário de preferência lateral podal de Porac e Coren (1981) foram aplicadas e somente os sujeitos com preferência lateral e podal direita ${ }^{1}$ foram incluídos no estudo. Os indivíduos eram ingênuos quanto ao propósito do estudo, e não praticavam regularmente atividades esportivas em espaço de grande escala.

\subsection{Espaço experimental}

As tarefas experimentais foram realizadas em um campo de futebol de aproximadamente $90 \times 60 \mathrm{~m}$ de superfície plana e gramada, localizado no complexo esportivo

\footnotetext{
${ }^{1}$ Segundo a literatura existente, a preferencia lateral do individuo pode influenciar a direção lateral dos desvios de direção em tarefas de orientação espacial (Day \& Coins,1997).
} 
do Centro Universitário Moura Lacerda (Unidade II) situado a Av. Dr. Oscar de Moura Lacerda $n^{\circ} 1520$, na cidade de Ribeirão Preto, São Paulo. Neste campo foram discretamente demarcadas quatro distâncias egocêntricas, definidas pela extensão física entre o ponto de origem ou a posição inicial para se executar a tarefa perceptual $(\mathrm{O})$ e o ponto de localização do alvo, cujos valores foram iguais a 30,00; 41,60;57,69; 80,00 metros. A fim de minimizar a interferências de pistas solares no desempenho dos participantes, as sessões experimentais ocorreram sempre no mesmo horário, das $16 \mathrm{hs} 00 \mathrm{~min}$ às $19 \mathrm{hs} 00$.

As distâncias dos alvos foram determinadas a partir da equação abaixo. A escala seguiu uma progressão geométrica (PG) com uma razão q=1,39 e n variando de 1 a 4, onde $a_{n}$ é o n-ésimo termo da PG e $a_{1}$ é o primeiro termo da PG $\left(a_{1}=30,00 \mathrm{~m}\right)$.

$$
a_{n}=a 1 \cdot q^{n-1}(1)
$$

Portanto, $a_{1}=30,00, \mathrm{a}_{2}=41,60, \mathrm{a}_{3}=57,69$ e $\mathrm{a}_{4}=80,00$ metros.

\subsection{Materiais}

Para a operacionalização das coletas e análise dos dados foram utilizados os seguintes equipamentos e softwares:

- $\quad$ Cone de sinalização de $p v c$ rígido para sinalização viária, medindo $75 \mathrm{~cm}$ de altura, na cor laranja com faixas brancas, usado e apresentado como alvo;

- $\quad$ Trena Longa em Fibra de Vidro KTS537- 100m-S100m e pinos de golfe coloridos para demarcação das distâncias no espaço experimental;

- $\quad$ Educador postural (espaldeira) Chantal;

- $\quad$ Fone de ouvido conectado a um Mp3 player utilizado para emitir ruído branco com intensidades ajustáveis com a finalidade de mascarar qualquer informação acústica que pudesse indicar a orientação espacial dos sons ambientais;

- Venda de tecido preto com área do nariz bloqueada, utilizada para garantir que nenhuma informação visual (tanto central como periférica), estivesse disponível aos participantes durante a execução da tarefa perceptual;

- $\quad$ Receptor GPS portátil Juno Handheld AS-Trimble;

- $\quad$ Software Terrasync Standard-Trimble (instalado no receptor GPS), 
- Software PathFinder Office(PFO)-Trimble para pós-processamento, tratamento e correção diferencial dos dados obtidos;

- $\quad$ Software de análise estatística IBM SPSS Statistics 20.0.

\subsection{Procedimento}

Antes de iniciar os experimentos, foi avaliada a dominância manual e podal, e histórico de doenças oculares e neurológicas. Os voluntários que não preencheram os critérios estabelecidos não foram incluídos na amostra. Todos os participantes leram e assinaram o Termo de Consentimento Livre e Esclarecido antes de iniciar as sessões experimentais. Cada indivíduo participou somente de uma tarefa experimental.

Após a realização dessas etapas iniciais, individualmente, cada participante foi conduzido ao espaço experimental, e instruído a vestir como se fosse as alças de uma mochila um educador postural e colocar uma venda de tecido preto sobre sua cabeça. Feito isso, o pesquisador fixava na parte frontal do educador postural um gravador (MP3) conectado a fones de ouvido, e na parte dorsal (entre as escapulas) o receptor GPS. Então, o sujeito era orientado a colocar os fones de ouvido, ligar o MP3 e ajustar a intensidade sonora do ruído de modo que mascarasse os sons ambientais. Logo após, o gravador era desligado e o sujeito era instruído que o gravador seria ligado novamente somente no início da sessão e assim mantido até o seu término. Em seguida, o participante era instruído verbalmente de como deveria executar a tarefa (Apêndice A), seguindo-se uma ou duas práticas como exemplo. As distâncias utilizadas no treino foram escolhidas pelo pesquisador de modo aleatório e não correspondiam a nenhuma das distâncias utilizadas no estudo.

$\mathrm{Na}$ primeira tarefa perceptual realizada, designada tarefa de produção de distâncias a um alvo visualmente percebido (tarefa V), o participante era posicionado no ponto de origem e instruído a observar e memorizar a distância de localização de um alvo (o cone de sinalização), de maneira que fosse possível representar mentalmente o espaço percebido, mesmo com os olhos fechados. Em seguida, após ter os olhos vendados, o MP3 e o receptor GPS ligados, o participante caminhava, na sua cadência preferida, em linha reta em direção ao alvo, ou seja, deslocando-se até o ponto onde ele julgava que o alvo estava localizado (Figura 2A). Para evitar colisões, o alvo foi retirado e colocado ao lado do trajeto durante o deslocamento por um auxiliar. 
Na caminhada com a visão-oclusa até o alvo, o pesquisador caminhava ao lado do participante, e quando necessário, ele segurava levemente o cotovelo do sujeito, a fim de minimizar os desvios severos de orientação e aumentar os níveis de conforto e segurança no decorrer da caminhada às cegas. Ao término da caminhada, ao parar, a distância caminhada era registrada no receptor GPS pelo pesquisador, e o participante vendado e com a audição mascarada era guiado à origem por trajetórias complexas e reposionado para iniciar uma nova tarefa. Durante a sessão experimental, os sujeitos vendados e com a audição mascarada, caminharam três vezes cada uma das distâncias testes, em ordem aleatória. A série das distâncias foi igual a todos os participantes.

Ao finalizar a sessão, o participante foi instruído a realizar uma tarefa controle para cada uma das distâncias testes, ou seja, ele deveria caminhar em direção ao alvo sob condições visuais e auditivas. Em média, os sujeitos caminharam a uma velocidade de aproximadamente $\quad 0,978 \quad( \pm 0,067 \mathrm{~m} / \mathrm{s}), \quad 1,052( \pm 0,0753 \mathrm{~m} / \mathrm{s}), \quad 1,132( \pm 0,275 \mathrm{~m} / \mathrm{s})$, $1,084( \pm 0,141 \mathrm{~m} / \mathrm{s})$, para as distâncias de 30,00; 41,60; 57,69 e 80,00 metros respectivamente.

Na segunda tarefa perceptual, denominada tarefa de reprodução de distâncias após o caminhar sob condições visuais (tarefa Lv), as instruções preparatórias para ocluir os olhos e mascaramento de sons ambientais antes de iniciar a tarefa e distâncias alvos, foram iguais àquelas da primeira tarefa (tarefa $\mathrm{V}$ ), exceto que durante a fase de estimulo, o participante deveria caminhar até o alvo (um cone de sinalização) com os olhos abertos (Apêndice A). Assim, a tarefa era iniciada com o participante no ponto de origem, posicionado de frente para o alvo, e, em seguida, ele era instruído a caminhar com os olhos abertos, na sua cadência preferida, em linha reta até o ponto onde o alvo estava localizado. Também, foi solicitado que ele mantivesse sua cabeça voltada sempre para frente, em direção ao alvo, e que evitasse olhar para o chão e não contasse seus passos. Ao alcançar o alvo, ao parar, o participante era vendado, realizava com ajuda do pesquisador um giro de corpo de $180^{\circ}$ (nesse interim o receptor GPS era ligado), e o sujeito sozinho deveria retornar em linha reta tentando alcançar a origem do trajeto (Figura 2B). Ao término da caminhada, ao parar, a distância caminhada era registrada no receptor GPS pelo pesquisador, e o participante vendado e com a audição mascarada era conduzido à origem por trajetórias complexas e reposionado para iniciar uma nova tarefa. Durante a sessão experimental, os sujeitos vendados e com a audição mascarada, caminharam três vezes cada uma das distâncias testes, em ordem aleatória. A série das distâncias foi igual a todos os participantes.

Ao final da sessão, o participante foi instruído a realizar uma tarefa controle (sob condições visuais e auditivas) para cada uma das distâncias testes. Em média, os participantes 
caminharam a uma velocidade de aproximadamente $1,16( \pm 0,103 \mathrm{~m} / \mathrm{s}) ; 1,09( \pm 0,114 \mathrm{~m} / \mathrm{s})$; $1,23( \pm 0,297 \mathrm{~m} / \mathrm{s}), 1,22( \pm 0,300 \mathrm{~m} / \mathrm{s})$ para as distâncias de 30,$00 ; 41,60 ; 57,69$ e 80,00 metros respectivamente.

E, a terceira tarefa perceptual, denominada de reprodução de distâncias após o caminhar não visual (Tarefa L), foi delineada de maneira análoga uma sessão experimental das tarefas anteriores, e seguiu o mesmo procedimento (instruções ver Apêndice A). A única diferença se refere à fase de estimulo, o participante deveria reproduzir através do caminhar uma distância percebida durante o caminhar não visual (Figura 2C). A tarefa era iniciada com o participante posicionado na origem, vendado, usando o educador postural, com o gravador e o receptor GPS devidamente fixados, e a audição mascarada. Então, o participante era conduzido pelo guiar do pesquisador em linha reta, segurando seu antebraço, do ponto de origem por uma distância pré-determinada. Ao final da caminhada, ao parar, o participante com a ajuda do pesquisador realizava um giro de $180^{\circ}$ (nesse interim o receptor GPS era ligado), e, então ele sozinho retornava em linha reta tentando alcançar a origem do trajeto. Ao término da caminhada de retorno à origem, ao parar, a distância caminhada era registrada no GPS, e o participante vendado era conduzido pelo pesquisador à origem por trajetórias complexas e reposionado para iniciar uma nova tarefa.

Durante a sessão experimental, os sujeitos vendados e com a audição mascarada, caminharam três vezes cada uma das distancias testes, em ordem aleatória. A série das distâncias foi igual a todos os participantes. Como nas tarefas anteriores, após finalizar a sessão experimetnal, o participante foi instruído a realizar uma tarefa controle (sob condições visuais e auditivas) para cada uma das distâncias teste. Em média, os participantes caminharam a uma velocidade de aproximadamente $1,06( \pm 0,167 \mathrm{~m} / \mathrm{s}) ; 1,040( \pm 0,137 \mathrm{~m} / \mathrm{s})$; $1,130( \pm 0,293 \mathrm{~m} / \mathrm{s}) ; 1,132( \pm 0,284 \mathrm{~m} / \mathrm{s})$ para as distâncias de 30,00; 41,60; 57,69 e 80,00 metros respectivamente. 


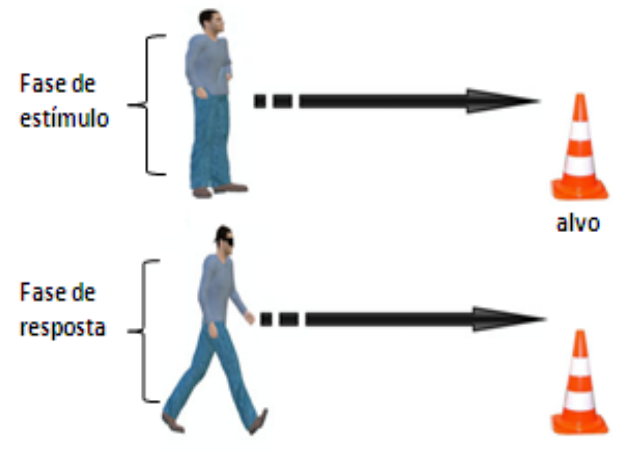

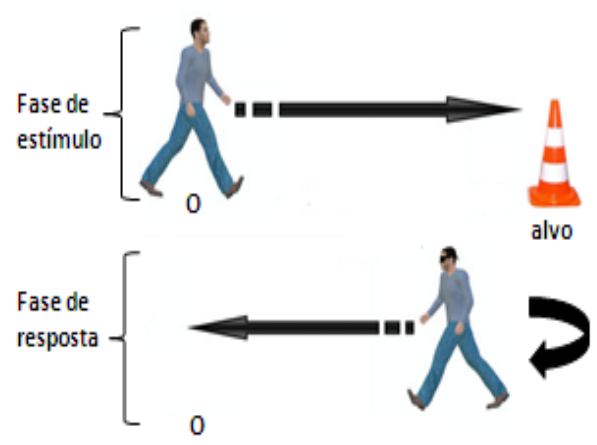

B

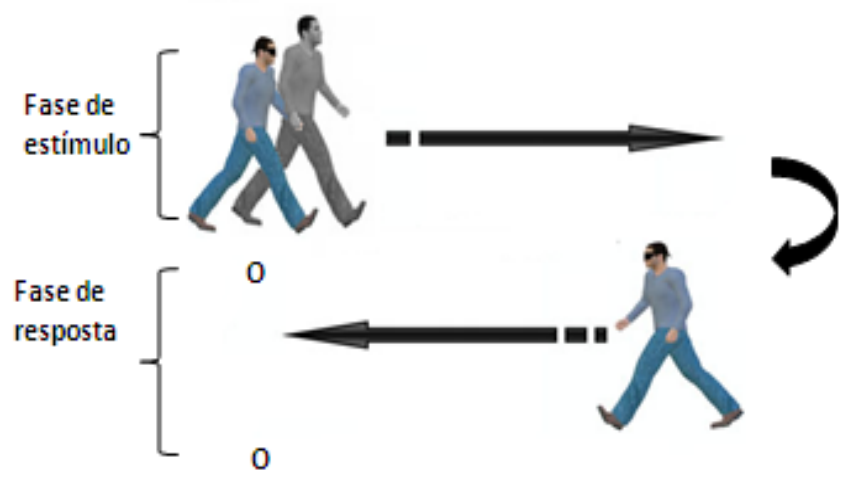

C

Figura 1. Representação esquemática dos procedimentos das três tarefas de produção de distâncias pelo indicativo de resposta do caminhar com a visão ocluída: (A) produção de distâncias a um alvo visualmente percebido (V) Fase de estímulo: o participante observa diretamente a sua frente, um alvo posicionando a uma determinada distância. Fase de resposta: o participante é solicitado a caminhar vendado até o local onde ele julga que o alvo está localizado. (B) reprodução de distâncias caminhada sob condições visuais (Lv). Fase de estímulo: o participante caminha vidente até um alvo, diretamente posicionado a sua frente, a uma determinada distância. Fase de resposta: ao alcançar o alvo, o participante é vendado, realiza um giro de corpo de $180^{\circ}$, e retornar ao ponto de origem (O), tentando reproduzir a distância percorrida na fase de estímulo. (C) reprodução de distância caminhada não visual (L). Fase de estímulo: o participante é conduzido pelo guiar do pesquisador em linha reta (segurando seu antebraço) do ponto de origem por uma determinada distância. Fase de resposta: ao final da caminhada, o participante realiza um giro de corpo de $180^{\circ}$, e retorna ao ponto de origem $(\mathrm{O})$, tentando reproduzir a distância percorrida na fase de estímulo.

\subsection{Registro do Movimento}

Em todas as tarefas experimentais, a distância caminhada (em metros) e o tempo total (em segundos) de cada trajetória na fase de resposta foram registrados e os seus dados coletados utilizando um receptor GPS, cuja frequência de aquisição de dados foi de $f_{G P S}=$ 
$1 \mathrm{~Hz}$, ou seja, o GPS registrou a posição e o tempo associado a cada 1 segundo.

A fim de reduzir as incertezas em tais medições, os dados foram extraídos e pósprocessados utilizando a correção diferencial do software Path Finder Office da empresa Trimble, junto com os dados providos pelo sítio eletrônico da Rede Brasileira de Monitoramento Contínuo dos Sistemas GNSS, Instituto Brasileiro de Geografia e Estatística. Desta forma, desvio padrão da distância medida foi reduzido de 2 a $5 \mathrm{~m}$ para 1 a $3 \mathrm{~m}$, valor que satisfaz aos requisitos experimentais.

Em seguida, as grandezas físicas associadas ao movimento de cada sujeito foram calculadas, a saber, a distância percorrida (metros), a velocidade linear $\vec{v}$ (metros por segundo), a desvio angular $\alpha$ (graus) e, para os casos de trajetória circular ou reta e circular, a velocidade angular média $\dot{\psi}$ (radianos por segundo) e o raio da trajetória circular teórica $R_{m}$ (metros) .

A distância percorrida $\mathrm{S}$ (em metros) foi calculada pelo somatório das distâncias das coordenadas medidas no campo.

$$
S=\sum_{i=1}^{n} \sqrt{\left(x_{i}-x_{i-1}\right)^{2}+\left(y_{i}-y_{i-1}\right)^{2}}
$$

Já a velocidade linear (em metros por segundo) foi determinada usando a posição em dois momentos consecutivos em cada trajetória,

$$
\vec{v}(\mathrm{t}) \approx\left(\frac{\mathrm{x}(\mathrm{t})-\mathrm{x}(\mathrm{t}-\Delta \mathrm{t})}{\Delta \mathrm{t}}, \frac{\mathrm{y}(\mathrm{t})-\mathrm{y}(\mathrm{t}-\Delta \mathrm{t})}{\Delta \mathrm{t}}\right)
$$

Sendo o intervalo de tempo $\Delta t$ de 1 segundo,

$$
\vec{v}(t) \approx(x(t)-x(t-1), y(t)-y(t-1))(4)
$$

A comparação de quão próxima da trajetória reta sujeitos é medida por meio de o desvio angular $\alpha$ (em graus). Onde $\mathrm{x}_{\mathrm{c}}$ e $\mathrm{y}_{\mathrm{c}}$ da posição final relativas ao referencial do campo de futebol. A interpretação geométrica desta grandeza é representada na Figura 2. 


$$
\alpha=\operatorname{atan}\left(\frac{\mathrm{x}_{\mathrm{c}}}{\mathrm{y}_{\mathrm{c}}}\right)
$$

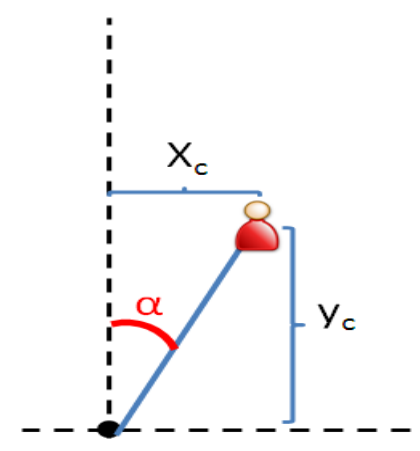

Figura 2. Interpretação geométrica do desvio angular

No caso particular da trajetória circular, a velocidade angular média $\dot{\Psi}_{m}$ e o raio médio da trajetória circular teórica $\mathrm{R}_{\mathrm{m}}$ podem ser estimados indiretamente, apesar de $\mathrm{o}$ receptor não medir diretamente a velocidade angular, mas tão somente a posição do sujeito ao longo da trajetória. Supondo que a velocidade linear $\vec{v}$ e a velocidade angular $\dot{\psi}$ sejam constantes durante toda a trajetória percorrida, é possível provar que a trajetória resultante é um círculo de raio $R$, dado por (6),

$$
\mathrm{R}=\frac{v}{\dot{\psi}}(6)
$$

A trajetória circular pode ser descrita como função do tempo usando (7).

$$
s(t)=\left(\frac{v}{\dot{\psi}}-\frac{v}{\dot{\psi}} \cos \dot{\psi} t, \frac{\mathrm{v}}{\dot{\psi}} \sin \dot{\psi} \mathrm{t}\right)(7)
$$

Por meio de um funcional de erro $J$ (8) definido como a diferença entre a trajetória circular teórica $\left(\mathrm{x}_{\mathrm{est}}, \mathrm{y}_{\mathrm{est}}\right)$ e a trajetória aproximadamente circular observada $\left(\mathrm{x}_{\mathrm{obs}}, \mathrm{y}_{\mathrm{obs}}\right)$, a velocidade angular média $\dot{\Psi}_{m}$ é estimada minimizando $J$.

$$
J\left(\dot{\psi}_{m}\right)=\sum_{\mathrm{i}=1}^{\mathrm{N}}\left[\mathrm{x}_{\mathrm{est}}(\mathrm{i} . \mathrm{T})-\mathrm{x}_{\mathrm{obs}}(\mathrm{i} . \mathrm{T})\right]^{2}+\sum_{\mathrm{i}=1}^{\mathrm{N}}\left[\mathrm{y}_{\mathrm{est}}(\mathrm{i} . \mathrm{T})-\mathrm{y}_{\mathrm{obs}}(\mathrm{i} . \mathrm{T})\right]^{2}
$$


Onde $\mathrm{N}$ é o número total de pontos medidos na trajetória. $T=1$ segundo é a periodicidade de coleta de dados do GPS.

Generalizando a expressão (3) para uma trajetória aproximadamente circular, tem-se que o raio médio é dado por (9).

$$
\mathrm{R}_{\mathrm{m}}=\frac{v_{m}}{\dot{\psi}_{m}}(4)
$$

Onde $v_{m}$ é a velocidade media ao longo da trajetória $(\mathrm{m} / \mathrm{s})$ e $\dot{\Psi}_{\mathrm{m}}(\mathrm{rad} / \mathrm{s})$ é a velocidade angular média ao longo da trajetória.

\subsection{Transformação de Coordenadas}

Para descrever a posição de um objeto sobre a superfície terrestre, é necessário usar um sistema de coordenadas específico. Este sistema está associado com um referencial sobre o qual todos os cálculos serão desenvolvidos. As coordenadas de posição de um corpo podem ser representadas de diversos modos, como por exemplo, por meio uma superfície esférica recebendo a denominação de coordenadas geodésicas ou por meio de uma superfície plana recebendo a denominação da projeção às quais estão associadas, como por exemplo, as coordenadas planas Universais Transversas de Mercator (UTM) (IBGE, 2015). No presente estudo, os dados da trajetória foram obtidos pelo receptor GPS e foram transformados em coordenadas Norte-Leste (NEU) para facilitar a análise das trajetórias. Como a distância caminhada mais longa é menor do que 100m, a hipótese da Terra plana é razoável.

Com relação às medidas de incerteza, elas foram diretamente obtidas após o pósprocessamento, enquanto que a incerteza das grandezas físicas derivadas, tais como velocidade, distância total percorrida e desvio angular, foram determinadas pela teoria estatística de propagação do erro.

É importante notar que a orientação de cada sujeito com relação ao campo de futebol variou para cada uma das tarefas experimentais, e, por conseguinte, algumas correções de caráter angular foram feitas sobre os dados pós-processados obtidos. Em outras palavras, a orientação do sujeito no inicio da caminhada com a visão ocluída (fase de resposta) teve de ser cuidadosamente considerada para que fosse possível comparar as trajetórias produzidas 
em diferentes tarefas experimentais, já que os sujeitos tinham suas faces voltadas para diferentes direções a cada condição experimental. Apesar das posições da origem ser distintas, sem perda de generalidade, pode-se abstrair e considerar que todas as trajetórias partiram de uma origem comum, bastando apenas levar em consideração a direção de início da trajetória com o intuito de deixar a análise dos dados uniformes e sempre com relação a um sistema igual de coordenadas (coordenadas locais norte e leste).

$\mathrm{Na}$ primeira tarefa (tarefa $\mathrm{V}$ ), o participante deveria observar um alvo por alguns instantes e depois disso caminhar com a visão ocluída até ele. Para analisar os dados corretamente, foi preciso fazer uma correção angular nos dados pós-processados do GPS. Mediu-se que a trajetória obtida do tratamento dos dados tinha uma inclinação de $12^{\circ}$ graus com relação ao sistema de coordenadas locais norte e leste, devido à inclinação do campo de futebol com tal sistema de coordenadas. Para a segunda tarefa (tarefa Lv), que consistiu no participante caminhar com os olhos abertos até o alvo e retornar a origem vendado, foi necessário não somente fazer a correção angular da primeira tarefa (tarefa V), mas também fazer uma nova rotação de $180^{\circ}$, pois o sujeito realizou uma rotação de mesma intensidade. Este mesmo procedimento foi repetido para a terceira tarefa experimental (tarefa L), por ser muito semelhante a segunda tarefa, com a única diferença que na fase de estímulo a informação de distância foi gerada pela informação da trajetória percorrida pelo caminhar não visual.

Com todas as correções descritas anteriormente, foi possível a análise dos dados de maneira padronizada e uniformes, sempre com relação a um sistema igual de coordenadas. Somente depois de realizadas estas correções de caráter puramente angular, as grandezas importantes para a análise da trajetória, bem como a observação do seu formato, foram determinadas. 


\section{ANÁLISE DOS DADOS}

\section{Resultados: desvios de orientação}

\subsection{Análise estatística}

O tratamento estatístico foi realizado comparando-se os valores das diversas grandezas medidas ou calculadas para verificar a existência de diferenças estatisticamente significativas entre os desvios de orientação das distâncias observadas ou caminhadas dentro de cada tarefa, e também entre as três tarefas experimentais. Para tanto, foram utilizados: os testes estatísticos não paramétricos de Friedamn, seguido do teste U de Mann-Whitney, para identificar diferenças nos índices dos padrões das trajetórias; o teste de Qui-quadrado para verificar a consistência da direção lateral dos desvios de orientação durante o caminhar não visual; teste de Shapiro-Wilk para verificar a condição de normalidade dos dados; o teste tStudent para amostras pareadas tendo como variável dependente os valores médios da velocidade das distâncias percorridas em cada uma das tarefas experimentais emparelhados aos valores médios da velocidade caminhada na tarefa controle para identificar possíveis diferenças no desempenho dos participantes; análise de variância (ANOVA) tendo como fatores: 3 tarefas experimentais (tarefa V, tarefa Lv e tarefa L), 4 distâncias $(30,00 ; 41,60$; 57,69 e 80,00 metros), sendo medidas repetidas no último fator para identificar diferenças entre os valores das variáveis, velocidade (metros por segundo), desvio angular (graus), e para os casos de trajetória circular, o raio da trajetória circular teórica (metros) e velocidade angular média (radianos por segundo), e testes a posteriori de Bonferroni para localizar diferenças significativas. Em todas as análises o valor de $\alpha \leq 0,05$ foi considerado como nível de significância. 


\subsection{Análises dos padrões das trajetórias}

Após concluir as três tarefas experimentais para cada uma das quatro distâncias $(30,00 ; 41,60 ; 57,69$ e 80,00 m) e calcular as trajetórias de acordo com os métodos específicos para cada uma, obtiveram-se os resultados para todos os sujeitos segundo o referencial local do campo de futebol. Para ilustrar os resultados, todas as trajetórias realizadas pelos indivíduos dentro da área experimental estão plotadas nas Figuras 3, 4, 5, 6, 7, 8, 9, 10, 11, 12, 13,14 utilizando-se o ponto de origem de cada tarefa experimental como a referência zero.

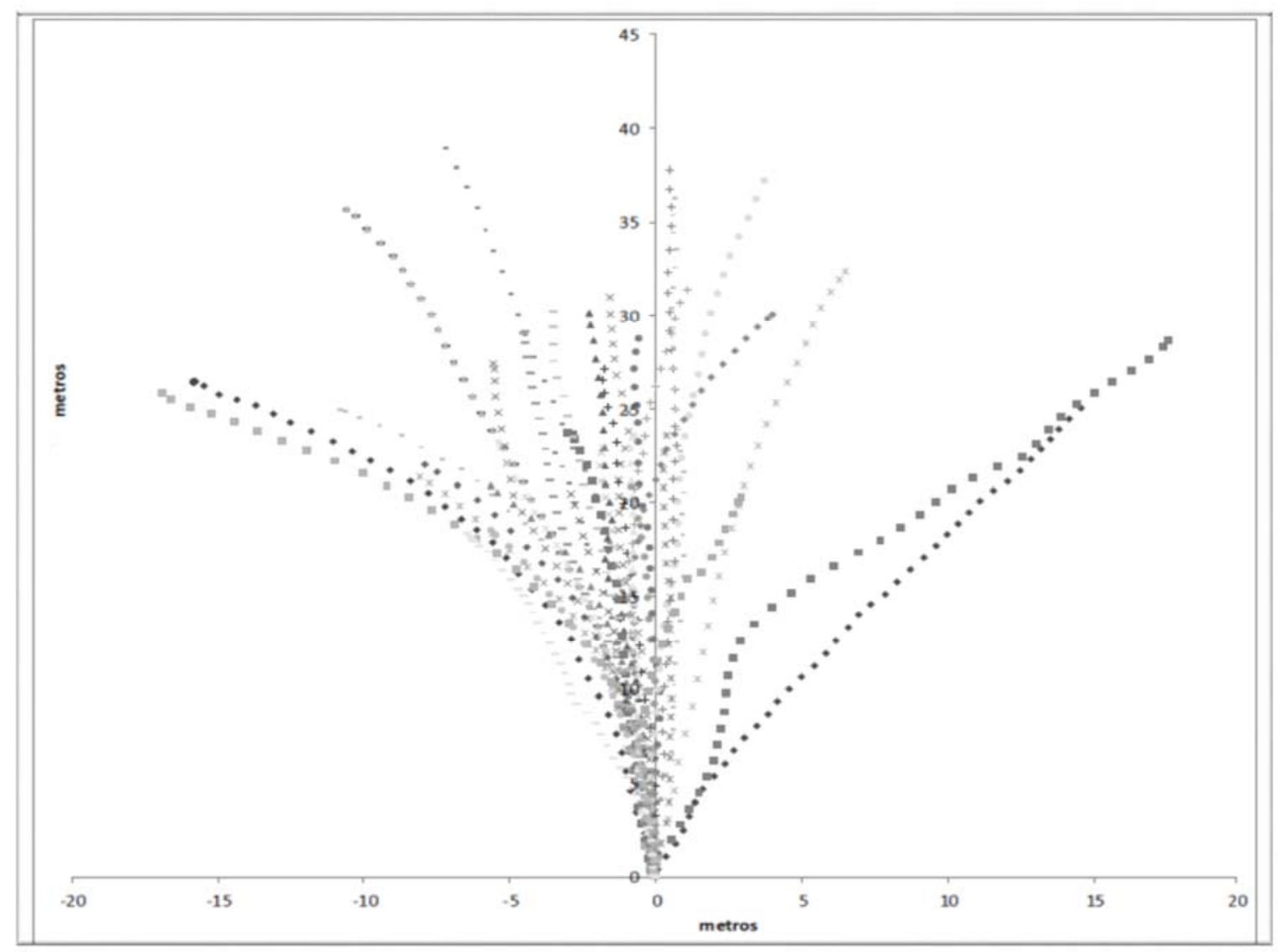

Figura 3. Trajetórias realizadas pelos participantes dentro da área experimental, durante o caminhar não visual ao alvo de $30,00 \mathrm{~m}$ na tarefa $\mathrm{V}$. 


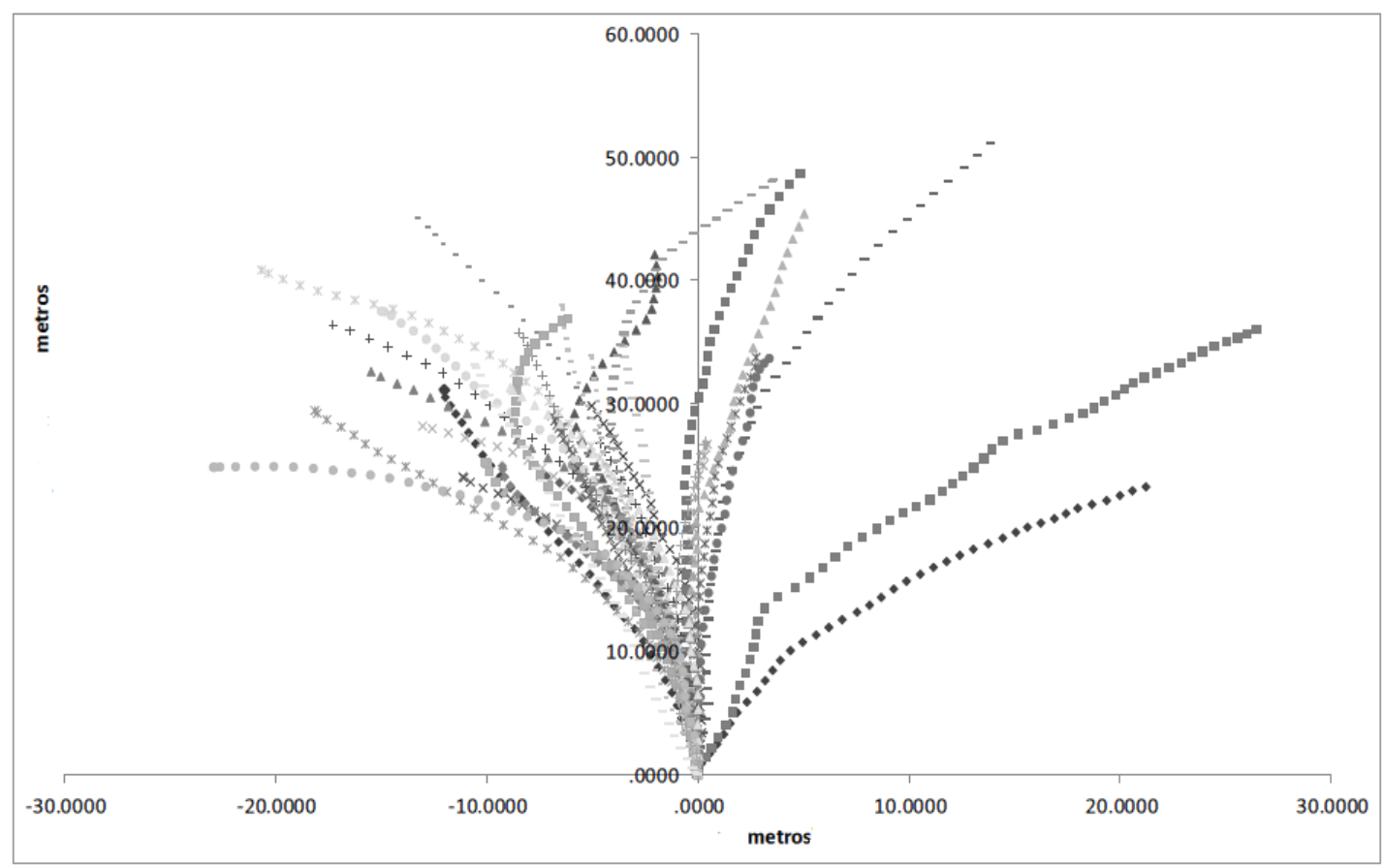

Figura 4. Trajetórias realizadas pelos participantes dentro da área experimental, durante o caminhar não visual ao alvo de 41,60 m na tarefa V.

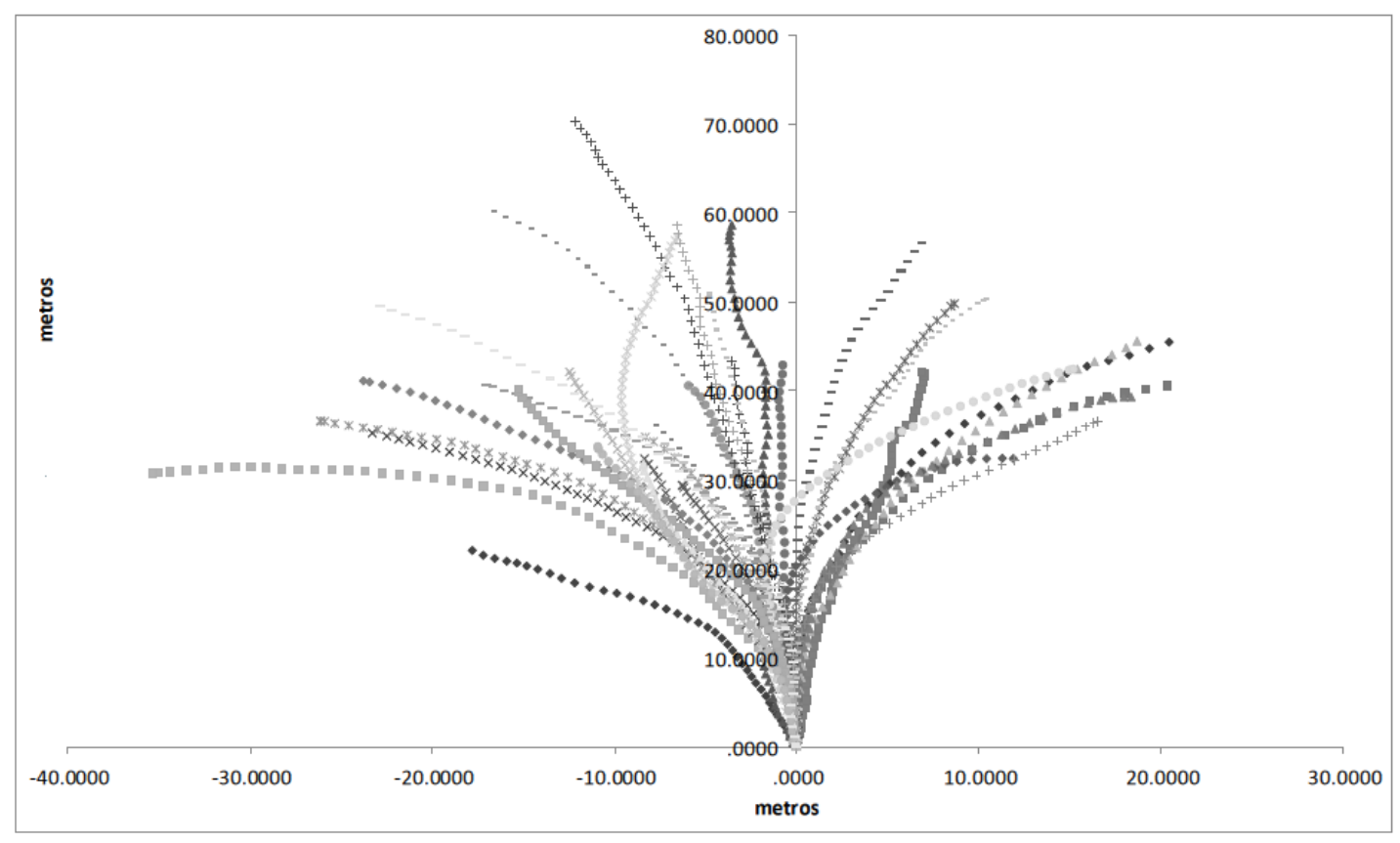

Figura 5. Trajetórias realizadas pelos participantes dentro da área experimental, durante o caminhar não visual ao alvo de $57,69 \mathrm{~m}$ na tarefa $\mathrm{V}$. 


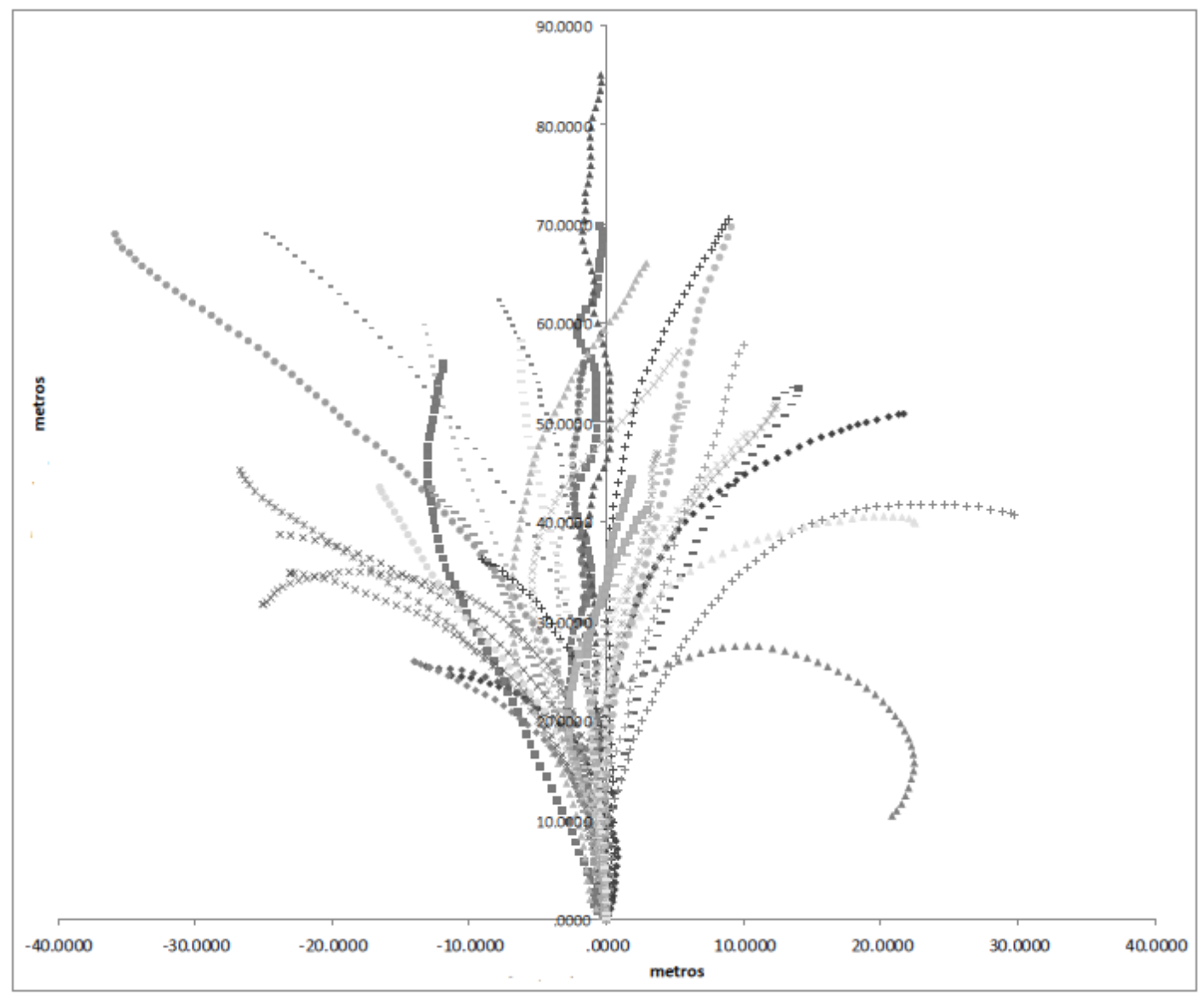

Figura 6. Trajetórias realizadas pelos participantes dentro da área experimental, durante o caminhar não visual ao alvo de $80 \mathrm{~m}$ na tarefa $\mathrm{V}$.

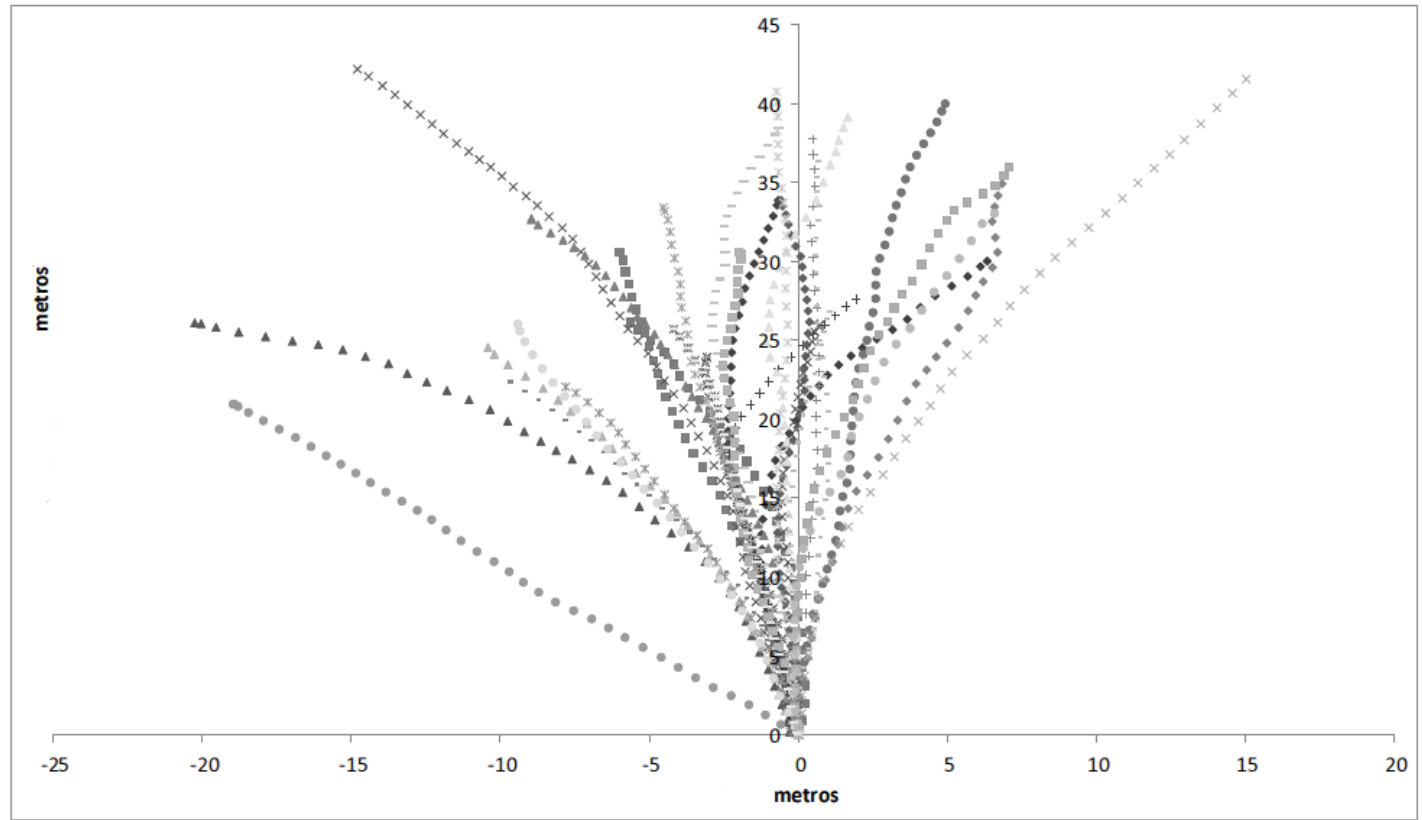

Figura 7. Trajetórias realizadas pelos participantes dentro da área experimental, durante o caminhar não visual no retorno à origem para a distância de $30 \mathrm{~m}$ na tarefa $\mathrm{Lv}$ 


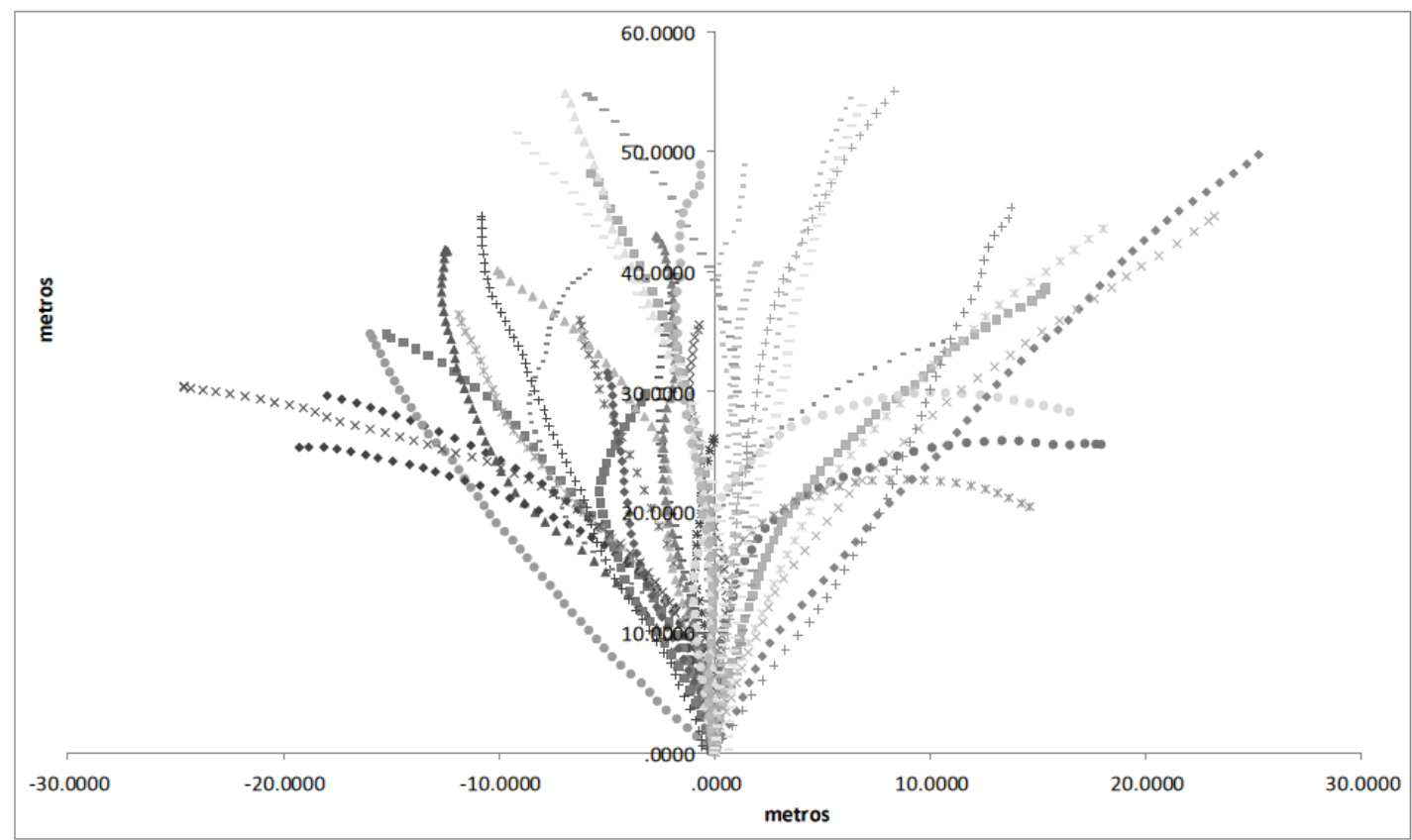

Figura 8. Trajetórias realizadas pelos participantes dentro da área experimental, durante o caminhar não visual no retorno à origem para a distância de $41,60 \mathrm{~m}$ na tarefa $\mathrm{Lv}$

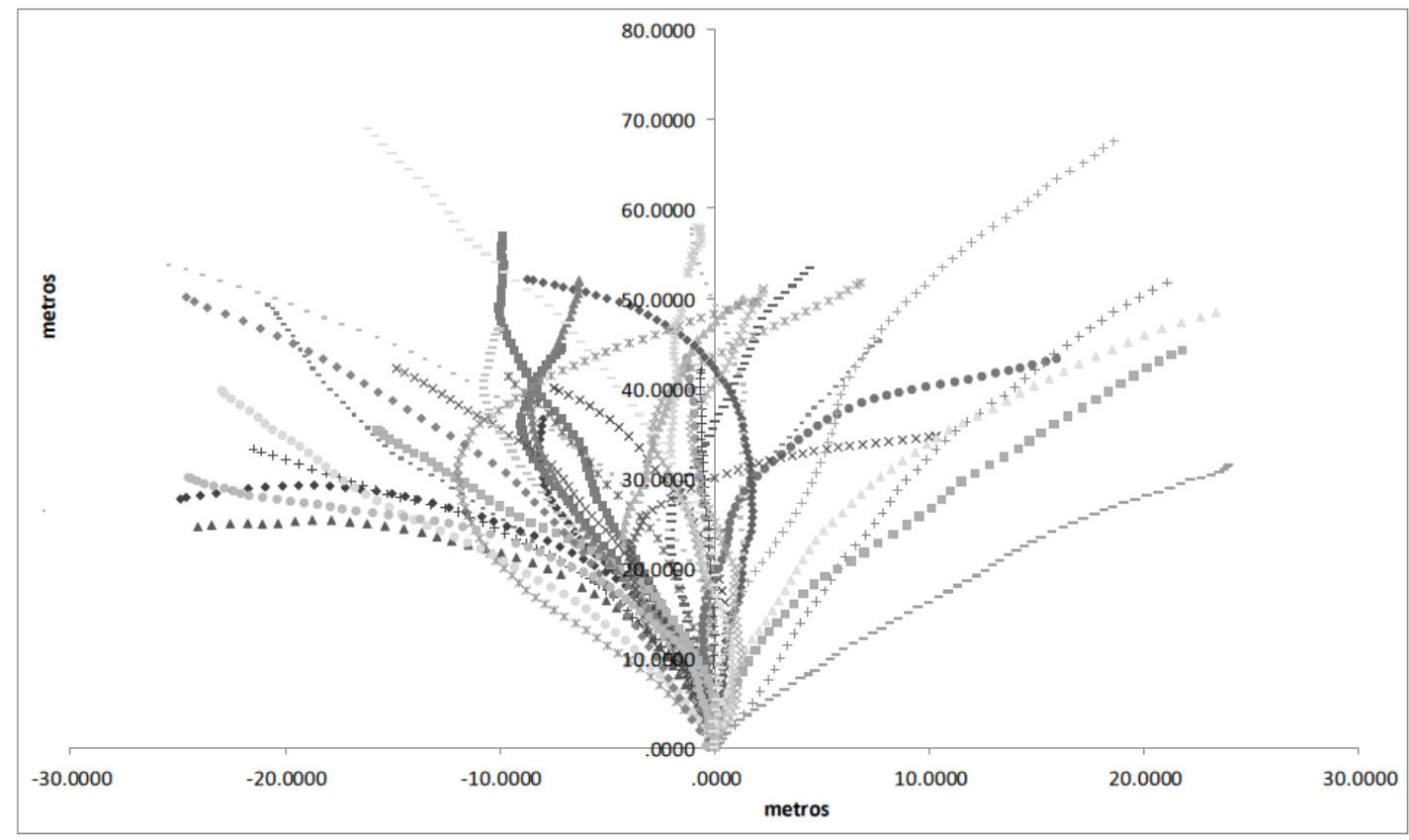

Figura 9. Trajetórias realizadas pelos participantes dentro da área experimental, durante o caminhar não visual no retorno à origem para a distância de 57,69m na tarefa Lv 


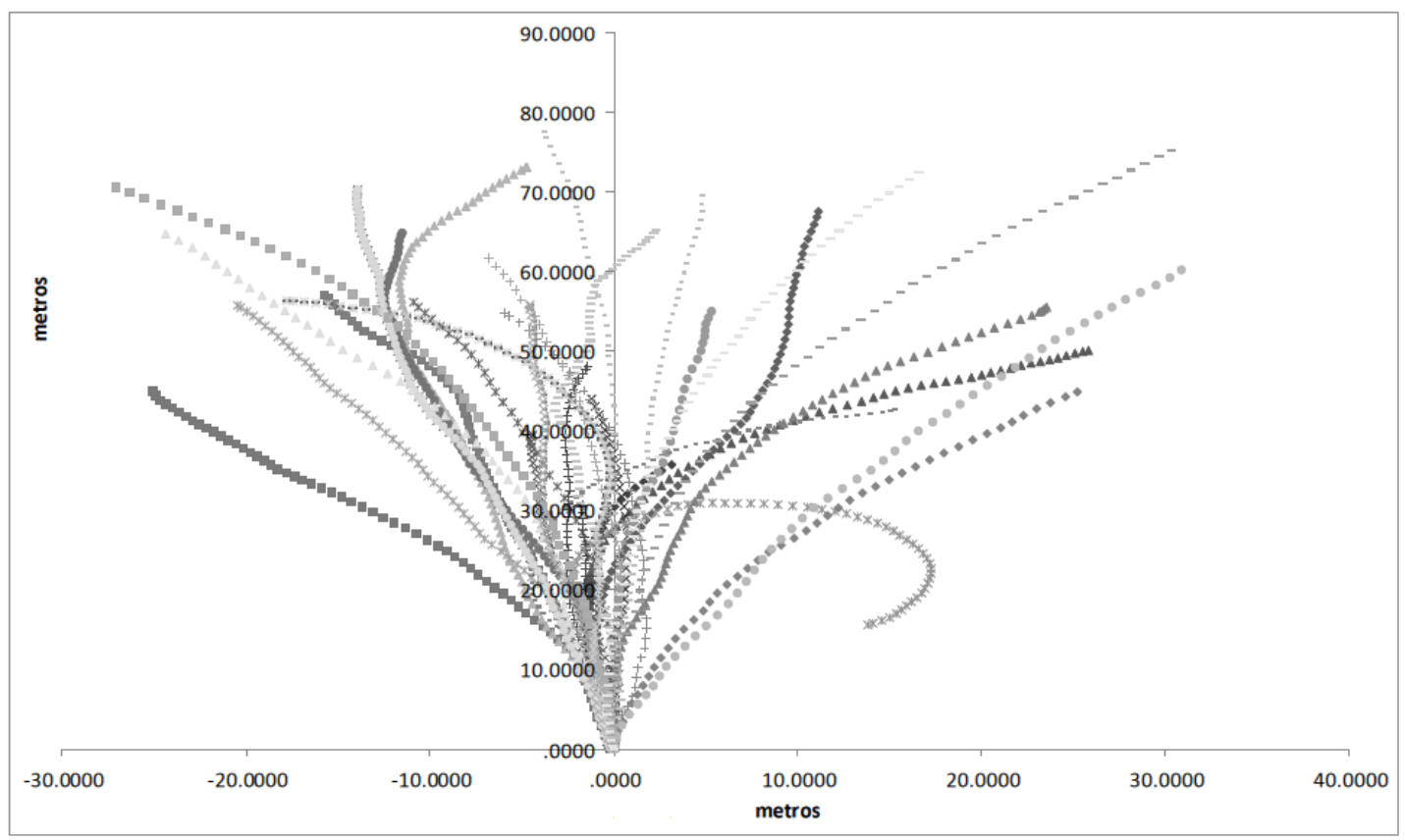

Figura 10. Trajetórias realizadas pelos participantes dentro da área experimental, durante o caminhar não visual durante no retorno à origem para a distância de 80,00 na tarefa $\mathrm{Lv}$

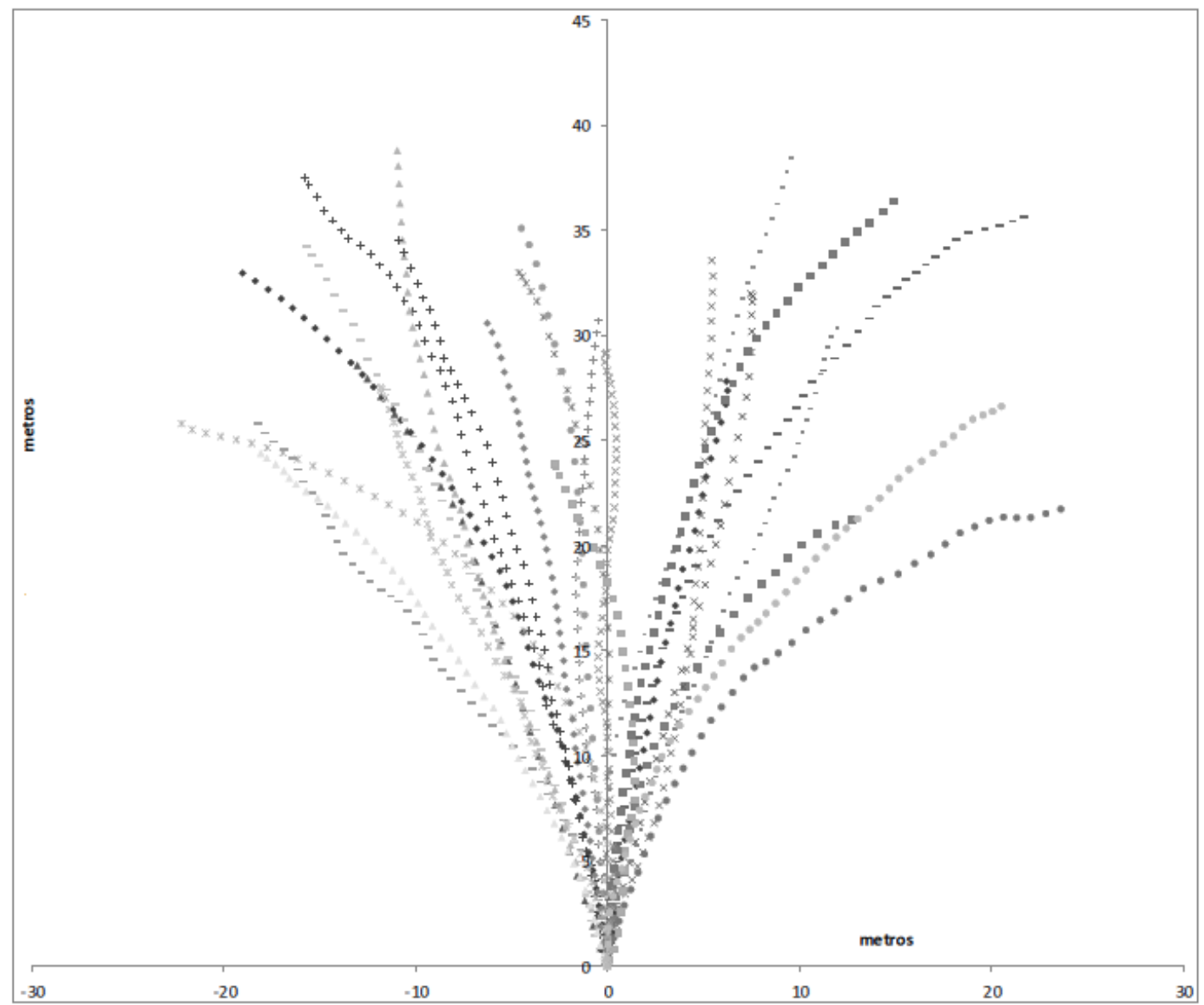

Figura 11. Trajetórias realizadas pelos participantes dentro da área experimental, durante o caminhar não visual no retorno à origem para a distância de $30 \mathrm{~m}$ na tarefa $\mathrm{L}$ 


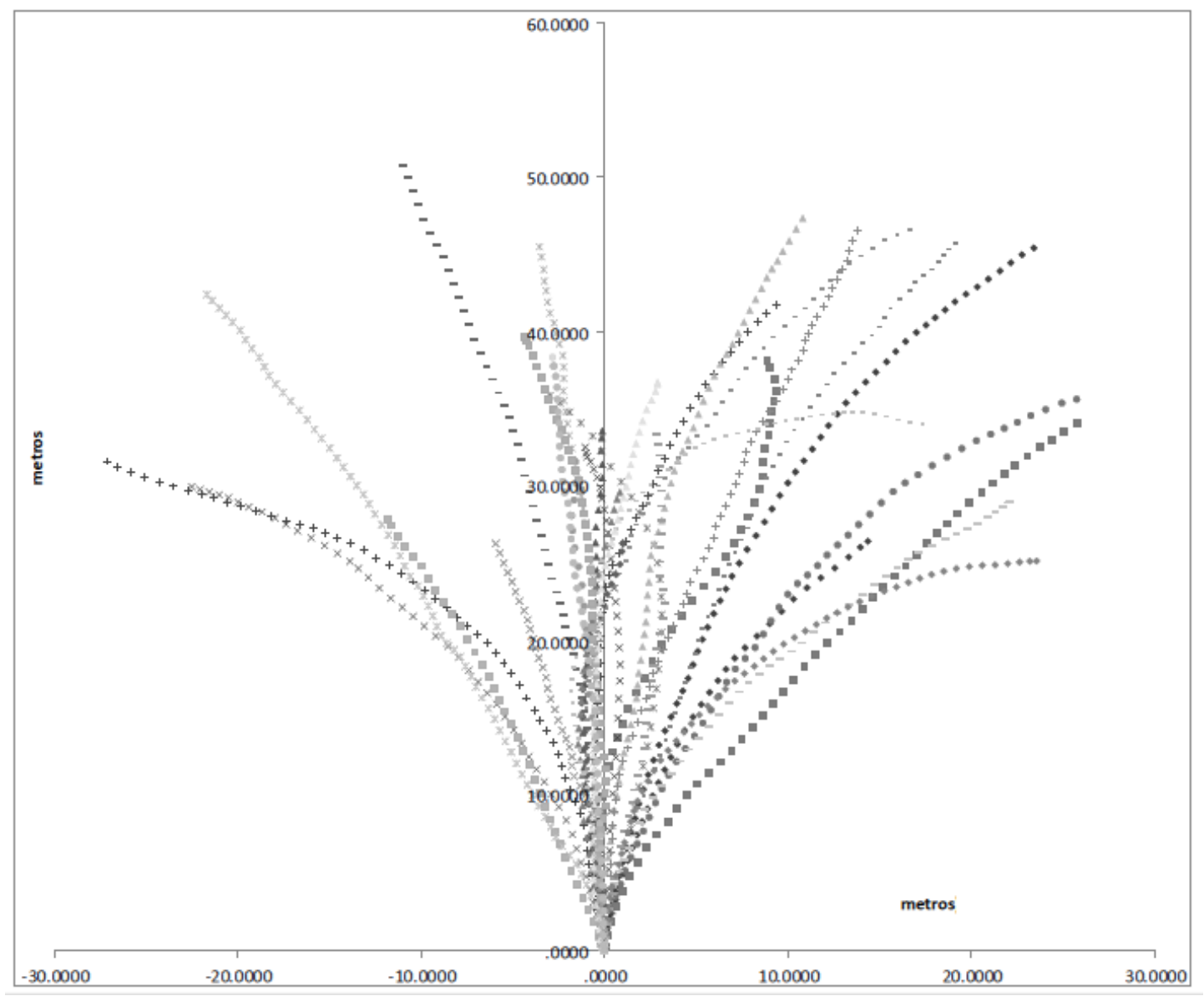

Figura 12. Trajetórias realizadas pelos participantes dentro da área experimental, durante o caminhar não visual no retorno à origem para a distância de $41,60 \mathrm{~m}$ na tarefa $\mathrm{L}$

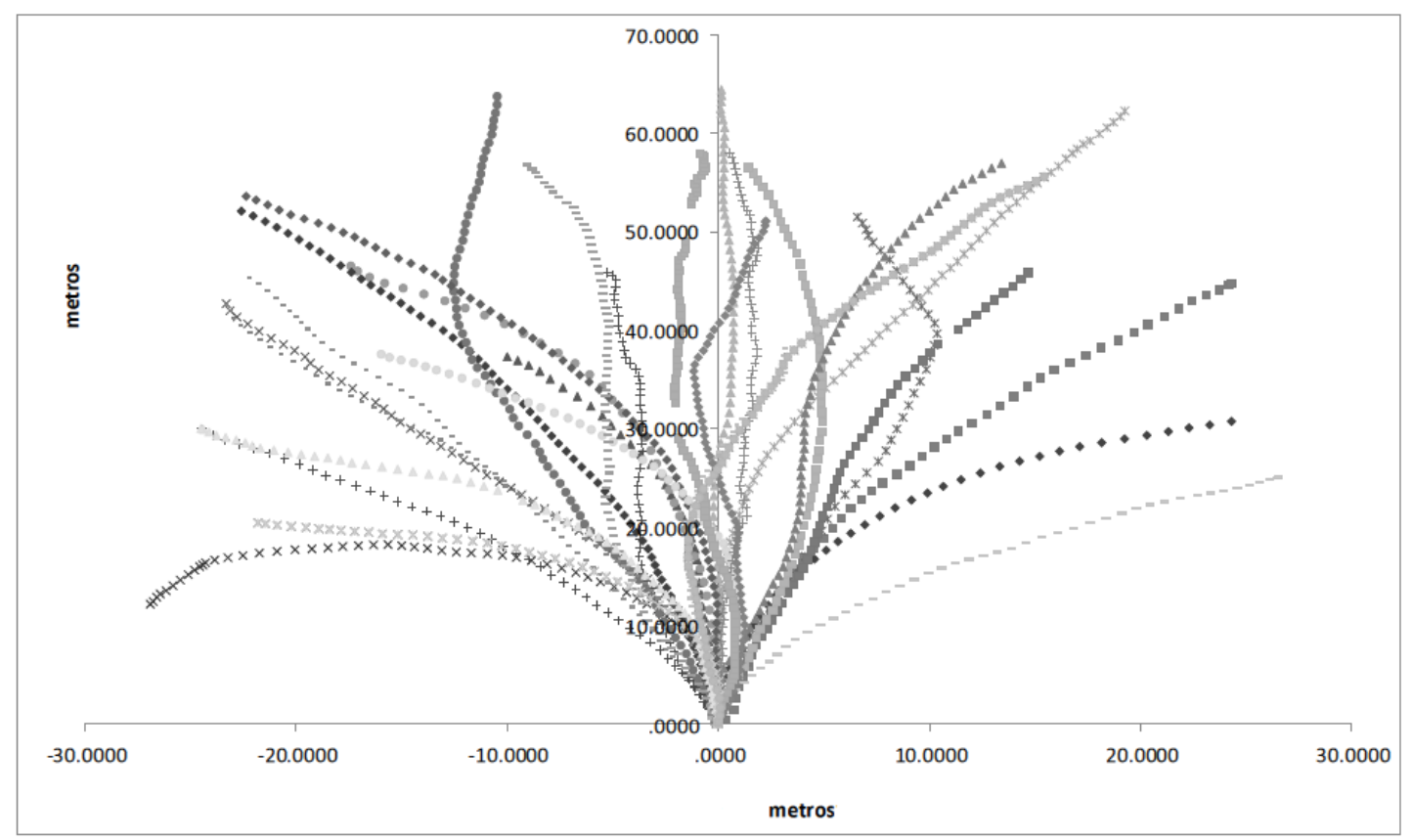

Figura 13. Trajetórias realizadas pelos participantes dentro da área experimental, durante o caminhar não visual no retorno à origem para a distância de $57,69 \mathrm{~m}$ na tarefa $\mathrm{L}$ 


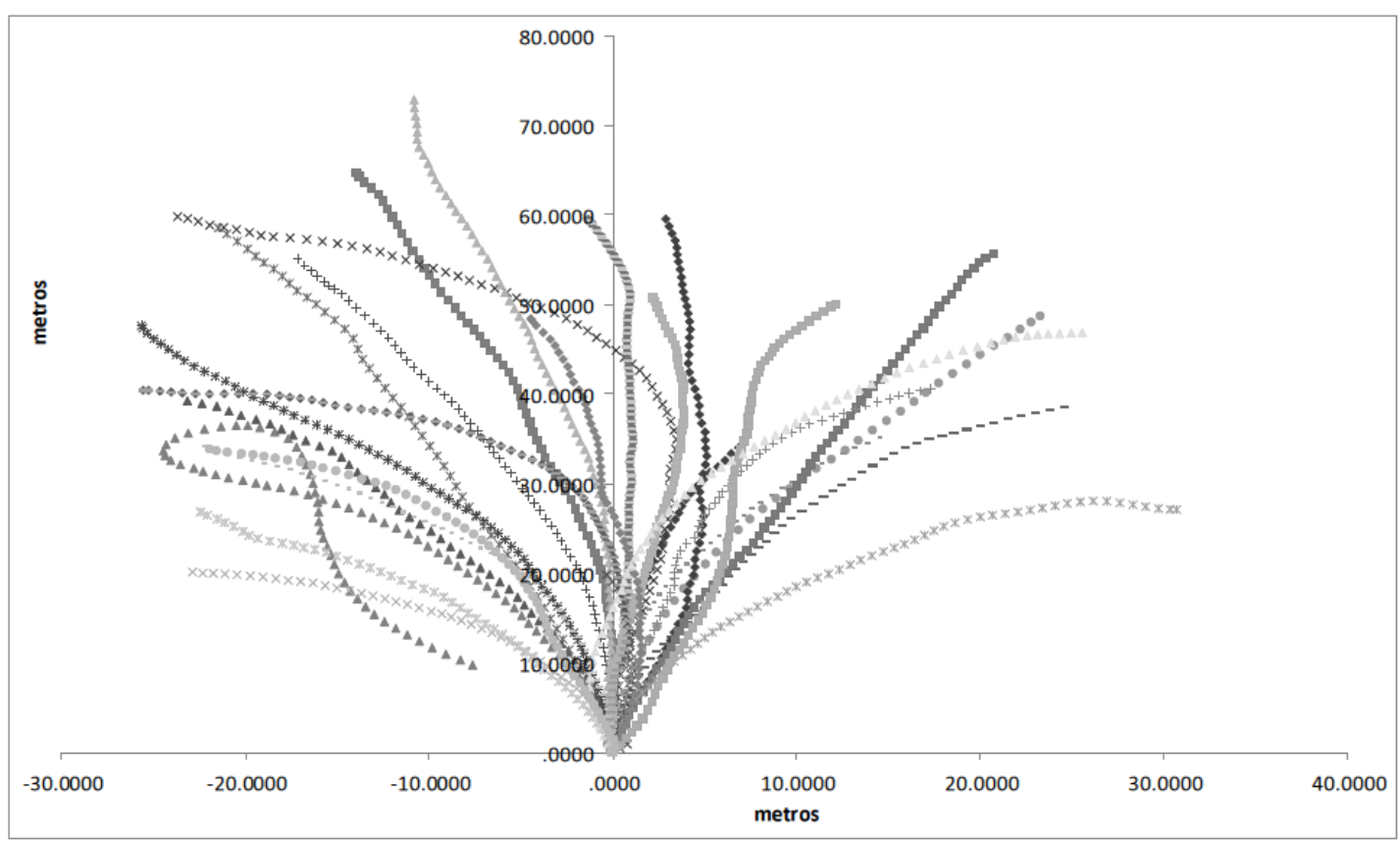

Figura 14. Trajetórias realizadas pelos participantes dentro da área experimental, durante o caminhar não visual no retorno à origem para a distância de $80,00 \mathrm{~m}$ na tarefa $\mathrm{L}$

Motivado pelo fato de que a maior parte das trajetórias formavam arcos de circunferências e/ou retas, tais trajetórias foram classificadas em cinco padrões geométricos, quais sejam: (a) trajetória reta, na qual os erros com relação a uma trajetória reta ideal foram ponto a ponto menores que $1,0 \mathrm{~m}$, (b) trajetória circular, na qual os erros com respeito a um arco de circunferência ideal foram ponto a ponto menores que $1,0 \mathrm{~m}$, (c) trajetória reta e circular, participante inicialmente próximo da trajetória reta e, depois, próximo da trajetória circular, com erros ponto a ponto menores que $1,0 \mathrm{~m},(\mathrm{~d})$ trajetória reta e reta, participante inicialmente próximo da trajetória reta e, após alguns metros caminhados, executou um ligeiro desvio de direção e moveu-se em uma nova trajetória reta inclinada da primeira, com erros ponto a ponto menores que $1,0 \mathrm{~m}$ e (e) trajetória alternada ou zig-zag, participante com alternância da trajetória entre desvios crescentes e decrescentes. Os padrões descritos anteriormente são mostrados na Figura 15 . Note que a trajetória reta engloba não somente a reta formada entre origem e a posição do alvo (correspondendo ao eixo vertical de referência do campo de futebol), mas também as diversas trajetórias retas e inclinadas com relação ao eixo vertical local e com origem no mesmo ponto de início. As trajetórias (c) e (d) possuem o mesmo padrão inicial, ou seja, o participante caminha uma trajetória reta ao longo do eixo vertical local, diferenciando-se pelo final da trajetória, que pode ser ora uma reta com diferente inclinação ou um arco de circunferência, respectivamente. Por fim é importante 
frisar que a trajetória alternada (e) não possui um padrão geométrico bem definido, exceto pelo fato que o sujeito alterna bruscamente o padrão de sua trajetória em determinado momento da tentativa.

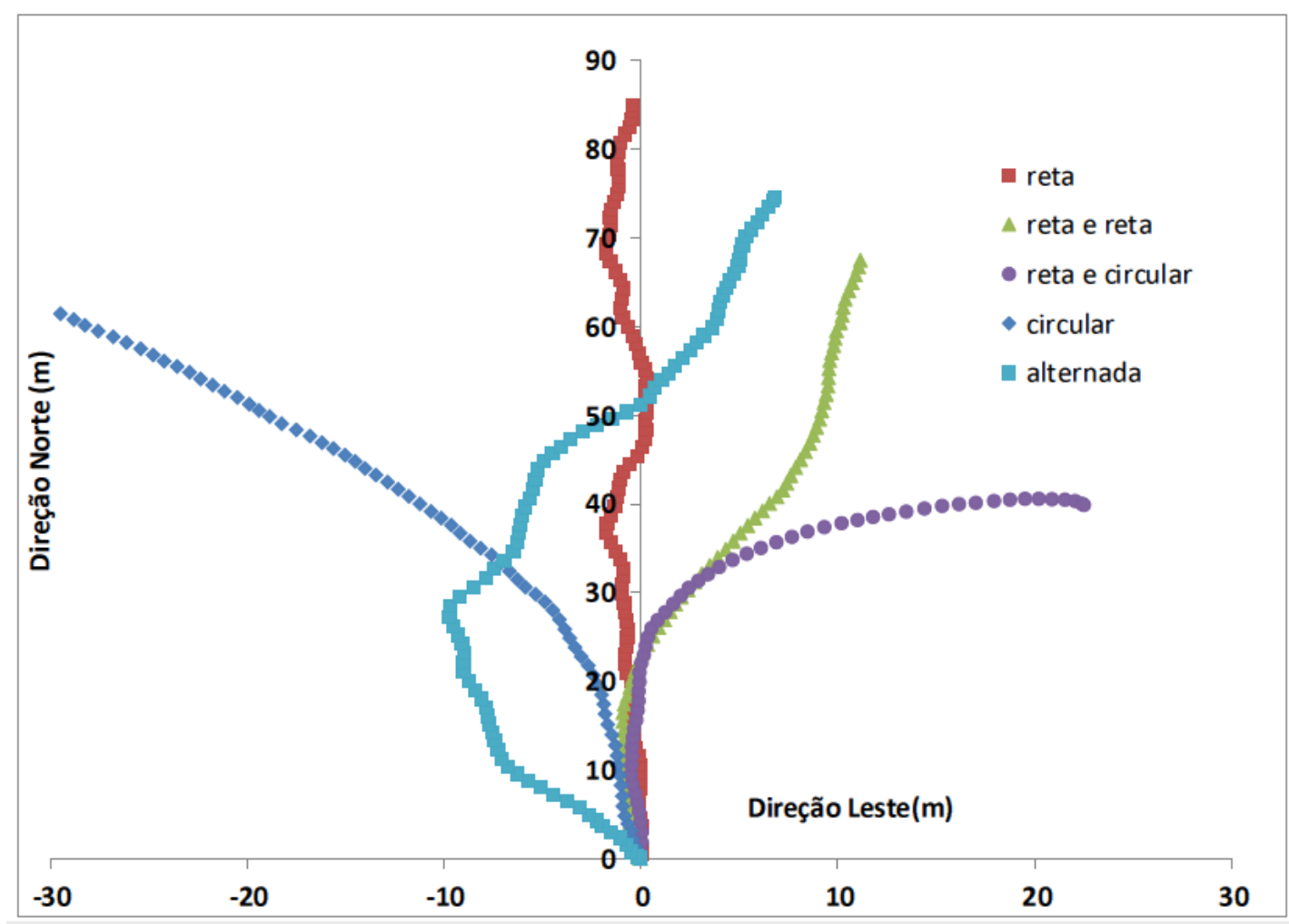

Figura 15. Exemplo das trajetórias observadas e suas diferentes classificações. No sistema de referência das tarefas $\mathrm{V}, \mathrm{Lv}$ e L, a direção horizontal é paralela às traves do campo e a direção vertical é perpendicular a elas. A origem está localizada na marca do pênalti.

Após quantificar as trajetórias dos participantes em função da classificação apresentada anteriormente em cada uma das distâncias, observou-se que o padrão mais comum encontrado foi o da trajetória circular, enquanto que o mais raro de ocorrer foi o da trajetória alternada. As análises descritivas dos padrões das trajetórias nas tarefas experimentais são apresentadas nas Tabelas 1,2 e 3. 
Tabela 1. Padrões das trajetórias da Tarefa V. Porcentagem (\%) das trajetórias observadas (reta, retacircular, circular, alternada, e reta-reta) em função das distâncias de apresentação do alvo de 30,00; 41,$60 ; 57,69$ e $80,00 \mathrm{~m}$.

\begin{tabular}{lccccc}
\hline Distância(m) & Reta(\%) & Reta- circular(\%) & Circular(\%) & Alternada(\%) & Reta-reta(\%) \\
\hline 30,00 & 28,57 & 2,86 & 65,71 & 0,00 & 2,86 \\
41,60 & 27,78 & 22,22 & 38,89 & 8,33 & 2,78 \\
57,69 & 25,00 & 33,33 & 36,11 & 2,78 & 2,78 \\
80,00 & 25,00 & 19,44 & 30,56 & 2,78 & 22,22 \\
\hline
\end{tabular}

Tabela 2. Padrões das trajetórias da Tarefa Lv. Porcentagem (\%) das trajetórias observadas (reta, retacircular, circular, alternada, e reta-reta) em função das distâncias de apresentação do alvo de 30,00; 41,$60 ; 57,69$ e $80,00 \mathrm{~m}$.

\begin{tabular}{lccccc}
\hline Distância(m) & Reta(\%) & Reta-circular(\%) & Circular(\%) & Alternada(\%) & Reta-reta(\%) \\
\hline 30,00 & 69,44 & 8,33 & 19,44 & 0,00 & 2,78 \\
41,60 & 52,78 & 13,89 & 11,11 & 5,56 & 16,67 \\
57,69 & 41,67 & 16,67 & 13,89 & 13,89 & 13,89 \\
80,00 & 36,36 & 24,24 & 12,12 & 3,03 & 24,24
\end{tabular}

Tabela 3. Padrões das trajetórias da Tarefa L. Porcentagem (\%) das trajetórias observadas (reta, retacircular, circular, alternada, e reta-reta) em função das distâncias de 30,00;41,60;57,69 e 80,00 m.

\begin{tabular}{lccccc}
\hline Distância(m) & Reta(\%) & Reta-circular(\%) & Circular(\%) & Alternada(\%) & Reta- reta(\%) \\
\hline 30,00 & 69,70 & 9,09 & 21,21 & 0 & 2,78 \\
41,60 & 66,67 & 0,00 & 15,15 & 5,56 & 16,67 \\
57,69 & 43,33 & 16,67 & 13,89 & 13,89 & 13,89 \\
80,00 & 36,67 & 13,33 & 11,11 & 2,78 & 22,22 \\
\hline
\end{tabular}

Para verificar possíveis diferenças entre as tarefas em cada uma das distâncias testadas, os índices dos padrões das trajetórias dos participantes foram analisados através do teste não paramétrico de Friedman seguido do teste U de Mann-Whitney, para identificação 
das diferenças entre tarefas e distâncias.

A análise dos dados evidenciou que os índices dos padrões das trajetórias foram heterogêneos entre as tarefas, $(\mathrm{Fr})=765,544, \mathrm{p} \leq 0,05$. Através da comparação par a par (tarefas e distâncias) foi possível identificar que nas tarefas Lv e L, os participantes exibiram maior índice de trajetórias retilíneas nas distâncias iniciais da escala (30,00 e 41,60 metros; respectivamente $69,44 \%$ e $52,78 \%$ e $69,70 \%$ e $66,67 \%$ ) em comparação aos participantes da tarefa V $(28,57 \%$ e $27,78 \%)(p s \leq 0,05)$.

Por outro lado, os participantes da Tarefa V apresentaram maior índice de trajetórias circulares nas distâncias de 30,00; 41,60; 57,69 e 80 m (respectivamente, 65,71\%; 38,89\%; $36,11 \%$ e 30,56\%) em comparação aos participantes da tarefa Lv (respectivamente, 19,44\%; $11,11 \% ; 13,89 \%$ e 12,12\%). E, em comparação à tarefa L, maior índice de trajetórias circulares em 30,00m $(19,44 \%)(p s \leq 0,05)$.

Também foram observadas diferenças significativas entre as tarefas $\mathrm{V}$ e Lv e L $(33,33 \%$ contra $16,67 \%$ e 16,67\%) nas trajetórias reta-circular na distância de 41,60m (ps $\leq$ 0,05). E, entre as tarefas Lv e L, somente na distância de 41,60m nos índices da trajetória reta $(52,78 \%$ contra $66,67 \%)$. Ademais, análise também revelou algumas curiosidades sobre o desempenho dos participantes. O número de trajetórias para os diferentes padrões tornam-se similares entre as tarefas na distância de maior amplitude $(80,00 \mathrm{~m})(p \geq 0,05)$.

\subsection{Preferência lateral}

Para verificar a consistência da direção dos desvios de orientação durante o caminhar às cegas, foi estabelecida uma pontuação que refletisse a preferência lateral das trajetórias dos participantes. Assim sendo, em cada tarefa, as trajetórias finalizadas para o lado direito foram indicadas com sinal positivo, e aquelas finalizadas para o lado esquerdo com sinal negativo. Após quantificar a direção lateral dos desvios dos participantes, nota-se que a maioria das trajetórias foi finalizada para o lado esquerdo do corpo (ver Figuras 16,17 e 18). Essa avaliação a partir dos dados descritivos foi corroborada pela análise inferencial, uma vez que as comparações dos índices de preferência lateral através do teste do Qui-quadro indicaram diferenças significativas entre as trajetórias finalizadas para o lado direito e esquerdo na tarefa $\mathrm{V}\left[30 \mathrm{~m}\left(\mathrm{X}^{2}=36,000 ; p=0,001\right) ; 41,60 \mathrm{~m}\left(\mathrm{X}^{2}=20,250 ; p=0,001\right) ; 57,69 \mathrm{~m}\right.$ $\left(\mathrm{X}^{2}=20,250 ; p=0,001\right)$ e $\left.80,00 \mathrm{~m}\left(\mathrm{X}^{2}=4,000 ; \mathrm{p}=0,046\right)\right]$ e tarefa $\operatorname{Lv}[30,00 \mathrm{~m}$ 
$\left(\mathrm{X}^{2}=18,458 ; p=0,001\right) ; 41,60 \mathrm{~m}\left(\mathrm{X}^{2}=18,458 ; p=0,001\right) ; 57,69 \mathrm{~m}\left(\mathrm{X}^{2}=14,254 ; p=0,001\right) \mathrm{e}$ $80 \mathrm{~m}\left(\mathrm{X}^{2}=13,755 ; p=0,001\right)$. Nessas tarefas, verificou-se que, independente da distância, a maioria das trajetórias significativamente desviaram-se para o lado esquerdo. Já, na tarefa L, os participantes desviaram-se mais frequentemente para o lado esquerdo nas distâncias de $30,00\left(\mathrm{X}^{2}=6,024 ; p=0,011\right)$ e 80,00 metros $\left(\mathrm{X}^{2}=8,647 ; p=0,001\right)$; para o lado direito na distância de 41,60m $\left(\mathrm{X}^{2}=8,647 ; p=0,003\right)$ e finalmente, na distância de 57,69m os índices foram similares $\left(\mathrm{X}^{2}=0,4890 ; p=0,484\right)$.

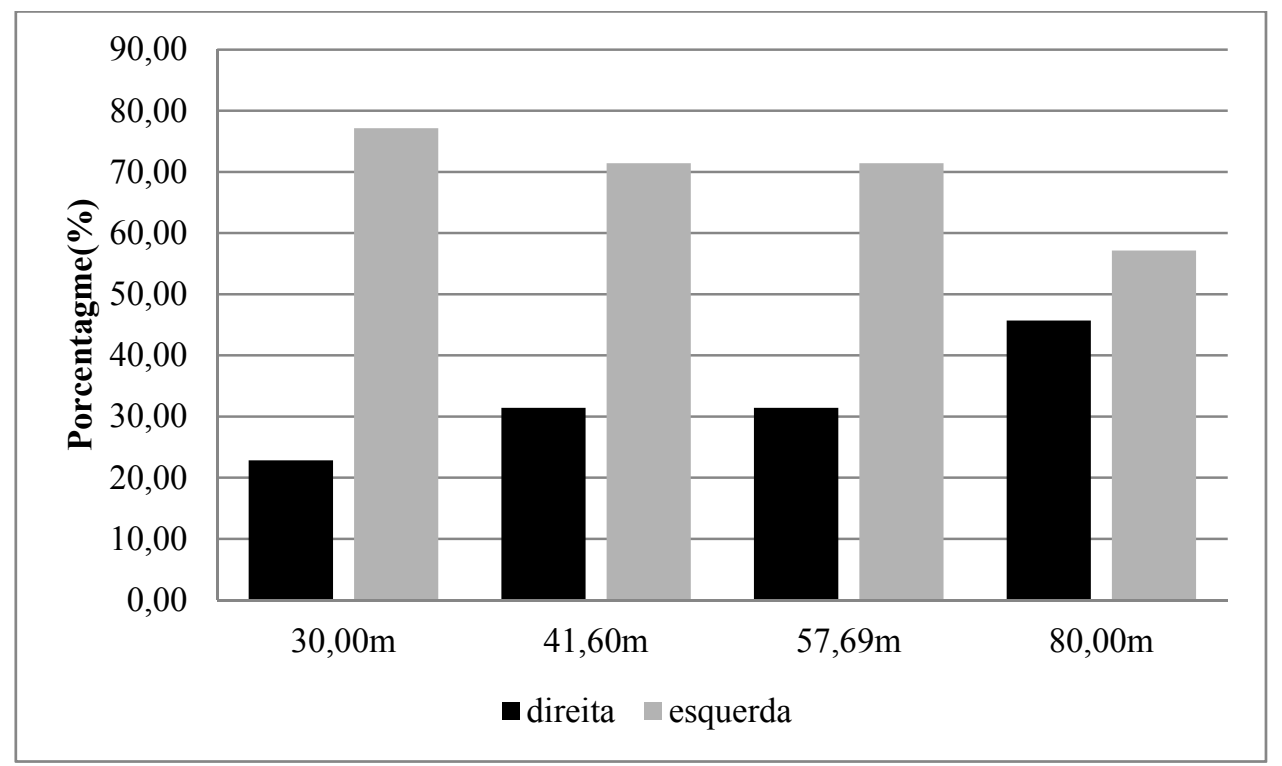

Figura 16. Pontuação dos desvios de orientação. Os resultados são expressos em termos de taxa de desvios para todos os participantes da tarefa $\mathrm{V}$.

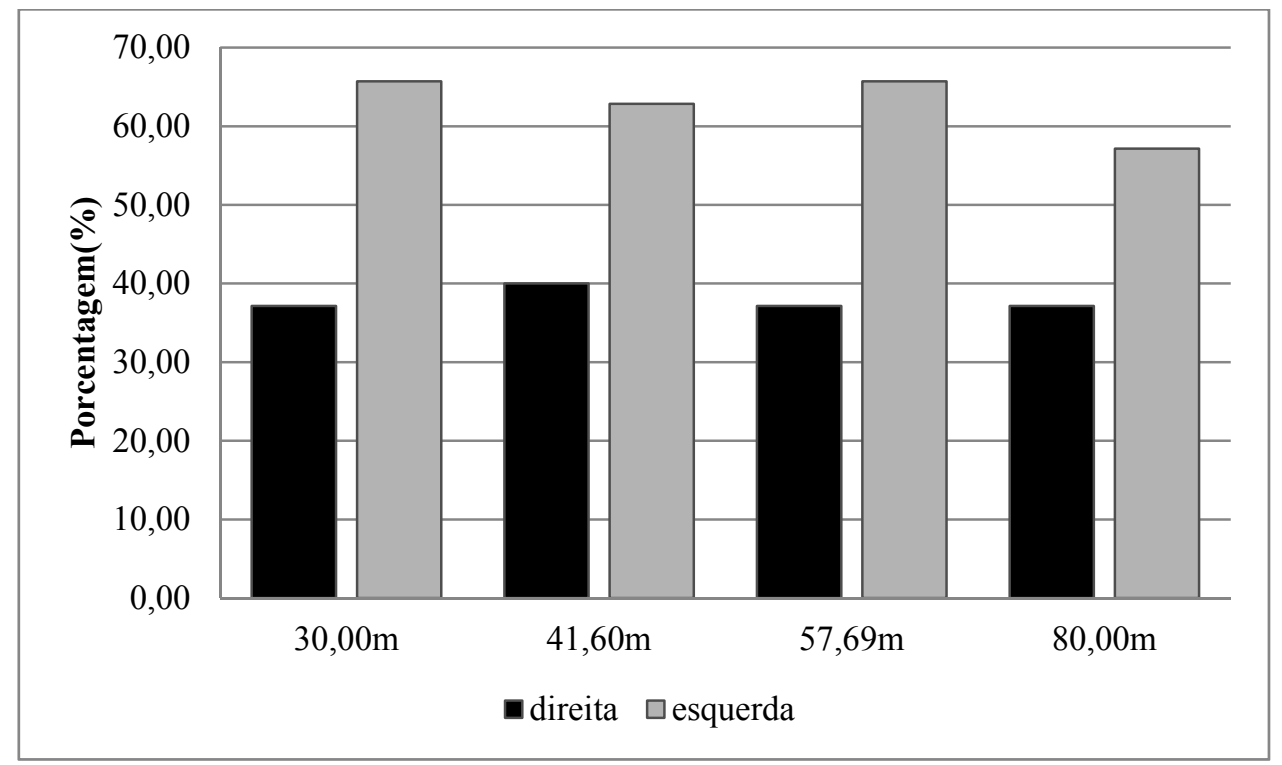

Figura 17. Pontuação dos desvios de orientação. Os resultados dos indivíduos são expressos em termos de taxa de desvios para todos os participantes da tarefa Lv. 


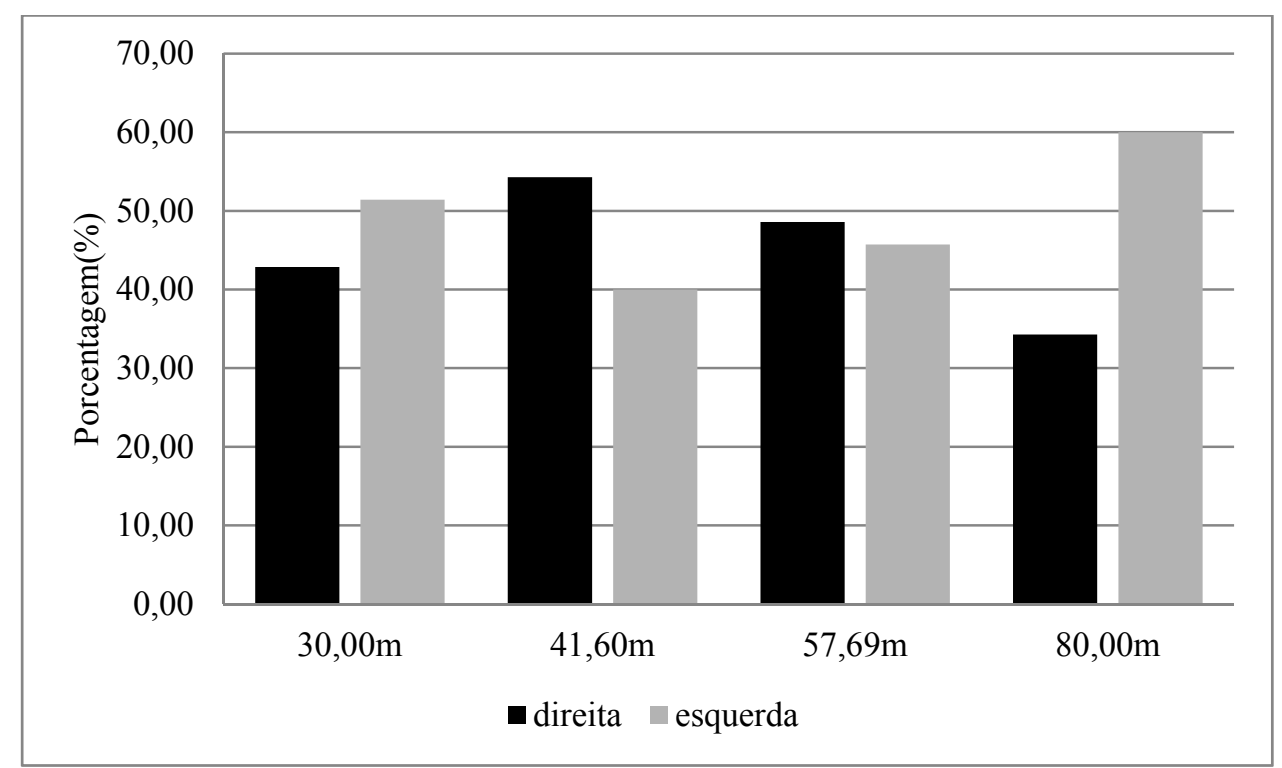

Figura 18. Pontuação dos desvios de orientação. Os resultados dos indivíduos são expressos em termos de taxa de desvios para todos os participantes da tarefa L.

\subsection{Análise da Trajetória Circular}

A inspeção visual de cada trajetória dos participantes, resultante do movimento do sujeito enquanto ele ou ela caminhava vendado, revelou que os sujeitos desviaram da trajetória reta inicial e realizaram como regra geral trajetórias circulares, tais como arcos de circunferência ou retas com arco de circunferência. Para verificar se a trajetória circular foi de fato o padrão de trajetória mais comum, utilizou-se uma análise matemática mais rigorosa apresentada no Apêndice B. De acordo com a explicação deste modelo matemático, calculouse a velocidade linear e estimou-se a velocidade angular com o objetivo de determinar o raio médio de cada trajetória para cada uma das quatro distâncias do sujeito ao alvo.

As análises descritivas dos resultados das trajetórias circulares nas tarefas três experimentais são apresentadas nas tabelas 4,5 e 6 . 
Tabela 4. Valores médios e respectivos desvios-padrão $( \pm \mathrm{dp})$ do deslocamento(m), da distância percorrida $(\mathrm{m})$, velocidade $\left(\mathrm{v}_{\mathrm{m}}\right)$, desvio angular $\left(\alpha_{\mathrm{m}}\right)$, velocidade angular $\left(\dot{\psi}_{\mathrm{m}}\right)$, e raio $\left(\mathrm{R}_{\mathrm{m}}\right)$ das trajetórias circulares dos participantes da tarefa $\mathrm{V}$, em função das distâncias de apresentação do alvo de 30,$00 ; 41,60 ; 57,69$ e 80,00 metros.

\begin{tabular}{ccccc}
\hline & \multicolumn{4}{c}{ Distância $(\mathrm{m})$} \\
\hline Deslocamento(m) & 30.00 & 41.60 & 57.69 & 80.00 \\
\hline & 28,24 & 33,41 & 44,35 & 44,35 \\
& $( \pm 7,40)$ & $( \pm 10,84)$ & $( \pm 10,84)$ & $( \pm 12,93)$ \\
\hline Distância Percorrida $(\mathrm{m})$ & 28,97 & 34,30 & 45,34 & 49,96 \\
\hline$v_{m}(\mathrm{~m} / \mathrm{s})$ & $( \pm 7,25)$ & $( \pm 11,26)$ & $( \pm 11,26)$ & $( \pm 12,98)$ \\
\hline$\alpha_{m}\left(^{\circ}\right)$ & 1,10 & 1,07 & 1,17 & 0,94 \\
& $( \pm 0,078)$ & $( \pm 0,072)$ & $( \pm 0,056)$ & $( \pm 0,043)$ \\
\hline$\dot{\psi}_{m}(\mathrm{rad} / \mathrm{s})$ & 20,86 & 18,43 & 16,24 & 25,58 \\
& $( \pm 11,26)$ & $( \pm 4,28)$ & $( \pm 2,84)$ & $( \pm 4,01)$ \\
\hline$R_{m}(\mathrm{~m})$ & 0,0190 & 0,0197 & 0,0143 & 0,0183 \\
& $( \pm 0,0014)$ & $( \pm 0,0045)$ & $( \pm 0,0017)$ & $( \pm 0,0025)$ \\
\hline & 59.19 & 71.45 & 80.67 & 84.57 \\
& $( \pm 28,80)$ & $( \pm 28.27)$ & $( \pm 33.25)$ & $( \pm 25.71)$ \\
\hline
\end{tabular}

Tabela 5. Valores médios e respectivos desvios-padrão $( \pm \mathrm{dp})$ do deslocamento(m), da distância percorrida $(\mathrm{m})$, velocidade $\left(\mathrm{v}_{\mathrm{m}}\right)$, desvio angular $\left(\alpha_{\mathrm{m}}\right)$, velocidade angular $\left(\dot{\psi}_{\mathrm{m}}\right)$, e raio $\left(\mathrm{R}_{\mathrm{m}}\right)$ das trajetórias circulares dos participantes da tarefa LV, em função das distâncias de apresentação do alvo de 30,$00 ; 41,60 ; 57,69$ e 80,00 metros.

\begin{tabular}{ccccc}
\hline & \multicolumn{4}{c}{ Distância $(\mathrm{m})$} \\
\hline Deslocamento(m) & 30,00 & 41,60 & 57,69 & 80,00 \\
\hline & 31,75 & 40,58 & 41,39 & 65,37 \\
& $( \pm 6,95)$ & $( \pm 1,39)$ & $( \pm 6,52)$ & $( \pm 12,92)$ \\
\hline Distância Percorrida(m) & 32,35 & 42,33 & 43,30 & 67,71 \\
\hline$v_{m}(m / s)$ & $( \pm 7,15)$ & $( \pm 0,73)$ & $( \pm 5,70)$ & $( \pm 9,18)$ \\
\hline$\alpha_{m}\left(^{\circ}\right)$ & 0,93 & 0,89 & 1,03 & 1,16 \\
& $( \pm 0,08)$ & $( \pm 0,053)$ & $( \pm 0,28)$ & $( \pm 0,13)$ \\
\hline$\dot{\psi}_{m}(\mathrm{rad} / s)$ & 20,67 & 50,04 & 26,20 & 25,69 \\
& $( \pm 5,14)$ & $( \pm 18,57)$ & $( \pm 11,37)$ & $( \pm 6,38)$ \\
\hline$R_{m}(m)$ & 0,006 & 0,018 & 0,020 & 0,016 \\
& $( \pm 0,003)$ & $( \pm 0,012)$ & $( \pm 0,006)$ & $( \pm 0,006)$ \\
\hline & 45,48 & 57,48 & 48,48 & 91,45 \\
& $( \pm 18,77)$ & $( \pm 34,50)$ & $( \pm 24,10)$ & $( \pm 31,74)$ \\
\hline
\end{tabular}


Tabela 6. Valores médios e respectivos desvios-padrão $( \pm \mathrm{dp})$ do deslocamento(m), da distância percorrida $(\mathrm{m})$, velocidade $\left(\mathrm{v}_{\mathrm{m}}\right)$, desvio angular $\left(\alpha_{\mathrm{m}}\right)$, velocidade angular $\left(\dot{\psi}_{\mathrm{m}}\right)$, e raio $\left(\mathrm{R}_{\mathrm{m}}\right)$ das trajetórias circulares dos participantes da tarefa $\mathrm{V}$, em função da distância de 30,00; 41,60;57,69 e 80,00 metros.

\begin{tabular}{|c|c|c|c|c|}
\hline & \multicolumn{4}{|c|}{ Distância (m) } \\
\hline & 30,00 & 41,60 & 57,69 & 80,00 \\
\hline \multirow[t]{2}{*}{ Deslocamento(m) } & 37,88 & 38,97 & 47,02 & 65,37 \\
\hline & $( \pm 5,16)$ & $( \pm 7,14)$ & $( \pm 7,68)$ & $( \pm 6,22)$ \\
\hline & 40,27 & 41,20 & 49,33 & 67,71 \\
\hline Distância Percorrida(m) & $( \pm 5,66)$ & $( \pm 7,29)$ & $( \pm 6,49)$ & $( \pm 5,99)$ \\
\hline \multirow[t]{2}{*}{$v_{m}(m / s)$} & 0,84 & 0,84 & 0,90 & 0,81 \\
\hline & $( \pm 0,028)$ & $( \pm 0,07)$ & $( \pm 0,20)$ & $( \pm 0,002)$ \\
\hline \multirow[t]{2}{*}{$\alpha_{m}\left(^{\circ}\right)$} & 32,07 & 35,29 & 32,26 & 34,80 \\
\hline & $( \pm 1,90)$ & $( \pm 6,34)$ & $( \pm 6,06)$ & $( \pm 1,92)$ \\
\hline \multirow[t]{2}{*}{$\dot{\psi}_{m}(\mathrm{rad} / \mathrm{s})$} & 0,024 & 0,026 & 0,022 & 0,023 \\
\hline & $( \pm 0,0037)$ & $( \pm 0,004)$ & $( \pm 0,002)$ & $( \pm 0,003)$ \\
\hline \multirow[t]{2}{*}{$R_{m}(m)$} & 34.66 & 33,73 & 30,94 & 41,73 \\
\hline & $( \pm 10,48)$ & $( \pm 9,57)$ & $( \pm 7,32)$ & $( \pm 13,06)$ \\
\hline
\end{tabular}

Por meio de testes t para amostras emparelhadas, compararam-se as médias da velocidade do caminhar entre a condição experimental e controle em cada uma das tarefas em função das distancias testadas. Conforme pode ser visto na Tabela 7, os resultados não indicaram diferenças significativas $(\mathrm{ps} \geq 0,05)$ entre as condições, em todas as tarefas Em função das distâncias testadas. 
Tabela 7. Teste t de Student para amostras emparelhadas para comparação entre as médias da velocidade do caminhar entre a condição experimental e controle para as tarefas: (A) produção de distâncias a um alvo visualmente percebido, (B) reprodução de distâncias caminhada sob condições visuais, e, (C) reprodução de distâncias após o caminhar não visual em função das distâncias testadas $(30,00 ; 41,60 ; 57,69$ e 80,00 metros).

A. Tarefa de produção de distâncias a um alvo visualmente percebido (V)

\begin{tabular}{|c|c|c|c|}
\hline Distâncias(m) & Condição & Velocidade $(\mathrm{m} / \mathrm{s})$ & p-valor \\
\hline \multirow{2}{*}{ Par $1(30,00 \mathrm{~m})$} & Experimental & $1,098( \pm 0,078 \mathrm{~m} / \mathrm{s})$ & \multirow{2}{*}{$\mathrm{p} \geq 0,05$} \\
\hline & Controle & $0,978( \pm 0,067 \mathrm{~m} / \mathrm{s})$ & \\
\hline \multirow{2}{*}{$\operatorname{Par} 2(41,60 \mathrm{~m})$} & Experimental & $1,074( \pm 0,0721 \mathrm{~m} / \mathrm{s})$ & \multirow{2}{*}{$\mathrm{p} \geq 0,05$} \\
\hline & Controle & $1,052( \pm 0,0753 \mathrm{~m} / \mathrm{s})$ & \\
\hline \multirow{2}{*}{ Par $3(57,69 m)$} & Experimental & $1,171( \pm 0,055 \mathrm{~m} / \mathrm{s})$ & \multirow{2}{*}{$\mathrm{p} \geq 0,05$} \\
\hline & Controle & $1,132( \pm 0,275 \mathrm{~m} / \mathrm{s})$ & \\
\hline \multirow{2}{*}{ Par $4(80,00 \mathrm{~m})$} & Experimental & $0,939( \pm 0,0434 \mathrm{~m} / \mathrm{s})$ & \multirow{2}{*}{$\mathrm{p} \geq 0,05$} \\
\hline & Controle & $1,084( \pm 0,141 \mathrm{~m} / \mathrm{s})$ & \\
\hline
\end{tabular}

B. Tarefa de reprodução de distâncias após o caminhar sob condições visuais (Lv)

\begin{tabular}{|c|c|c|c|}
\hline Distâncias(m) & Condição & Velocidade $(\mathrm{m} / \mathrm{s})$ & $p$-valor \\
\hline \multirow{2}{*}{ Par 1(30,00m) } & Experimental & $1,098( \pm 0,078 \mathrm{~m} / \mathrm{s})$ & \multirow{2}{*}{$\mathrm{p} \geq 0,05$} \\
\hline & Controle & $1,16( \pm 0,103 \mathrm{~m} / \mathrm{s})$ & \\
\hline \multirow{2}{*}{$\operatorname{Par} 2(41,60 \mathrm{~m})$} & Experimental & $1,074( \pm 0,0721 \mathrm{~m} / \mathrm{s})$ & \multirow{2}{*}{$\mathrm{p} \geq 0,05$} \\
\hline & Controle & $1,09( \pm 0,114 \mathrm{~m} / \mathrm{s})$ & \\
\hline \multirow{2}{*}{ Par 3(57,69m) } & Experimental & $1,171( \pm 0,055 \mathrm{~m} / \mathrm{s})$ & \multirow{2}{*}{$\mathrm{p} \geq 0,05$} \\
\hline & Controle & $1,23( \pm 0,297 \mathrm{~m} / \mathrm{s})$ & \\
\hline \multirow{2}{*}{$\operatorname{Par} 4(80,00 \mathrm{~m})$} & Experimental & $0,939( \pm 0,0434 \mathrm{~m} / \mathrm{s})$ & \multirow{2}{*}{$\mathrm{p} \geq 0,05$} \\
\hline & Controle & $1,22( \pm 0,300 \mathrm{~m} / \mathrm{s})$ & \\
\hline
\end{tabular}

C. Tarefa de reprodução de distâncias após o caminhar não visual (L)

\begin{tabular}{|c|c|c|c|}
\hline Distâncias(m) & Condição & Velocidade $(\mathrm{m} / \mathrm{s})$ & $p$-valor \\
\hline \multirow{2}{*}{ Par $1(30,00 \mathrm{~m})$} & Experimental & $0,823( \pm 0,028 \mathrm{~m} / \mathrm{s})$ & \multirow{2}{*}{$\mathrm{p} \geq 0,05$} \\
\hline & Controle & $1,059( \pm 0,167 \mathrm{~m} / \mathrm{s})$ & \\
\hline \multirow{2}{*}{ Par $2(41,60 m)$} & Experimental & $0,834( \pm 0,07 \mathrm{~m} / \mathrm{s})$ & \multirow{2}{*}{$\mathrm{p} \geq 0,05$} \\
\hline & Controle & $1,040( \pm 0,137 \mathrm{~m} / \mathrm{s})$ & \\
\hline \multirow{2}{*}{ Par $3(57,69 m)$} & Experimental & $0,899( \pm 0,198 \mathrm{~m} / \mathrm{s})$ & \multirow{2}{*}{$\mathrm{p} \geq 0,05$} \\
\hline & Controle & $1,130( \pm 0,293 \mathrm{~m} / \mathrm{s})$ & \\
\hline \multirow{2}{*}{$\operatorname{Par} 4(80,00 \mathrm{~m})$} & Experimental & $0,803( \pm 0,002 \mathrm{~m} / \mathrm{s})$ & \multirow{2}{*}{$\mathrm{p} \geq 0,05$} \\
\hline & Controle & $1,132( \pm 0,284 \mathrm{~m} / \mathrm{s})$ & \\
\hline
\end{tabular}


Testes de normalidade Shapiro-Wilk revelaram valores de significância acima de 0,05. A distribuição amostral dos grupos aproximou-se de uma distribuição normal.

Para verificar se a velocidade angular e o raio das trajetórias circulares produzidas pelos participantes do estudo variaram em função das condições experimentais das três tarefas realizadas, foram calculadas análises de variância mistas (3 tarefas x 4 distâncias) com medidas repetidas no último fator.

A ANOVA da variável velocidade angular revelou efeito do fator tarefas $[\mathrm{F}(2,10)=$ $4,665 ; \mathrm{p}=0,037]$ e distâncias $[\mathrm{F}(3,8)=10,247 ; \mathrm{p}=0,004]$. Não houve interação dos fatores distâncias e tarefas $[(\mathrm{F}(6,30)=0,804 ; \mathrm{p}=0,139]$. Comparando-se as medidas da variável entre as tarefas em cada uma das distâncias testadas por meio de testes t, observa-se que a velocidade angular na distância de $57,69 \mathrm{~m}$ na tarefa $\mathrm{V}(0,0143 \pm 0,0017 \mathrm{rad} / \mathrm{s})$ foi significativamente menor comparado à mesma variável nas tarefas $\operatorname{Lv}(0,022 \pm 0,0017 \mathrm{rad} / \mathrm{s})$ e $\mathrm{L}(0,0190 \pm 0,0014 \mathrm{rad} / \mathrm{s})$.

Em relação a variável raio da trajetória circular a ANOVA revelou efeito significativo do fator tarefas $[F(2,17)=9,633 ; p=0,002]$. Não houve efeito do fator distâncias $[F(3,51)=$ $0,530 ; p=0,664]$, nem da interação dos fatores tarefas e distâncias [(F6,51)=1,013; $p=0,428]$. Os contrastes a posteriori entre as tarefas indicaram que o raio da trajetória circular da tarefa $\mathrm{V}(80,673 \pm 33,35)$ foi, em média, significativamente maior comparado à mesma variável nas tarefas $\operatorname{Lv}(48,48 \pm 24,10)$ e L $(30,94 \pm 41,73)$ na distância de $41,60 \mathrm{~m}(\mathrm{p} \leq 0,05)$.

É interessante observar que o desempenho de uma tarefa específica de trajetória circular pode ser avaliado através da razão $\mathrm{v} / \psi^{\cdot}$, isto é, através do seu raio. Nos casos extremos, uma trajetória reta possui raio tendendo ao infinito (sujeito segue perfeitamente a trajetória reta ao alvo), enquanto que um ponto possui raio tendendo a zero (sujeito não sai do lugar).

Note que as hipóteses enumeradas no modelo matemático anterior são validas neste experimento. Os sujeitos, que caminham em um campo de futebol, possuem três graus de liberdade, pois seus movimentos ocorrem em um plano e eles não caminham de lado, mas sim sempre para frente. Além disso, a velocidade linear é aproximadamente constante. No final dos cálculos, observa-se que média dos erros entre a trajetória teórica calculada por (4) e a trajetória real é de $\mu=0,554 \mathrm{~m}$, com desvio padrão de $\sigma=0,285 \mathrm{~m}$ (veja Tabela 7). O erro médio está dentro da incerteza do GPS pós-processamento de 1-3 m e, portanto, a equação circular é uma aproximação adequada para estes dados. 
Tabela 8. Erro médio de $\mu$ entre as coordenadas do ponto da trajetória circular teórico e um ponto da trajetória real e o desvio padrão correspondente significa $\sigma$ como uma função de a distância do alvo

\begin{tabular}{clcccc}
\hline & & \multicolumn{4}{c}{ Distância $(\mathrm{m})$} \\
\hline \multirow{2}{*}{ Experimento 1 } & $\mu(m)$ & 0,300 & 41.60 & 57.69 & 80.00 \\
& $\sigma(m)$ & 0,30 & 0,54 & 0,42 & 0,61 \\
\multirow{2}{*}{ Experimento 2 } & $\mu(m)$ & 0,29 & 0,42 & 0,35 & 0,41 \\
& $\sigma(m)$ & 0,41 & 0,28 & 0,54 & 0,43 \\
& $\mu(m)$ & 0,50 & 0,64 & 0,30 & 0,34 \\
\hline \multirow{2}{*}{ Experimento 3 } & $\sigma(m)$ & 0,31 & 0,34 & 0,37 & 0,57 \\
& & & & & 0,32 \\
\hline
\end{tabular}

Por outro lado, é interessante notar que os maiores desvios entre a trajetória teórica e a trajetória real ocorreram no fim da caminhada, momento quando todos os sujeitos reduziam suas velocidades, pois consideravam que a trajetória aproximou-se da localização do alvo. Exemplos deste comportamento podem ser vistos na Figura 5. Com todas estas limitações, o modelo produz resultados impressionantes e comprovam que algumas trajetórias são de fato aproximadamente circulares.

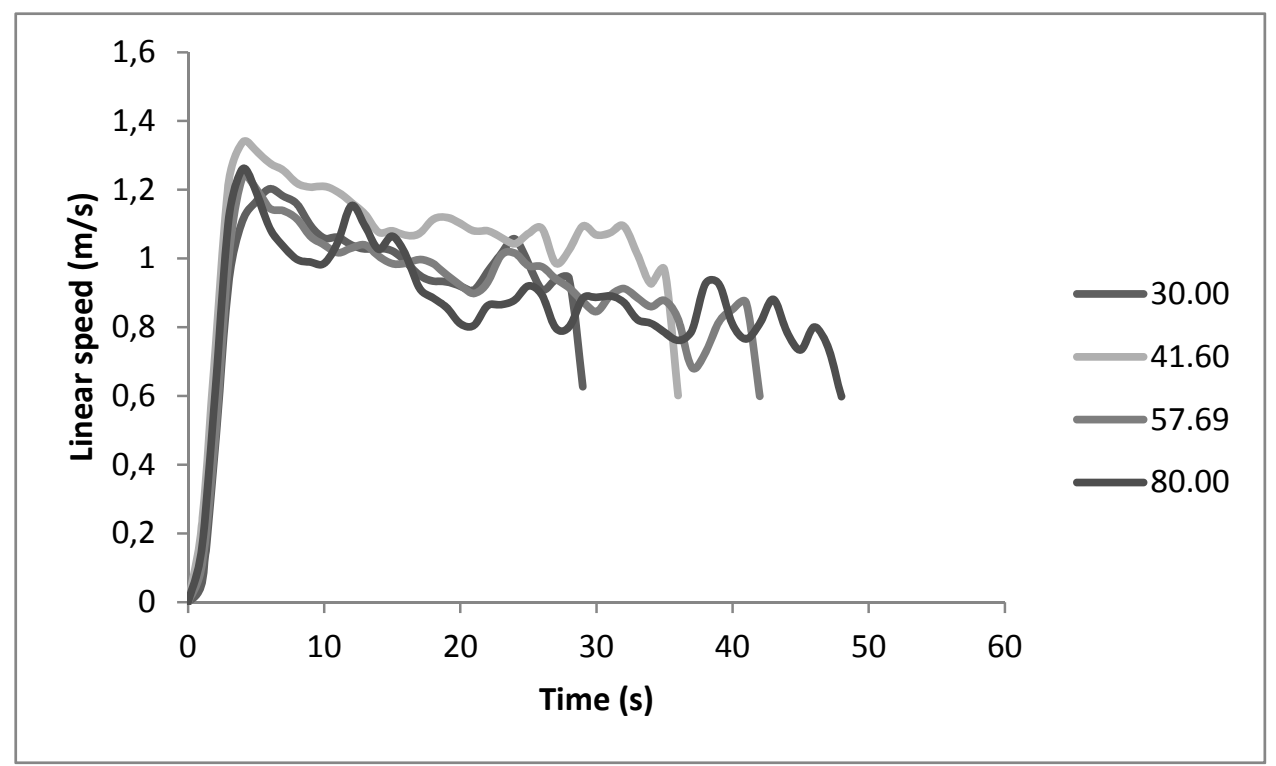

Figura 19. Exemplo do comportamento observado da velocidade angular $(\mathrm{m} / \mathrm{s})$ com relação ao tempo para um dos sujeitos no experimento $\mathrm{V}$ 


\subsection{Análise das trajetórias reta, reta-circular, alternada e reta-reta}

Também foram analisados os dados do deslocamento(m); da distância percorrida $(\mathrm{m})$, da velocidade $\left(\mathrm{v}_{\mathrm{m}}\right)$ e do desvio angular $\left(\alpha_{\mathrm{m}}\right)$, das trajetórias reta, reta-circular, reta-reta e alternada nas tarefas três experimentais (Tabelas 8,9 e 10). O objetivo desta analise foi avaliar se essas variáveis foram impactadas pelas características da tarefa e a amplitude das distâncias. É importante ressaltar que os piores desempenhos estão relacionados com maiores desvios angulares.

Tabela 9. Valores médios e respectivos desvios-padrão (dp) do deslocamento(m); da distância percorrida $(\mathrm{m})$, da velocidade $\left(\mathbf{v}_{\mathbf{m}}\right)$ e do desvio angular $\left(\boldsymbol{\alpha}_{\mathbf{m}}\right)$ das trajetórias reta, reta-circular, reta-reta e alternada dos participantes da tarefa $\mathrm{V}$ em função das distâncias de apresentação do alvo.

\begin{tabular}{crrrr}
\hline & \multicolumn{5}{c}{ Distancia $(\mathrm{m})$} \\
\hline Deslocamento(m) & 30.00 & 41.60 & 57.69 & 80.00 \\
\hline & 28,64 & 35,63 & 44,32 & 49,23 \\
& $( \pm 6,76)$ & $( \pm 7,43)$ & $( \pm 9,18)$ & $( \pm 13,60)$ \\
\hline Distância Percorrida(m) & 29,23 & 36,61 & 45,96 & 53,35 \\
\hline$v_{m}(m / s)$ & $( \pm 6,73)$ & $( \pm 7,82)$ & $( \pm 9,32)$ & $( \pm 15,24)$ \\
\hline$\alpha_{m}\left({ }^{\circ}\right)$ & 1,055 & 1,084 & 1,09 & 0,99 \\
& $( \pm 0,32)$ & $( \pm 0,25)$ & $( \pm 0,22)$ & $( \pm 0,19)$ \\
\hline & 20,26 & 16,16 & 15,72 & 19,82 \\
& $( \pm 11,84)$ & $( \pm 9,53)$ & $( \pm 1,78)$ & $( \pm 9,64)$ \\
\hline
\end{tabular}

Tabela 10. Valores médios e respectivos desvios-padrão (s) do deslocamento(m); da distância percorrida $(\mathrm{m})$, velocidade $\left(\mathrm{v}_{\mathrm{m}}\right)$ e desvio angular $\left(\alpha_{\mathrm{m}}\right)$ das trajetórias reta, reta-circular, reta-reta e alternada dos participantes da tarefa Lv em função das distâncias de apresentação do alvo.

\begin{tabular}{crrrr}
\hline & \multicolumn{5}{c}{ Distância (m) } \\
\hline & 30,00 & 41,60 & 57,69 & 80,00 \\
\hline Deslocamento(m) & 32,19 & 40,76 & 46,69 & 55,72 \\
& $( \pm 6,00)$ & $( \pm 9,05)$ & $( \pm 8,66)$ & $( \pm 13,21)$ \\
\hline Distância Percorrida $(\mathrm{m})$ & 32,56 & 42,58 & 49,25 & 59,26 \\
\hline$v_{m}(m / s)$ & $( \pm 6,10)$ & $( \pm 8,08)$ & $( \pm 8,17)$ & $( \pm 11,50)$ \\
\hline$\alpha_{m}\left({ }^{\circ}\right)$ & 0,72 & 0,83 & 0,91 & 0,99 \\
& $( \pm 0,17)$ & $( \pm 0,05)$ & $( \pm 0,15)$ & $( \pm 0,12)$ \\
\hline & 13,81 & 21,65 & 16,79 & 17,04 \\
& $( \pm 3,91)$ & $( \pm 2,92)$ & $( \pm 4,57)$ & $( \pm 2,52)$ \\
\hline
\end{tabular}


Tabela 11. Valores médios e respectivos desvios-padrão (s) do deslocamento(m); da distância percorrida $(\mathrm{m})$, velocidade $\left(\mathrm{v}_{\mathrm{m}}\right)$ e desvio angular $\left(\alpha_{\mathrm{m}}\right)$ das trajetórias reta, reta-circular, reta-reta e alternada dos participantes da tarefa $\mathrm{L}$ em função das distâncias de retorno a origem.

\begin{tabular}{|c|c|c|c|c|}
\hline & \multicolumn{4}{|c|}{ Distância (m) } \\
\hline & 30,00 & 41,60 & 57,69 & 80,00 \\
\hline \multirow[t]{3}{*}{ Deslocamento(m) } & 32,82 & 38,49 & 49,23 & 48,86 \\
\hline & $( \pm 4,98)$ & $( \pm 7,44)$ & $( \pm 10,13)$ & $( \pm 10,29)$ \\
\hline & 33,66 & 40,33 & 51,03 & 51,83 \\
\hline Distância Percorrida (m) & $( \pm 5,35)$ & $( \pm 7,88)$ & $( \pm 9,09)$ & $( \pm 9,18)$ \\
\hline \multirow[t]{2}{*}{$v_{m}(m / s)$} & 0,82 & 0,84 & 0,87 & 0,84 \\
\hline & $( \pm 0,15)$ & $( \pm 0,15)$ & $( \pm 0,25)$ & $( \pm 0,13)$ \\
\hline \multirow[t]{2}{*}{$\alpha_{\mathrm{m}}\left({ }^{\circ}\right)$} & 23,08 & 22,17 & 23,75 & 26,06 \\
\hline & $( \pm 13,56)$ & $( \pm 7,61)$ & $( \pm 6,68)$ & $( \pm 4,38)$ \\
\hline
\end{tabular}

Por meio de testes $\mathrm{t}$ para amostras emparelhadas, compararam-se as médias da velocidade do caminhar entre a condição experimental e controle em cada uma das tarefas em função das distancias testadas. Conforme pode ser visto na Tabela 12, os resultados não indicaram diferenças significativas $(\mathrm{ps} \geq 0,05)$ entre as condições, em todas as tarefas em função das distâncias testadas. 
Tabela 12. Teste $t$ de Student para amostras emparelhadas para comparação entre as médias da velocidade do caminhar entre a condição experimental e controle para as tarefas: (A) produção de distâncias a um alvo visualmente percebido, (B) reprodução de distâncias após o caminhar sob condições visuais a tarefa de reprodução de distâncias após o caminhar não visual, e, (C) reprodução de distâncias após o caminhar não visual em função das distâncias testadas $(30,00 ; 41,60 ; 57,69$ e 80,00 metros $)$.

A. Tarefa de produção de distâncias a um alvo visualmente percebido (V)

\begin{tabular}{|c|c|c|c|}
\hline Distâncias(m) & Condição & Velocidade $(\mathrm{m} / \mathrm{s})$ & $p$-valor \\
\hline \multirow{2}{*}{ Par $1(30,00 \mathrm{~m})$} & Experimental & $1,098( \pm 0,078 \mathrm{~m} / \mathrm{s})$ & \multirow{2}{*}{$p \geq 0,05$} \\
\hline & Controle & $0,978( \pm 0,067 \mathrm{~m} / \mathrm{s})$ & \\
\hline \multirow{2}{*}{ Par 2 (41,60m) } & Experimental & $1,074( \pm 0,0721 \mathrm{~m} / \mathrm{s})$ & \multirow{2}{*}{$p \geq 0,05$} \\
\hline & Controle & $1,052( \pm 0,0753 \mathrm{~m} / \mathrm{s})$ & \\
\hline \multirow{2}{*}{ Par $3(57,69 m)$} & Experimental & $1,171( \pm 0,055 \mathrm{~m} / \mathrm{s})$ & \multirow{2}{*}{$p \geq 0,05$} \\
\hline & Controle & $1,132( \pm 0,275 \mathrm{~m} / \mathrm{s})$ & \\
\hline \multirow{2}{*}{ Par $4(80,00 \mathrm{~m})$} & Experimental & $0,939( \pm 0,0434 \mathrm{~m} / \mathrm{s})$ & \multirow{2}{*}{$p \geq 0,05$} \\
\hline & Controle & $1,084( \pm 0,141 \mathrm{~m} / \mathrm{s})$ & \\
\hline
\end{tabular}

B. Tarefa de reprodução de distâncias após o caminhar sob condições (Lv)

\begin{tabular}{|c|c|c|c|}
\hline Distâncias(m) & Condição & Velocidade $(\mathrm{m} / \mathrm{s})$ & $p$-valor \\
\hline \multirow{2}{*}{ Par $1(30,00 m)$} & Experimental & $0,823( \pm 0,05 \mathrm{~m} / \mathrm{s})$ & \multirow{2}{*}{$\mathrm{p} \geq 0,05$} \\
\hline & Controle & $1,160( \pm 0,103 \mathrm{~m} / \mathrm{s})$ & \\
\hline \multirow{2}{*}{$\operatorname{Par} 2(41,60 \mathrm{~m})$} & Experimental & $0,838( \pm 0,046 \mathrm{~m} / \mathrm{s})$ & \multirow{2}{*}{$\mathrm{p} \geq 0,05$} \\
\hline & Controle & $1,090( \pm 0,114 \mathrm{~m} / \mathrm{s})$ & \\
\hline \multirow{2}{*}{ Par $3(57,69 m)$} & Experimental & $0,8713( \pm 0,064 \mathrm{~m} / \mathrm{s})$ & \multirow{2}{*}{$\mathrm{p} \geq 0,05$} \\
\hline & Controle & $1,230( \pm 0,297 \mathrm{~m} / \mathrm{s})$ & \\
\hline \multirow{2}{*}{ Par $4(80,00 \mathrm{~m})$} & Experimental & $0,839( \pm 0,075 \mathrm{~m} / \mathrm{s})$ & \multirow{2}{*}{$\mathrm{p} \geq 0,05$} \\
\hline & Controle & $1,220( \pm 0,300 \mathrm{~m} / \mathrm{s})$ & \\
\hline
\end{tabular}

C. Tarefa de reprodução de distâncias após o caminhar não visual (L)

\begin{tabular}{|c|c|c|c|}
\hline Distâncias(m) & Condição & Velocidade $( \pm d p)$ & $p$-valor \\
\hline \multirow{2}{*}{ Par $1(30,00 \mathrm{~m})$} & Experimental & $0,823( \pm 0,056)$ & \multirow{2}{*}{$\mathrm{p} \geq 0,05$} \\
\hline & Controle & $1,060( \pm 0,167 \mathrm{~m} / \mathrm{s})$ & \\
\hline \multirow{2}{*}{$\operatorname{Par} 2(41,60 \mathrm{~m})$} & Experimental & $0,838( \pm 0,047 \mathrm{~m} / \mathrm{s})$ & \multirow{2}{*}{$\mathrm{p} \geq 0,05$} \\
\hline & Controle & $1,040( \pm 0,137 \mathrm{~m} / \mathrm{s})$ & \\
\hline \multirow{2}{*}{ Par $3(57,69 m)$} & Experimental & $0,8712( \pm 0,064 \mathrm{~m} / \mathrm{s})$ & \multirow{2}{*}{$\mathrm{p} \geq 0,05$} \\
\hline & Controle & $1,130( \pm 0,293 \mathrm{~m} / \mathrm{s})$ & \\
\hline \multirow{2}{*}{ Par $4(80,00 \mathrm{~m})$} & Experimental & $0,838( \pm 0,075 \mathrm{~m} / \mathrm{s})$ & \multirow{2}{*}{$\mathrm{p} \geq 0,05$} \\
\hline & Controle & $1,132( \pm 0,284 \mathrm{~m} / \mathrm{s})$ & \\
\hline
\end{tabular}


Testes de normalidade Shapiro-Wilk revelaram valores de significância acima de 0,05. A distribuição amostral dos grupos aproximou-se de uma distribuição normal. A partir disso, para verificar se a velocidade e o desvio angular das trajetórias reta, reta-circular, alternada e reta-reta variaram em função das condições experimentais das tarefas, foram calculadas análises de variâncias de dois fatores (3 tarefas x 4 distâncias) com medidas repetidas no último fator.

A ANOVA calculada para a variável velocidade revelou efeito do fator distâncias $[F(3,273)=30,260 ; p=0,001]$. Não houve efeito do fator tarefas $[F(2,91)=2,389 ; p=0,097]$, nem da interação desses dois fatores $[(\mathrm{F} 6,273)=1,157 ; \mathrm{p}=0,330]$. Os testes a posteriori de Bonferroni identificaram diferenças significativas $(\mathrm{p} \leq 0,05)$ entre as velocidades produzidas na tarefa V entre as distâncias: 30,00 m x 41,60m; 30,00 m x 57,69m e 30,00 m x 80,00 m. Os participantes da tarefa $\mathrm{V}$ foram mais inconsistentes e apresentaram menor velocidade na distância percorrida de 30,00 m $(1,056 \pm 11,840 \mathrm{~m} / \mathrm{s})$ em comparação as distâncias de 41,60 e $57,69 \mathrm{~m}$ (respectivamente, $1,084 \pm 9,531 \mathrm{~m} / \mathrm{s}$ e $1,091 \pm 1,783 \mathrm{~m} / \mathrm{s}$ ) e maior velocidade em comparação a $80 \mathrm{~m}(0,994 \pm 9,6365 \mathrm{~m} / \mathrm{s})$.

Em relação a variável desvio angular da trajetória, a análise indicou efeito do fator distâncias $[F(3,48)=23,556 ; p=0,001]$. Não houve efeito do fator tarefas $[F(2,16)=0,147$; $p=0,864]$, nem da interação entre os fatores tarefas e distâncias $[(F 6,48)=0,864 ; p=0,988]$. As comparações a posteriori de Bonferroni identificaram diferenças significativas $(p \leq 0,05)$ dos desvios produzidos na tarefa $\mathrm{V}$ entre as distâncias percorridas de $30,00 \mathrm{~m}$ x 41,60m;30,00 x $57,69 \mathrm{~m}$ e $30,00 \times 80,00 \mathrm{~m}(\mathrm{ps} \leq 0,05)$. Os participantes apresentaram em maior desvio na distância de 30,00 m (20,26 $\left.111,84^{\circ}\right)$ em comparação as distâncias de 41,60; 57,69 e 80,00 metros (respectivamente, $16,16 \pm 9,53^{\circ} ; 15,73 \pm 1,78^{\circ} ; 19,82 \pm 9,64^{\circ}$ ).

Também, encontraram-se diferenças significativas $\left(\mathrm{p}_{\mathrm{s}} \leq 0,05\right)$ dos desvios produzidos pelos participantes da tarefa Lv entre as distâncias percorridas de 41,60m x 30,00m; 41,60m x $57,69 \mathrm{~m}$ e $41,60 \mathrm{~m} \times 80,00 \mathrm{~m}$ ( $\mathrm{ps} \leq 0,05)$. Os participantes apresentaram maiores desvios na distância de 41,60m $\left(21,65 \pm 2,92^{\circ}\right)$ em comparação as distâncias de 30,00; 57,69 e 80,00 m (respectivamente $\left(13,81 \pm 3,91^{\circ} ; 16,79 \pm 4,57^{\circ}\right.$ e $\left.17,04 \pm 2,52^{\circ}\right)$. 


\subsection{Discussão}

\subsubsection{Frequências dos padrões das trajetórias e o desempenho na tarefa de caminhada}

Os resultados do presente estudo confirmam que a percepção da trajetória do corpo durante deslocamento às cegas não é acurado. Na ausência de indícios visuais e auditivos, os participantes não foram capazes de manter um deslocamento em linha reta, produzindo trajetórias com padrões geométricos bem definidos (reta, reta-circular, circular, alternada e reta-reta). Ademais, os resultados sugerem que esses padrões das trajetórias são influenciados por vários fatores da situação experimental, tais como, o tamanho do espaço, a amplitude de distância testada e as características da tarefa. Tais efeitos produzidos pelas características da tarefa experimental, provavelmente, contribuem para a variedade e discrepâncias dos resultados empíricos observados na literatura da área.

Um aspecto importante que poderia explicar essas discrepâncias observadas entre os estudos é a forma como os dados foram coletados e calculados. A maioria dos estudos (Kallie, Schrater, \& Legge, 2007; Cicinelli, 1989; Klatzky Loomis, Golledge, Cicinelli, Doherty, et al.,1990; Boyadjian, Marin, \& Danion,1999; Courtine \& Schieppati ,2003; Mohr, Brugger, Bracha , Landis, \& Viaud-Delmon ,2004; Vieilledent, Kosslyn , Berthoz, \& Giraudo,2003; Mohr \& Lievesley,2007) realizaram as medições dos pontos inicial e final da trajetória de sujeitos caminhando com ausência do sentido da visão, desprezando os pontos intermediários da tarefa de caminhar. Consequentemente estes estudos avaliam como as grandezas distância a origem e o desvio angular variam para avaliar o desempenho dos participantes entre diferentes experimentos, o que empobrece a análise do fenômeno e fornece poucas evidências que demonstrem similaridades e diferenças entre os experimentos.

Outro ponto importante é o tamanho do espaço experimental. Como demonstrado pela análise dos padrões da trajetória, o incremento na taxa de movimento em função do aumento nas distâncias leva os indivíduos a ampliar seus desvios e, muitas vezes alterar seu padrão da trajetória. Por exemplo, o caminhar por mais tempo pode levar o individuo a alterar sua trajetória iniciada em linha reta por uma trajetória circular. Esses achados estão em concordância com Bestaven e colaboradores (2012), que afirmam que muito dos estudos que lidam com o comportamento de veering (Kallie, Schrater, \& Legge, 2007; Cicinelli, 1989; Klatzky Loomis, Golledge , Cicinelli, Doherty, et al.,1990; Boyadjian, Marin, \& 
Danion,1999; Courtine \& Schieppati ,2003; Mohr, Brugger, Bracha , Landis, \& ViaudDelmon ,2004; Vieilledent, Kosslyn , Berthoz \& Giraudo,2003; Mohr \& Lievesley,2007) foram realizados em espaços relativamente pequenos, usando distâncias curtas (entre 10 a 20 m) o que dificulta uma análise confiável desse fenômeno.

Além disso, em função do equipamento de medição, foi possível determinar geometricamente o formato das trajetórias formadas e também calcular outras grandezas derivadas do movimento, como a velocidade e a distância percorrida. Apesar de não ter sido encontrado efeito expressivo da velocidade do caminhar sobre os padrões das trajetórias, outros estudos apontam ao contrario. É o caso de Bestaven e colaboradores (2012) que obtiveram como resultado uma significante correlação negativa entre a velocidade do caminhar e o raio da trajetória circular, e que na ausência da informação visual e índicos auditivos os sujeitos sempre caminhavam a uma velocidade ligeiramente menor que o caminhar com os olhos abertos. Klatzky e colaboradores (1990), também obtiveram resultados indicativos da relação entre a velocidade do caminhar e o comportamento veering. Tal diferença entre a literatura da área pode-se dever a diferenças aos procedimentos e equipamento (GPS) adotados nesse estudo.

Para os humanos, manter o controle da orientação espacial durante o caminhar com redução total da informação visual é difícil, mas pode ser facilitado quando se conhece previamente o caminho. Os resultados obtidos comprovam este aspecto no qual a resposta de retornar ao ponto de origem da tarefa após deslocamento com os participantes sob completa privação visual com e sem prévia observação do alvo (tarefas Lv e L) mostra melhor desempenho em comparação à tarefa $\mathrm{V}$, em que foi observado maior frequência de trajetórias circulares. O desempenho dos participantes durante o deslocamento ás cegas, após a visualização estática, fixa do alvo (tarefa V), poderia ter sido prejudicado pela falta de consciência do próprio corpo (Mohler, Bülthoff, Thompson, \& Creem-Regehr, 2008). O padrão da caminhada do observador poderia funcionar como auto referência, facilitando o controle e a manutenção da direção durante o movimento.

É possível que, ao serem privados da visão e os indícios não estavam claros em torno da chegada, os participantes utilizaram-se da experiência passada, garantida pela mobilidade na fase de estímulo, para reconstruir internamente o espaço a ser percorrido. Isto implica que a experiência visual não é absolutamente equivalente ao ato de caminhar. Tais achados confirmam que o controle da orientação espacial durante as tarefas navegação e locomoção requer uma atualização dinâmica da representação das relações entre o corpo e o ambiente. Adicionalmente, esta atualização depende da integração central de informações 
multissensoriais, e a comparação dos sinais sensoriais percebidos e aprendidos por meio de trajetórias planejadas, do esquema corporal e da memória (Berthoz \& Viaud-Delmon, 1999; Vuillerme, Nougiera, \& Camicioli, 2002).

Por tudo o que foi exposto anteriormente, é importante analisar não somente os pontos inicial e final da caminhada com ausência de visão, mas também a forma com que o participante caminha desde a origem até seu ponto final, incluindo diversos pontos intermediários. Este tipo de análise puramente geométrica mostra que os sujeitos que utilizam somente a informação visual da distancia tem dificuldade de caminhar em linha reta, apesar de seu desvio angular ser parecido com o dos sujeitos que utilizam também a informação locomotora.

\subsubsection{Velocidade angular e o padrão das trajetórias}

Embora a velocidade angular não foi diretamente medida, pode-se aplicar o modelo matemático apresentado no Anexo A nos resultados de todas as tarefas e intuitivamente prever o comportamento da velocidade angular associado a cada padrão de trajetória. $\mathrm{Na}$ discussão a seguir, assume-se que os sujeitos possuem considerável controle de sua velocidade, a qual foi medida em todas as tarefas e é aproximadamente constante (ver Figura 19), enquanto que os seus sistemas de orientação angular podem livremente variar em função do tempo. Esta análise não procura determinar precisamente a trajetória associada com uma determinada função de velocidade angular com relação ao tempo, mas prover para estudos futuros alguma compreensão do seu comportamento usando uma abordagem intuitiva. Os resultados são apresentados na Figura 6.

Da mesma maneira que a velocidade linear pode-se argumentar que a velocidade angular pode variar consideravelmente no início e no fim da trajetória e que, portanto, esta análise não é útil para fornecer ideias sobre o comportamento verdadeiro da velocidade angular. Entretanto, devemos considerar que estes estágios da trajetória são relativamente breves em relação ao movimento como um todo.

Neste trabalho, o modelo matemático foi usado para explicar e quantificar os padrões das trajetórias observadas durante a caminhada na ausência de indícios visuais e auditivos em ambientes amplos e naturais. Embora o modelo possua abstrações específicas que podem ser considerados divergências do comportamento verdadeiro, ele captura os aspectos mais 
relevantes do comportamento de veering.

Os resultados comprovaram que a trajetória circular foi um padrão frequentemente reproduzido por todos os sujeitos e em todas as distâncias. Esta descoberta corrobora com resultados de estudos anteriores (Bestaven et al., 2012; Souman et al., 1999), ainda que sob condições experimentais diferentes. Na ausência da informação visual e indícios auditivos, a manutenção da locomoção de uma rota em linha reta é quase impossível, e via de regra todos os sujeitos desviam para um lado ou outro, e inconscientemente tendem a andar em círculos. Durante as tarefas foi possível observar que os participantes raramente corrigiam suas trajetórias após o inicio de sua caminhada, o que sugere que a ausência de pistas sensórias confiáveis não incentivou qualquer correção dos desvios por parte dos sujeitos.

Tanto a caminhada a curtas distâncias quanto a caminhada a longas distâncias requerem o mesmo controle da orientação espacial durante as tarefas de navegação e locomoção ao longo da trajetória. Entretanto, se o desempenho individual das trajetórias circulares for comparado em função das diferentes distâncias ao alvo $(30,00 ; 41,60 ; 57,69$ e $80,00 \mathrm{~m}$ ), o melhor desempenho (i.e. menor velocidade angular) esteve relacionado com maiores distâncias na tarefa $\mathrm{V}$.

A fim de explicar este comportamento, várias hipóteses foram enumeradas. Um dos fatores que poderia influenciá-lo seria a lateralidade, dado que a maioria das trajetórias foi finalizada para o lado esquerdo do corpo. De acordo com Day e Goins (1999), indivíduos que tem a perna direta como dominante tendem a desviar-se para o lado esquerdo, e indivíduos que tem a perna esquerda como dominante tendem a desviar-se para o lado direito. Entretanto, existem poucas evidências cientificas que apoiam essa explicação. A investigação de um grupo maior de sujeitos envolvendo sujeitos com preferência lateral direita e esquerda poderia clarificar esta questão. Outros possíveis fatores que poderiam causar o comportamento circular incluem baixos a altos níveis de assimetrias dos sistemas proprioceptivo e vestibular.

Antes de estudar os mecanismos que regulam os sistemas proprioceptivo e vestibular, é importante entender como é definida matematicamente uma rotação e um importante teorema clássico sobre a equivalência de rotações. O Teorema de Rotação de Euler afirma que em um espaço tridimensional, qualquer composição de rotações é equivalente a uma única rotação em torno de um eixo de rotação. Particularmente, aplicando este teorema a caminhada de seres humanos e sabendo que o ponto fixo são os pés, há um eixo de rotação que descreve perfeitamente o movimento resultante das diversas rotações do sujeito durante a caminhada. Dado que o sujeito caminha em uma superfície aproximadamente plana, ele ou ela somente pode rodar em torno de um eixo vertical que vai aproximadamente de sua cabeça aos 
seus pés. Em termos estruturais do corpo humano, este eixo coincide aproximadamente com a espinha. Assim, por hipótese, considera-se que o eixo de rotação coincide com o tronco do sujeito. Basta agora saber quais órgãos que iniciariam a rotação do sujeito em torno de sua espinha.

Dado que qualquer membro conectado a espinha potencialmente tem alguma influencia no movimento de rotação, variações pequenas na direção natural da cabeça podem induzir um desvio pela modificação do centro da atividade locomotora em nível espinhal (Toussaint, Do, \& Fagard, 2008). Para manter o equilíbrio durante a locomoção, sujeitos normais tentam estabilizar sua cabeça (Pozzo, Berthoz, \& Lefort, 1990) e aparentemente a visão facilita o equilíbrio da direção normal da cabeça. A estabilidade da cabeça muito provavelmente induz não somente a estabilidade do olhar fixo, mas também induz uma referência para organizar o movimento de outros segmentos (Pozzo, Levik, \& Berthoz, 1995). Quando a visão é excluída, as informações para os sistemas vestibular e proprioceptivo vindas da região do pescoço agem simultaneamente para posicionar o tronco com relação ao espaço (Karnath, Sievering, \& Fetter, 1994; Yoder \& Taube, 2014).

Além disso, as informações de entrada dos músculos do pescoço e os sinais vestibulares desempenham um importante papel em construir e atualizar as representações espaciais, incluindo a posição, a orientação e o movimento do corpo (Bottini et al., 2001). A evidência do papel destes aferentes sensoriais vem dos efeitos específicos de lateralidade ou da estimulação direcional-específica dos sistemas sensoriais periféricos, tais como estimulação térmica vestibular e vibração mecânica dos músculos posteriores do pescoço. Esta estimulação em particular pode induzir a distorções das coordenadas egocêntricas, causando, por exemplo, desvios não intencionais da trajetória durante a caminhada. (Bove, Diverio, Pozzo, \& Schieppati, 2001; Fitzpatrick, Wardman, \& Taylor, 1999) e rotação do corpo durante o pisar no mesmo local em sujeitos normais (Bove, Courtine, \& Schieppati, 2002).

Portanto, o desequilíbrio das diversas informações de entrada que convergem às redes centrais que são responsáveis pela representação do plano sagital médio-sagital pode criar condições para comportamentos cíclicos (Bove et al., 2002). Apesar dos resultados não suportarem uma relação direta causal entre a rotação da cabeça e o comportamento de caminhada circular, estudos futuros podem certamente investigar estas correlações. 



\section{Resultados: Distância caminhada}

Para a análise dos julgamentos perceptivos, foram utilizadas as medidas das distâncias percorridas às cegas pelos participantes e as medidas reais das distâncias. A distância percorrida é definida como a medida da trajetória descrita pelo movimento do sujeito; e o seu valor depende da trajetória. Compreende o espaço percorrido pelo corpo ao longo do seu movimento até a posição final, é a medida da linha de trajetória do corpo. Imaginemos que é possível esticar a linha de trajetória do corpo e medir essa mesma linha (wikipedia/Displacement, 2014). Como calculado:

$$
d_{\text {origem }}=\sum_{i=1}^{n} \Delta S_{i}(9)
$$

Onde,

$$
\Delta S_{i}=\sqrt{\left(x_{i}-x_{i-1}\right)^{2}+\left(y_{i}-y_{i-1}\right)^{2}}(10)
$$

E,

$$
x_{0}=0 \text { e } y_{0}=0 \text { (origem) (11) }
$$

Os dados das distâncias percorridas foram analisados através da função de potência proposta por Stevens (2000). A análise psicofísica incluiu o cálculo do expoente (n; índice de sensibilidade), da constante escalar (k) e do coeficiente de determinação $\left(r^{2}\right)$ da função de potência. Adicionalmente, foi calculado o erro relativo médio dessas variáveis para analisar a extensão da variabilidade direta das respostas a partir da subtração do estímulo físico (a distância física ou real) pela resposta subjetiva (a distância caminhada às cegas).

\subsection{Análise estatística}

O tratamento estatístico foi realizado comparando-se os valores do expoente derivados da função de potência para verificar a existência de diferenças estatisticamente 
significativas entre as diversas distâncias observadas ou caminhadas dentro de cada tarefa e também entre as tarefas experimentais. Assim sendo, foi utilizado: o teste de Shapiro-Wilk para verificar a condição de normalidade dos dados; a análise de variância simples (ANOVA) para verificar diferenças do valor médio dos expoentes entre as tarefas; teste t-Student para amostras independentes tendo como variável dependente os valores dos expoentes (emparelhados ao valor de expoente 1,0) para identificar a tendência perceptiva: linearidade, subconstância ou superconstância, e finalmente análise de variância (ANOVA) dois fatores: 3 tarefas(V, Lv e L), 4 distâncias (30,00;41,60; 57,69 e 80,00metros) sendo medidas repetidas no último fator para identificar diferenças entre as tarefas e as distâncias da variável erro relativo e testes a posteriori de Bonferroni para localizar diferenças significativas. Adotou-se o nível de $5 \%$ de significância $(\mathrm{p} \leq 0,05)$ em todos esses testes estatísticos.

\subsection{Resultados}

A análise descritiva dos parâmetros psicofísicos das três tarefas experimentais é

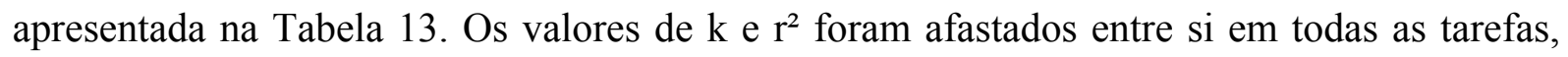
indicando uma irregularidade nos julgamentos para estes parâmetros. Os desvios-padrão da variável $\mathrm{K}$ foram altos para as tarefas $\mathrm{Lv}$ e $\mathrm{L}$ em relação à tarefa $\mathrm{V}$, indicando que a produção das distâncias variou mais de indivíduo para indivíduo. $\mathrm{O}$ valor do $\mathrm{r}^{2}$ permite observar a correlação entre o estímulo e a resposta. $\mathrm{O}$ coeficiente de determinação $\left(\mathrm{r}^{2}\right)$ é uma medida da proporção de variação de uma variável determinada pela variação da outra. Assim, um $\mathrm{r}^{2}$ de 0,79 significa que $79 \%$ da variação das respostas dos sujeitos podem ser explicadas pela variação do estímulo. A média dos valores para o $\mathrm{r}^{2}$ nas tarefas $\mathrm{V}$ e Lv ficou próxima de 0,80 , indicando uma boa relação entre estímulo e resposta para todos os sujeitos.

Tabela 13. Valores médios e desvios-padrão $( \pm d p)$ do expoente (n), constante escalar $(k)$ e coeficiente de determinação $\left(r^{2}\right)$ para os participantes nas tarefas $\mathrm{V}, \mathrm{Lv}$ e L.

\begin{tabular}{lccc}
\hline & $\mathrm{k}$ & $\mathrm{n}$ & $\mathrm{r}^{2}$ \\
\hline Tarefa V & $4,20(5,09)$ & $0,72(0,29)$ & $0,79(0,20)$ \\
Tarefa Lv & $6,09(13,11)$ & $0,65(0,23)$ & $0,81(0,23)$ \\
Tarefa L & $9,82(13,11)$ & $0,46(0,22)$ & $0,69(0,30)$ \\
\hline
\end{tabular}


Testes de normalidade Shapiro-Wilk revelaram valores de significância acima de 0,05. A distribuição amostral dos grupos aproximou-se de uma distribuição normal. A partir disso, para verificarmos possíveis diferenças entre os julgamentos perceptivos dos indivíduos nas tarefas experimentais, foi calculada uma análise de variância simples para a variável expoente.

O resultado da análise realizada entre os expoentes obtidos nas tarefas experimentais $\mathrm{V}, \mathrm{Lv}$ e $\mathrm{L}$ revelou diferenças significativas para tarefas $[\mathrm{F}(2,102)=9,218 ; \mathrm{p}=0,001]$. Isto implica que as condições experimentais parecem diferir entre si. Através do pós-teste de Bonferroni foi possível observar que os expoentes das tarefas V $(0,72 \pm 0,29)$ e $\operatorname{Lv}(0,65 \pm 0,23)$ foram significativamente maiores e mais próximos do expoente 1,0 (acurácia perceptiva) em comparação ao expoente da tarefa $\mathrm{L}(0,46 \pm 0,22)(\mathrm{p} \leq 0,05)$. Baseado nas comparações entre as tarefas percebe-se que quanto mais informações o sujeito obteve por meio dos diferentes sistemas sensoriais envolvidos na tarefa, maior o expoente, e consequentemente maior o índice de sensibilidade.

Em seguida, para encontrar a tendência perceptiva dos julgamentos, foi aplicado o teste t-Student para amostras independentes aos expoentes de cada uma das tarefas experimentais emparelhados ao expoente 1,0. Os resultados indicaram que os expoentes foram significativamente menores que 1,0 , em todas as tarefas. Isso implica a presença de subconstância perceptiva para a tarefa $\mathrm{V}: \mathrm{t}(35)=-5,782 \mathrm{p} \leq 0,05(0,72 \pm 0,29)$; para tarefa Lv: $\mathrm{t}(35)=-9,088 \mathrm{p} \leq 0,05(0,65 \pm 0,23)$ e para tarefa $\mathrm{L}, \mathrm{T}(32)=-13,811, \mathrm{p} \leq 0,05(0,46 \pm 0,22)$. É importante notar que o fenômeno da subconstância significa que, mesmo que os indivíduos tenham superestimado as distâncias iniciais (30,00 e 41,60m), o conjunto global das respostas ao longo da escala testada tende a desacelerar a inclinação da reta psicofísica. Isto decorre da diminuição gradual da proporção de magnitude julgada para cada distância em relação à anterior. Isto diminui a inclinação da reta psicofísica e, consequentemente gera expoentes inferiores a 1.0 (Figura 20). A tarefa V, apesar da subconstância, foi a mais próxima da constância perceptiva. 


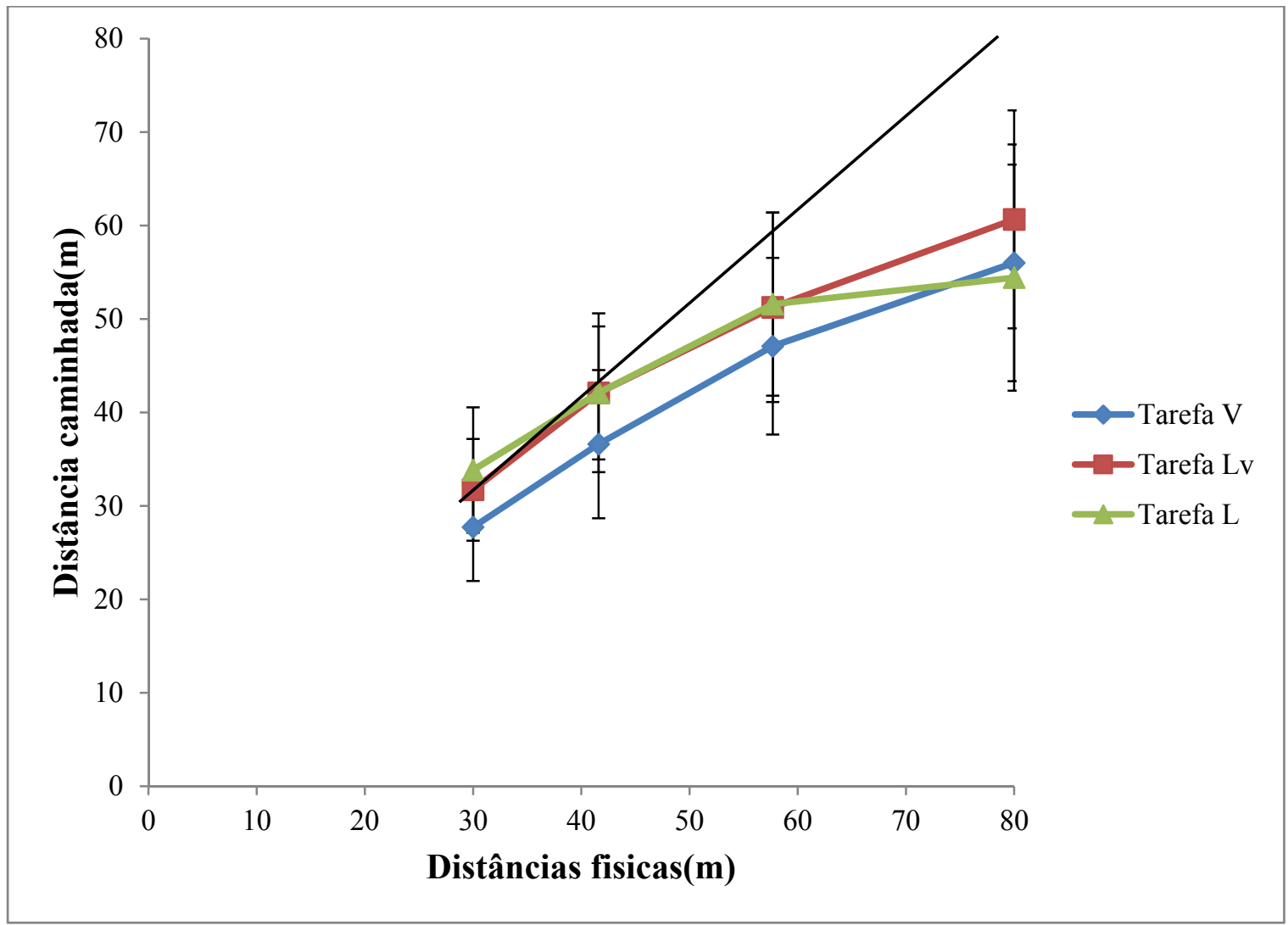

Figura 20. Médias das distâncias caminhadas e respectivos desvios-padrão dos participantes do estudo em função das distâncias físicas de 30,00; 41,60; 57,69 e 80,00 m para a tarefa $\mathrm{V}$, tarefa Lv e Tarefa L (em valores absolutos). A linha diagonal indica acurácia perfeita

\subsection{Análise do erro}

As médias e desvios-padrão para o erro relativo dos julgamentos de distância para cada tarefa estão representados na Tabela 14. Em todas as tarefas, a média tende a aumentar com o aumento da distância teste.

Tabela 14. Valores médios e respectivos desvios-padrão (s) para o erro relativo dos julgamentos de distância (distância percorrida) em função das distâncias físicas de 30,00; 41,60; 57,69 e 80,00 metros nas tarefas experimentais $\mathrm{V}, \mathrm{Lv}$ e $\mathrm{L}$

\begin{tabular}{ccccc}
\hline & $30,00 \mathrm{~m}$ & $41,60 \mathrm{~m}$ & $57,69 \mathrm{~m}$ & $80 \mathrm{~m}$ \\
\hline Tarefa V & $-0,72(6,73)$ & $-5,28(7,70)$ & $-10,61(9,45)$ & $-24,69(12,54)$ \\
Tarefa Lv & $1,72(6,11)$ & $0,49(7,82)$ & $-6,45(8,72)$ & $-18,32(11,70)$ \\
Tarefa L & $3,82(5,27)$ & $-0,21(7,27)$ & $-6,65(9,18)$ & $-27,19(10,72)$ \\
\hline
\end{tabular}


Testes de normalidade Shapiro-Wilk revelaram valores de significância acima de 0,05. A distribuição amostral dos grupos aproximou-se de uma distribuição normal.

A ANOVA calculada para a variável magnitude do erro relativo revelou efeito significativo para os fatores: tarefas $[F(2,102)=4,027, p=0,021]$ e distâncias $[F(3,306)=$ $145,362, p=0,0001]$. $E$, também, para a interação entre esses dois fatores $[F(6,306)=3,678$, $\mathrm{p}=0,006]$.

Os testes a posteriori de Bonferroni identificaram diferenças $(\mathrm{p} \leq 0,05)$ entre tarefas (V x Lv; V x L) nas distâncias de 30,00 e 41,60 metros. Em média, os participantes da tarefa $\mathrm{V}$ apresentaram menor erro no estímulo inicial da escala $(-0,72 \pm 6,73)$ em comparação aos participantes das tarefas Lv $(1,72 \pm 6,11)$ e L $(3,82 \pm 5,27)$. E, maior erro na distância de $41,60 \mathrm{~m}$ $(-5,28 \pm 7,70)$ em comparação as tarefas Lv e V $(0,49 \pm 7,82$ e -0,21 $\pm 7,27)$. Além disso, os sujeitos da tarefa L exibiram um aumento do erro $(-27,19 \pm 10,72)$ na distância de $80,00 \mathrm{~m}$ (maior distância) em comparação aos sujeitos da tarefa $\operatorname{Lv}(-18,32 \pm 11,70)$. Baseado nas comparações entre as tarefas percebe-se que a magnitude do erro no continuo da escala de distâncias variou em função da amplitude das distâncias e das informações que o sujeito obteve por meio dos diferentes sistemas sensoriais envolvidos na tarefa (sistemas visual, proprioceptivo e vestibular).

\subsection{Discussão}

A presente seção examinou o desempenho de voluntários em tarefas envolvendo o julgamento de distância egocêntrica pelo indicativo de resposta do caminhar com a visão ocluída da localização visualmente e proprioceptivamente percebida dentro do espaço vista (distâncias entre 30 a 80 metros). As tarefas incluíram a informação visual estática em relação à distância a um alvo visualmente percebido (tarefa $\mathrm{V}$ ), e a informação dinâmica em relação à distância percorrida gerada através da locomoção, durante a caminhada de olhos vendados (tarefa L) e durante a caminhada vidente (Lv) em rotas retilíneas.

A comparação entre as tarefas experimentais evidenciou diferenças entre o valor médio do expoente da tarefa L e as tarefas V e Lv. Embora o desempenho dos participantes em todas as tarefas mostrou uma tendência à subconstância perceptiva por conta do valor do expoente psicofísico abaixo de 1,0, esta tendência foi mais acentuada para os participantes da tarefa L. 
O expoente de função potencia é um bom indicador do grau de compressão do espaço, pois integra a discriminação do observador em função da magnitude da intensidade do estímulo (Da-Silva et al., 2006). Assim, quando expoente é menor do que 1,0 há uma aceleração negativa na função que relaciona o estímulo físico (distância física) e a resposta estimada (distância caminhada) (Da-Silva, 1985). Isto corresponde a uma situação psicofísica em que a magnitude da sensação cresce de forma gradativamente menor conforme aumenta a magnitude do estímulo. Dessa forma, os participantes da tarefa L, perceberam as distâncias físicas em amplitudes cada vez mais reduzidas, em relação a distancia real. Essa tendência à subconstância perceptiva por parte desses indivíduos indica menor acurácia perceptiva.

Esses resultados corroboram a literatura da área, que sugere que as distâncias estimadas em ambiente naturais que contém amplos indícios perceptuais para os julgamentos, os expoentes variam entre 1,0 a 1,47, e sob pequena incerteza os expoentes variam entre $0,80 \mathrm{a}$ 1,0, mas podem atingir valores próximos a 0,40 quando a situação for extremamente reduzida em indícios (Da-Silva, Santos \& Silva, 1983). Isto demonstra que quanto mais informações o sujeito puder obter através dos diferentes sistemas sensoriais envolvidos no relacionamento dinâmico entre o indivíduo e o meio ambiente, maior será a probabilidade de julgamento acurado sobre o espaço e os objetos nele contidos (Berthoz \& Viaud-Delmond, 1999). Além disso, é conhecido que a informação visual facilita a formação de representações mentais de espaço (Philbeck, Klatzky, Behrmann, Loomis,\& Goodridge, 2001).

Independente da tarefa observou-se que o aumento das distâncias gerou uma compressão substancial dos julgamentos. Em média, as distâncias mais próximas aos observadores (30,00 e 42,60m) a informação foi mais eficaz, levando a menores erros nas distâncias percorridas. Enquanto que, nas distâncias mais distantes dos observadores (57,69 e $80,00 \mathrm{~m}$ ), os indícios perderam sua eficácia e comprometeram os julgamentos, levando os participantes a encerrarem suas caminhadas aquém da distância esperada. Essa subestimação crescente em função do aumento das distâncias poderia ser atribuída a fatores não perceptuais e processos inferenciais, tal como a tendência do observador (Gogel, 1974). Essa tendência ocorre na ausência de fontes eficazes de informações específicas para a distância do estímulo e com o aumento da distância absoluta da cena, que causa a perda de eficácia de muitos indícios visuais e não visuais que operam no espaço peripessoal e no espaço de ação (DaSilva et al., 2006). Gogel (1974) considera que em condições reduzidas de estímulos os observadores tendam a melhorar suas estimativas usando correções cognitivas, que ele chamou de tendências do observador. Logo, é provável que quando os indivíduos foram 
privados da visão e os indícios não estavam claros em torno da chegada ou do retorno à origem, eles possam ter preferido inventar uma resposta a dar nenhuma.

Além da influência da amplitude das distâncias, o espaço onde o estudo foi realizado, um ambiente natural e amplo, também poderia gerar uma tendência negativamente acelerada sobre os expoentes (Da-Silva, Santos e Silva, 1983). Essa explicação pode ser corroborada com os resultados encontrados por Iosa, Fusco, Morone, \& Paolucci (2012); Lappin, Shelton,\& Rieser(2006); Riener, Witt, Stefanucci, \& Proffitt( 2005); Witt, Stefanucci, Riener, $\&$ Proffitt (2007). Os autores demonstraram através de diferentes indicadores espaciais, que o contexto do ambiente afeta a percepção de distância, mesmo quando todos os indícios informativos de profundidade são constantes. De acordo com Witt e colaboradores (2007) indícios informativos de profundidade tanto no espaço compreendido entre o observador e o alvo, quanto àqueles presentes no ambiente visível ao observador além do alvo podem causar diferenças na distância aparente. E, na ausência da informação visual, o ambiente memorizado atuaria como um sintonizador seletivo entre as várias estratégias baseadas na informação sensorial durante o caminhar em comparação a uma representação interna do ambiente e do próprio corpo (Iosa, Fusco, Morone, \& Paolucci, 2012). No presente estudo, em todas as tarefas o espaço ente o observador e o estimulo e o espaço além do alvo foram os mesmos, assim sendo não é possível determinar quais fatores do contexto experimental impactaram sobre os resultados observados. Provavelmente, a falta de dicas no ambiente além do alvo (dentro do espaço vista) em relação ao tamanho familiar e o tamanho relativo do marcador de distância, não foram suficientes para manter a constância nos julgamentos de distância.

Os resultados ainda mostraram que a expansão (erros positivos) e a compressão (erros negativos) do espaço percebido variaram em função da natureza ou combinações de indícios presentes na tarefa experimental (Da-Silva et al., 2006). Essa assimetria nos erros observados poderia ser atribuída a diferenças intrínsecas nas representações internas do espaço após a exposição à informação visual (estática e dinâmica) em comparação a informação não visual (Sun et al.,2004). A literatura indica que as representações perceptivas do espaço podem ser construídas em função da resposta requerida pela tarefa, e estas podem ser afetadas de modo diferente pela qualidade da manipulação dos indícios de distância. Alguns indícios podem ser utilizados de uma forma similar através das medidas, e outros podem ter tratados, ou talvez ponderados de forma diferente (Bergmann, Krauß, Münch, Jungmann, Oberfeld, \& Hecht, 2011; Cutting \& Vishton, 1995; Kunz, Wouters, Smith, Thompson, \& Creem-Regehr, 2009). 
$\mathrm{Na}$ tarefa Lv, a despeito da análise dos erros das variáveis não revelar diferenças significativas entre tarefas em todas as distâncias testadas, observou-se que os valores das distâncias caminhadas foram mais próximos de sua contraparte física (menores erros) do que aqueles indicados nas tarefas $\mathrm{L}$ e $\mathrm{V}$. Isso sugere que o conhecimento visual ou locomotor do espaço por si só não foi suficiente para alterar a percepção de distância. Ao invés disso, um melhor desempenho ao longo das distâncias testadas foi observado na tarefa em que ambas as informações estavam presentes.

Tomados em conjunto, esses resultados confirmam estudos anteriores que demonstraram que o desempenho em tarefas espaciais é facilitado quando indivíduos saudáveis são capazes de antecipar suas futuras trajetórias e controlar mais ativamente sua locomoção (Philbeck, Klatzky, Behrmann, Loomis, Goodridge, 2001; Yamamato, 2012). De acordo com Yamamato (2012), um dos papeis da locomoção ativa na percepção do espaço é o de facilitar a interação entre a informação visual a cerca do ambiente e a informação não visual relativa aos movimentos corporais. Em outras palavras, a informação não visual gerada pela locomoção ativamente controlada pelo participante interage de maneira mais efetiva com a informação visual do ambiente, e por sua vez, quando esta interação entre diferentes modalidade sensoriais é facilitada, conduz a uma maior qualidade da representação mental do espaço. 


\section{CONCLUSÃO}

A partir da análise e discussão dos resultados obtidos foi possível concluir que:

- $\quad$ A percepção da trajetória do corpo durante deslocamento às cegas não é acurado. $\mathrm{Na}$ ausência de indícios visuais e auditivos, os participantes não foram capazes de manter um deslocamento em linha reta, produzindo trajetórias com padrões geométricos bem definidos (reta, reta-circular, circular, alternada e reta-reta).

- Os padrões geométricos das trajetórias (reta, reta-circular, circular, alternada e retareta) produzidos pelos participantes, foram influenciados por vários fatores da situação experimental, tais como, o tamanho do espaço, a amplitude de distância testada e as características da tarefa.

- Para os humanos, manter o controle da orientação espacial durante o caminhar com redução total da informação visual é difícil, mas pode ser facilitado quando se conhece previamente o caminho. Os resultados obtidos comprovam este aspecto no qual a resposta de retornar ao ponto de origem da tarefa após deslocamento com os participantes sob completa privação visual com e sem prévia observação do alvo (tarefas Lv e L) mostra melhor desempenho em comparação à tarefa $\mathrm{V}$, em que foi observado maior frequência de trajetórias circulares.

- O desempenho dos participantes em todas as tarefas mostrou uma tendência à subconstância perceptiva por conta do valor do expoente psicofísico abaixo de 1,0, esta tendência foi mais acentuada para os participantes da tarefa L.

- Independente da tarefa observou-se que o aumento das distâncias gerou uma compressão substancial dos julgamentos. Em média, as distâncias mais próximas aos observadores (30,00 e 41,60m) a informação (visual; locomotora-visual e locomotora) foi mais eficaz, levando a menores erros nos julgamentos das distâncias. Enquanto que, nas distâncias mais distantes dos observadores (57,69 e 80,00m), os indícios perderam sua eficácia e comprometeram os julgamentos, levando os participantes a encerrarem suas caminhadas aquém da distância esperada.

- Na tarefa Lv, a despeito da análise dos erros das variáveis não revelar diferenças significativas entre tarefas em todas as distâncias testadas, observou-se que os valores das distâncias caminhadas foram mais próximos de sua contraparte física (menores erros) do que aqueles indicados nas tarefas $\mathrm{L}$ e V. Isso sugere que o conhecimento visual ou locomotor do 
espaço por si só não foi suficiente para alterar a percepção de distância. Ao invés disso, um melhor desempenho ao longo das distâncias testadas foi observado na tarefa em que ambas as informações estavam presentes. 


\section{REFERÊNCIAS}

Andre, J., \& Rogers, S. (2006). Using verbal and blind-walking distance estimates to investigate the two visual systems hypothesis. Perception \& Psychophysics, 68(3), 353361.

Bee, L. (1991). Effect of magnification on distance estimation. Army personnel research establishment ministry of defence, Farnborough Hampshire.

Bergmann, J., Krauß, E., Münch, A., Jungmann, R., Oberfeld, D., \& Hecht, H. (2011).

Locomotor and verbal distance judgments in action and vista space. Experimental brain research, 210(1), 13-23.

Berthoz, A., Israël, I., Georges-François, P., Grasso, R., \& Tsuzuku, T. (1995). Spatial memory of body linear displacement: what is being stored?.Science, 269(5220), 95-98.

Bestaven, E., Guillaud, E., \& Cazalets, J. R. (2012). Is “Circling” Behavior in Humans Related to Postural Asymmetry?. PloS One, 7(9), e43861.

Bove, M., Diverio, M., Pozzo, T., \& Schieppati, M. (2001). Neck muscle vibration disrupts steering of locomotion. Journal of Applied Physiology, 91(2), 581-588.

Bove, M., Courtine, G., \& Schieppati, M. (2002). Neck muscle vibration and spatial orientation during stepping in place in humans. Journal of Neurophysiology, 88(5), 2232-2241.

Bove, M., Brichetto, G., Abbruzzese, G., Marchese, R., \& Schieppati, M. (2004). Neck proprioception and spatial orientation in cervical dystonia. Brain,127 (12), 2764-2778.

Boyadjian, A., Marin, L., \& Danion, F. (1999). Veering in human locomotion: the role of the effectors. Neuroscience Letters, 265(1), 21-24

Bremmer, F., \& Lappe, M. (1999). The use of optical velocities for distance discrimination and reproduction during visually simulated self motion. Experimental Brain Research, 127(1), 33-42.

Brasil, I. B. G. E. (2015). Instituto Brasileiro de geografia e Estatística. Disponível em: http://www.ibge.gov.br/home/ Acesso em: 07/ janeiro/2015.

Cheung, A., Zhang, S., Stricker, C., \& Srinivasan, M. V. (2007). Animal navigation: the difficulty of moving in a straight line. Biological cybernetics,97(1), 47-61.

Cheung, A., Zhang, S., Stricker, C., \& Srinivasan, M. V. (2008). Animal navigation: general properties of directed walks. Biological cybernetics, 99(3), 197-217. 
Courtine, G., \& Schieppati, M. (2003). Human walking along a curved path. I. Body trajectory, segment orientation and the effect of vision. European Journal of Neuroscience, 18(1), 177-190.

Cutting, J.; Vishton, P.E. (1995). Perceiving layout and knowing distances: the integration, relative potency, and contextual use of different information about depth. In: Epstein W, Rogers SP, editors. Perception of space and motion. San Diego CA: Academic Press; p.66-117.

Da Silva, J. A. (1985). Scales for perceived egocentric distance in a large open field: Comparison of three psychophysical methods. The American Journal of Psychology, 119-144.

Da-Silva, J. A.; Aznar-Casanova, J. A.; Pinto-Ribeiro Filho, N.; Santilhán, J. E. (2006). Acerca da métrica da percepção do espaço visual. Arquivos Brasileiros de Oftalmologia, 69, 127-135.

Da-Silva, J. A., dos Santos, R. A., \& da Silva, C. B. (1983). Análise psicofísica do espaço visual-teoria e pesquisa: tributo a SS Stevens.Arquivos Brasileiros de Psicologia.

Daum, S. O., \& Hecht, H. (2009). Distance estimation in vista space. Attention, Perception, \& Psychophysics, 71(5), 1127-1137.

Day, H. D., \& Vickie, J. (1997). Veering in women: inconsistency of forward and backward progression. Perceptual and Motor Skills, 85(2), 587-596.

Displacement. In Wikipedia, The Free Encyclopedia. Disponível em: http://en.wikipedia.org/w/index.php?title=Displacement\&oldid=635290729. Acesso em: 05 de Janeiro de 2015.

Durgin, F. H., Reed, C., \& Tigue, C. (2007). Step frequency and perceived self-motion. $A C M$ Transactions on Applied Perception (TAP), 4(1), 5.

Ellard, C. G., \& Shaughnessy, S. C. (2003). A comparison of visual and nonvisual sensory inputs to walked distance in a blind-walking task. Perception-London, 32(5), 567-578.

Elliott, D. (1986). Continuous visual information may be important after all: A failure to replicate Thomson (1983). Journal of Experimental Psychology: Human Perception and Performance, 12(3), 388-391.

Fine, B. J., \& Kobrick, J. L. (1983). Individual differences in distance estimation: Comparison of judgments in the field with those from projected slides of the same scenes. Perceptual and motor skills, 57(1), 3-14. 
Fukusima, S. S., Loomis, J. M., \& Da Silva, J. A. (1997). Visual perception of egocentric distance as assessed by triangulation. Journal of Experimental Psychology: Human Perception and Performance, 23(1), 86.

Gallistel, C. R. (1990). The organization of learning (pp. 317-350). Cambridge, MA: MIT press.

Gibson, J. J. (1950). The Perception of the Visual World (Boston, MA: Houghton Mifflin).

Glasauer, S., Amorim, M. A., Viaud-Delmon, I., \& Berthoz, A. (2002). Differential effects of labyrinthine dysfunction on distance and direction during blindfolded walking of a triangular path. Experimental Brain Research, 145(4), 489-497.

Gogel, W. C. (1964) Visual perception of spatial extent. Journal of the Optical Society of America, 54, 411-416, 1964.

Gogel, W. C. (1974). Cognitive factors in spatial responses. Psychologia: An International Journal of Psychology in the Orient.

Gogel, W. C. (1990). A theory of phenomenal geometry and its applications.Perception \& Psychophysics, 48(2), 105-123.

Grüsser, O.J. (1983). Multimodal structure of the extrapersonal space. In: Hein, A. \& Jeannerod, M. (eds.), Spatially Oriented Behavior. New York: Springer-Verlag, 327$352,1983$.

Gulbberg, F. 0. (1897) Die Circularbewegung als tierisehe Grundbewegung, ihre Ursache, Phenomenalitit und Bedeutung. Zeits. f. Biol., Bd, 35, 419-458.

Harris, L. R., Jenkin, M., \& Zikovitz, D. C. (2000). Visual and non-visual cues in the perception of linear self motion. Experimental Brain Research, 135(1), 12-21.

Howard, I. P., \& Templeton, W. B. (1966). Human Spatial Orientation. New York: Wiley.

Iosa, M., Fusco, A., Morone, G., \& Paolucci, S. (2012). Walking there: environmental influence on walking-distance estimation. Behavioural brain research, 226(1), 124-132.

Israël, I., Grasso, R., Georges-Francois, P., Tsuzuku, T., \& Berthoz, A. (1997). Spatial memory and path integration studied by self-driven passive linear displacement. I. Basic properties. Journal of Neurophysiology, 77(6), 3180-3192.

Joseph S. Lappin, Amy L. Shelton, and John J. Rieser (2006). Environmental context influences visually perceived distance. Attention, Perception, \& Psychophysics 68, 4 (2006), 571-581.

Lappin, J. S., Shelton, A. L., \& Rieser, J. J. (2006). Environmental context influences visually perceived distance. Perception \& psychophysics, 68(4), 571-581. 
Kallie, C. S., Schrater, P. R., \& Legge, G. E. (2007). Variability in stepping direction explains the veering behavior of blind walkers. Journal of Experimental Psychology: Human Perception and Performance, 33(1), 183.

Klatzky, R. L., Loomis, J. M., Beall, A. C., Chance, S. S., \& Golledge, R. G. (1998). Spatial updating of self-position and orientation during real, imagined, and virtual locomotion. Psychological science, 9(4), 293-298.

Klatzky, R. L., Loomis, J. M., Golledge, R. G., Cicinelli, J. G., Doherty, S., \& Pellegrino, J. W. (1990). Acquisition of route and survey knowledge in the absence of vision. Journal of motor behavior, 22(1), 19-43.

Kunz, B. R., Wouters, L., Smith, D., Thompson, W. B., \& Creem-Regehr, S. H. (2009). Revisiting the effect of quality of graphics on distance judgments in virtual environments: A comparison of verbal reports and blind walking. Attention, Perception, \& Psychophysics, 71(6), 1284-1293.

Lambrey, S., Viaud-Delmon, I., \& Berthoz, A. (2002). Influence of a sensorimotor conflict on the memorization of a path traveled in virtual reality.Cognitive brain research, 14(1), 177-186.

Lappe, M. (Ed.). (2000). International Review of Neurobiology: Neuronal Processing of Optic Flow. Academic Press.

Lappin, J. S., Shelton, A. L., \& Rieser, J. J. (2006). Environmental context influences visually perceived distance. Perception \& psychophysics, 68(4), 571-581.

Larish, J. F., \& Flach, J. M. (1990). Sources of optical information useful for perception of speed of rectilinear self-motion. Journal of Experimental Psychology: Human Perception and Performance, 16(2), 295.

Loomis, J. M., Da Silva, J. A., Fujita, N., \& Fukusima, S. S. (1992). Visual space perception and visually directed action. Journal of Experimental Psychology: Human Perception and Performance, 18(4), 906.

Loomis, J. M., \& Philbeck, J. W. (2008). Measuring spatial perception with spatial updating and action. In Carnegie Symposium on Cognition, 2006, Pittsburgh, PA, US. Psychology Press.

Mach, E. (1885). The Analysis of Sensations. New York: Dover [translated and reprinted, 1959].

Mittelstaedt, M. L., \& Mittelstaedt, H. (2001). Idiothetic navigation in humans: estimation of path length. Experimental Brain Research, 139(3), 318-332. 
Mohr, C., Landis, T., Bracha, H. S., Fathi, M., \& Brugger, P. (2003). Human locomotion: levodopa keeps you straight. Neuroscience Letters, 339(2), 115-118.

Mohr, C., Brugger, P., Bracha, H. S., Landis, T., \& Viaud-Delmon, I. (2004). Human side preferences in three different whole-body movement tasks.Behavioural brain research, 151(1), 321-326.

Mohr, C., \& Lievesley, A. (2007). Test-retest stability of an experimental measure of human turning behaviour in right-handers, mixed-handers, and left-handers. Laterality, 12(2), 172-190.

Mohler, B. J., Bülthoff, H. H., Thompson, W. B., \& Creem-Regehr, S. H. (2008, August). A full-body avatar improves egocentric distance judgments in an immersive virtual environment. In Proceedings of the 5th symposium on Applied perception in graphics and visualization (p. 194). ACM.

Oldfield, R.C. (1971).The assessment and analysis of handedness: The Edinburgh inventory. Neuropsychologia, 9, pp. 97-113.

Philbeck, J. W., Klatzky, R. L., Behrmann, M., Loomis, J. M., \& Goodridge, J. (2001). Active control of locomotion facilitates nonvisual navigation. Journal of Experimental Psychology: Human Perception and Performance, 27(1), 141.

Porac, C., \& Coren, S. (1981). Lateral preferences and human behavior. Springer Science \& Business Media.

Previc, F. H. (1990). Functional specialization in the lower and upper visual fields in humans: Its ecological origins and neurophysiological implications.Behavioral and Brain Sciences, 13(03), 519-542.

Previc, F. H. (1998). The neuropsychology of 3-D space. Psychological bulletin, 124(2), 123.

Previc, F.H., \& Saucedo, J.C. (1992). The relationship between turning behavior and motoric dominance in humans. Perceptual and Motor Skills, 75, 935-944.

Renner, R. S., Velichkovsky, B. M., \& Helmert, J. R. (2013). The perception of egocentric distances in virtual environments-a review. ACM Computing Surveys (CSUR), 46(2), 23.

Rieser, J. J., Ashmead, D. H., Talor, C. R., \& Youngquist, G. A. (1990). Visual perception and the guidance of locomotion without vision to previously seen targets. Perception, 19(5), 675-689.

Rieser, J. J., Pick, H. L., Ashmead, D. H., \& Garing, A. E. (1995). Calibration of human locomotion and models of perceptual-motor organization. Journal of Experimental Psychology: Human Perception and Performance, 21(3), 480. 
Schaeffer, A.A. (1928). Spiral movement in man. Journal of Morphology. 45(1), 293-398.

Scharine, A. A., \& McBeath, M. K. (2002). Right-handers and Americans favor turning to the right. Human Factors: The Journal of the Human Factors and Ergonomics Society, 44(2), 248-256.

Souman, J. L., Frissen, I., Sreenivasa, M. N., \& Ernst, M. O. (2009). Walking straight into circles. Current Biology, 19(18), 1538-1542.

Stevens, S. S. (2000). Psychophysics: Introduction to its perceptual, neural and perceptual prospects. New York: Willey. (Trabalho original publicado em 1975)

Sun, H. J., Campos, J. L., Young, M., Chan, G. S., \& Ellard, C. G. (2004). The contributions of static visual cues, nonvisual cues, and optic flow in distance estimation. PerceptionLondon-, 33(1), 49-66.

Takei, Y., Grasso, R., Amorim, M. A., \& Berthoz, A. (1997). Circular trajectory formation during blind locomotion: a test for path integration and motor memory. Experimental Brain Research, 115(2), 361-368.

Thompson, W., Willemsen, P., Gooch, A., Creem-Regehr, S., Loomis, J., \& Beall, A. (2004). Does the quality of the computer graphics matter when judging distances in visually immersive environments?. Presence, 13(5), 560-571.

Toussaint, Y., Do, M. C., \& Fagard, J. (2008). What are the factors responsible for the deviation in stepping on the spot?. Neuroscience letters, 435(1), 60-64.

Unknown author (1893), Why lost people walk in circles, Scientific American, (February), 18, 100.

Varraine E.; Bonnard M.; Pailhous, J. The top down and bottom up mechanisms involved in the sudden awareness of low level sensorimotor behavior. Cognitive Brain Research, 13, 357-361, 2002.

Vieilledent, S., Kosslyn, S. M., Berthoz, A., \& Giraudo, M. D. (2003). Does mental simulation of following a path improve navigation performance without vision? Cognitive Brain Research, 16(2), 238-249.

Vuillerme, N., Nougier, V., \&Camicioli, R. (2002).Veering in human locomotion: modulatory effect of attention. Neuroscience Letters, 331(3), 175-178.

Warren, R., \& Wertheim, A. H. (Eds.). (2014). Perception and Control of Self-motion. Psychology Press.

Wersényi, G., \& Répás, J. (2012). Comparison of Localization Performance of Blind and Sighted Subjects on a Virtual Audio Display and in Real-Life Environments. Watermark, 1 . 
Yamamoto, N. (2012). The role of active locomotion in space perception.Cognitive processing, 13(1), 365-368.

Yoder, R. M., \& Taube, J. S. (2014). The vestibular contribution to the head direction signal and navigation. Frontiers in integrative neuroscience, 8. 



\section{APÊNDICES}

\section{APÊNDICE A - Instruções das Tarefas Experimentais}

Instruções da tarefa de produção de distâncias a um alvo visualmente percebido

"Estamos interessados em estudar como as pessoas se locomovem e se orientam no espaço na ausência de informações visuais e pistas auditivas. Para estudarmos isto, apresentaremos um cone de sinalização em várias distâncias neste campo e você será solicitado a observá-lo, memorizar sua localização e posteriormente caminhar em linha reta, de olhos vendados, até o ponto onde você imagina que o cone está localizado. Não se preocupe em tropeçar no cone, pois esse será retirado do seu caminho enquanto você se locomove. Fique tranquilo, pois um de nós estará sempre ao seu lado durante todo o percurso. Você deverá usar essa venda. Será necessário que a deixe repousando em sua cabeça, para facilitar a colocação na hora apropriada. Você deverá vestir esse educador postural, como se fosse as alças de uma mochila. Feito isso, prenderemos no educador postural: nas suas costas, um receptor GPS, para registrar sua distância caminhada; e, na frente, um MP3 conectado a fones de ouvido. Nos fones de ouvido, você irá escutar um leve ruído e que será usado para disfarçar os sons do ambiente. O som e o GPS somente serão ligados quando iniciarmos a tarefa. Antes de começar, nos iremos realizar algumas tentativas como treinamento: primeiro você fara uma tarefa com visão e depois uma com a venda. Ok? Então, vamos começar. Você deve ficar posicionado nesta marca branca, direcionando seu corpo de frente ao cone. Você deverá observar o cone, e quando memorizar a localização diga: Estou pronto. Então, olhe para frente em direção ao cone, que iremos vendá-lo e ligaremos o som e o GPS, e, imediatamente, você deverá andar normalmente em linha reta até onde você imagina que o cone estaria localizado. Quando você chegar ao local imaginado, pare. Não retire a venda, nem o fone de ouvido, pois você será conduzido até a posição inicial. Faremos esse procedimento várias vezes. Você poderá solicitar um intervalo entre as tentativas para descansar, ir ao banheiro, tomar água ou até mesmo se retirar do experimento. Estes intervalos também acontecerão quando julgarmos necessário. Alguma dúvida até aqui?’”.

\section{Instruções da tarefa de reprodução de distâncias após o caminhar sob condições visuais}

"Estamos interessados em estudar como as pessoas se locomovem e se orientam no espaço na ausência de informações visuais e pistas auditivas. Para estudarmos isto, apresentaremos um 
cone de sinalização em várias distâncias neste campo e você será solicitado a observá-lo e memorizar sua localização ao caminhar em sua direção. Ao alcançar o cone, você deverá parar, pois você será vendado. A partir disso, você deverá dar meia volta e retornar sozinho ao local onde iniciou sua caminhada, tentando reproduzir a distância percorrida até o cone, caminhando normalmente. Fique tranquilo, pois um de nós estará sempre ao seu lado durante todo o percurso, e quando necessário, irá segurar levemente seu cotovelo. Você deverá usar essa venda. Será necessário que a deixe repousando em sua cabeça, para facilitar a colocação na hora apropriada. Você deverá vestir esse educador postural, como se fosse as alças de uma mochila. Feito isso, prenderemos no educador postural: nas suas costas, um receptor GPS, para registrar sua distância caminhada; e, na frente, um MP3 conectado a fones de ouvido. Nos fones de ouvido, você irá escutar um leve ruído e que será usado para disfarçar os sons do ambiente. O som e o GPS somente serão ligados quando iniciarmos a tarefa. Antes de começar o experimento iremos realizar algumas tentativas como treinamento: primeiro faremos uma com visão e depois com a venda. OK? Alguma pergunta? Então, vamos começar? Você deverá se posicionar nesta marca branca, direcionando seu corpo de frente ao cone. Preste atenção na distância que você irá caminhar, mantenha seu olhar sempre para frente em direção ao cone e evite olhar para o chão, procure memorizar a distância caminhada entre o ponto de partida e o cone. Não conte seus passos, pois isto poderá atrapalhar nossos resultados. Tão logo ligarmos o som, e iremos começar. Olhe para o cone enquanto você caminha em linha reta até a sua posição. Quando chegar ao local onde o cone está posicionado, pare. Neste momento você será vendado, o GPS será ligado, e imediatamente será auxiliado a dar meia volta e retornar sozinho ao local que você imagina ser o início da tarefa. Quando você chegar ao local imaginado, o ponto de inicio da tarefa, pare. Não retire a venda, nem o fone de ouvido, pois você será conduzido até a posição inicial. Faremos esse procedimento várias vezes. Você poderá solicitar um intervalo entre as tentativas para descansar, ir ao banheiro, tomar água ou até mesmo se retirar do experimento. Estes intervalos também acontecerão quando julgarmos necessário. Alguma dúvida?”.

\section{Instruções da tarefa de reprodução de distâncias após o caminhar não visual}

"Estamos interessados em estudar como as pessoas se locomovem e se orientam espaço sem a visão e sem pistas auditivas. Para estudarmos isto, faremos uma tarefa bem simples. Você será solicitado a caminhar vendado em linha reta até um determinado local, que iremos chamar de ponto de parada, dar meia volta e retornar ao local onde iniciamos a caminhada. No trajeto de ida você será guiado, ou seja, você irá segurar meu braço e caminharemos juntos até o ponto 
de parada. A partir do ponto de parada, você será auxiliado a dar meia volta e deverá retornar sozinho, caminhando normalmente. Fique tranquilo, pois estaremos sempre ao seu lado durante todo o percurso. Você deverá usar essa venda. Será necessário que a deixe repousando em sua cabeça, para facilitar a colocação na hora apropriada. Você deverá vestir esse educador postural, como se fosse as alças de uma mochila. Feito isso, prenderemos no educador postural: nas suas costas, um receptor GPS, para registrar sua distância caminhada; e, na frente, um MP3 conectado a fones de ouvido. Nos fones de ouvido, você irá escutar um leve ruído e que será usado para disfarçar os sons do ambiente. Vamos colocá-lo em você, e o som somente será ligado quando iniciarmos o experimento. Antes de começá-lo iremos realizar algumas tentativas como treinamento: primeiro faremos uma com visão e depois com a venda. OK? Alguma pergunta? Então, vamos começar? Você deverá se posicionar nesta marca branca, direcionando seu corpo de frente ao espaço. Preste muita atenção na distância que iremos caminhar, procure memorizar a distância caminhada entre o ponto de partida e o ponto de parada. Não conte seus passos, pois isto poderá atrapalhar nossos resultados. Agora iremos vendá-lo e ligaremos o gravador. Em seguida você deverá segurar com uma das mãos o meu antebraço e caminharemos juntos uma distância. Quando pararmos, você será auxiliado a dar meia volta e retornar sozinho ao local que você imagina ser o ponto de início do experimento. Quando você chegar ao local imaginado, o ponto de início pare. Não retire a venda, nem o fone de ouvido, você será conduzido a origem para iniciar uma nova tarefa. Faremos esse procedimento várias vezes. As distâncias caminhadas podem mudar de uma tarefa para outra. Você poderá solicitar um intervalo entre as tentativas para descansar, ir ao banheiro, tomar água ou até mesmo se retirar do experimento. Estes intervalos também acontecerão quando julgarmos necessário. Alguma dúvida até aqui?’”. 
APÊEDICE B - Modelo matemático para trajetórias circulares

Pode-se provar que um corpo se movimenta em uma trajetória circular quando o módulo de sua velocidade linear $v$ e sua velocidade angular $\dot{\psi}$ são constantes. Considere um corpo com três graus de liberdade, que pode se mover em duas coordenadas espaciais e também pode rotacionar sobre seu eixo vertical.

Em coordenadas cartesianas, considerando que o corpo inicia seu movimento da origem, sua velocidade pode ser expressa por (A.1).

$\vec{v}=(v \sin \dot{\psi} t, v \cos \dot{\psi} t)$

A trajetória $\mathrm{s}(\mathrm{t})$ é calculada integrando a velocidade com relação ao tempo (A.2).

$s(t)=\int \vec{v} d t$

Assim,

$\mathrm{s}(\mathrm{t})=\left(\frac{\mathrm{v}}{\dot{\psi}}-\frac{\mathrm{v}}{\dot{\psi}} \cos \dot{\psi} \mathrm{t}, \frac{\mathrm{v}}{\dot{\psi}} \sin \dot{\psi} \mathrm{t}\right)$

A equação acima (A.3) representa um círculo de raio $R=\frac{\mathrm{v}}{\dot{\psi}}$ e centro em $\left(\frac{\mathrm{v}}{\dot{\psi}}, 0\right)$. De fato, isto pode ser provado através da equação que define uma circunferência em termos de sua equação paramétrica (A. 4).

$\left(\mathrm{x}-\frac{\mathrm{v}}{\dot{\psi}}\right)^{2}+(\mathrm{y})^{2}=\mathrm{R}^{2}$ 
APÊNDICE C - Artigo apresentado no exame de qualificação e publicado na revista

Psychology \& Neuroscience

PSYCHOLOGY

Psychology \& Neuroscience, 2014, 7, 3, $269-276$

DOI: 10.3922/j.psns.2014.037

\title{
Humans tend to walk in circles as directed by memorized visual locations at large distances
}

\author{
Patricia Consolo ${ }^{1}$, Humberto C. Holanda ${ }^{2}$, and Sérgio S. Fukusima ${ }^{1}$ \\ 1. Universidade de São Paulo, Ribeirão Preto, SP, Brazil \\ 2. Mectron - Organização Odebrecht, São José dos Campos, SP, Brazil
}

\begin{abstract}
Human veering while walking blindfolded or walking straight without any visual cues has been widely studied over the last 100 years, but the results are still controversial. The present study attempted to describe and understand the human ability to maintain the direction of a trajectory while walking without visual or audio cues with reference to a proposed mathematical model and using data collected by a global positioning system (GPS). Fifteen right-handed people of both genders, aged 18-30 years, walked without vision in an open ficld directly toward a target after secing it for a bricf period of time. Time and distance were directly measured by the GPS receiver. The mathematical analysis indicated that both linear and angular velocities determined the shape of the trajectory. Careful observation of the trajectories clearly showed a geometrical pattern, and the circular trajectory was the most frequent. Such behavior can be explained by the almost constant linear and angular velocity during the walk. From the perspective of the mathematical model, angular velocity is the observable physical quantity that most determines the trajectory pattern. One can notice that better performance (i.e., lower angular velocity) is related to longer distances when comparing an individual's circular trajectory walking performance as a function of different target distances (i.e., 30.00, 41.60, 57.69, and $80.00 \mathrm{~m}$ ). Keywords: space perception, blind walking, veering, navigation.
\end{abstract}

Received 05 January 2014; received in revised form 06 May 2014; accepted 14 May 2014. Available online 25 November 2014.

\section{Introduction}

Without external cues provided by vision, maintaining a straight-ahead direction is almost impossible while walking. This tendency to deviate from an intended route while progressing under conditions of restricted environmental cues is called veering (Kallie, Schrater, \& Legge, 2007). Questions related to this natural directional bias while walking, especially its cause, have drawn the attention of researchers over the last 100 years (Guldberg, 1897; Howard \& Templeton, 1966; Mach, 1959; Schaeffer, 1928; "Why lost people walk in circles", 1893). However, such behavior is still not well understood and has raised multiple explanations. For example, the reason for this tendency toward directional walking is diversely attributable to (1) an inapt spiraling mechanism in the nervous system that is used in the absence of vision (Guldberg, 1897; Schaeffer, 1928), (2) biomechanics and

Patricia Consolo and Sérgio S. Fukusima, Universidade de São Paulo, Ribeirão Preto, Brazil. Humberto C. Holanda, Mectron, Organização Odebrecht, São José dos Campos, Brazil. Correspondence regarding this article should be directed to: Patricia Consolo, Universidade de São Paulo, Faculdade de Filosofia Ciências e Letras de Ribcirão Preto, Departamento de Psicologia, Av. Bandeirantes, 3900, Monte Alegre, Ribcirão Preto, SP, 14040-901, Brazil. Phone: +55-16-36024448. E-mail: pconsolo@pg.ffclrp.usp.br sensorial asymmetries, particularly hand and foot laterality (Day \& Goins, 1999; Scharine \& McBeath, 2002), (3) otolith system asymmetry from the fetal position (Previc \& Saucedo, 1992), (4) hemispheric asymmetry of the dopaminergic system (Mohr, Landis, Bracha, Fathi, \& Brugger, 2003; Mohr, Brugger, Bracha, Landis, \& ViaudDelmon, 2004; Mohr \& Lievesley, 2007), and (5) sensorial signal interference, in which acoustic signals, such as unpredictable noises, and postural signals can lead to greater directional deviance (Millar, 1999).

Based on these findings, there are many reasons to believe that veering cannot be adequately described by a single factor. This directional tendency ought to be a multifactor phenomenon, and such behavior emerges from an inter-relationship between central and peripheral mechanisms.

Although the literature in this field has presented divergent results and interpretations about the matter, a common aspect among all of the studies is the belief that humans, when walking blindfolded or in environments with reduced visual cues, many times involuntarily move in a large circle or spiral (Day and Goins, 1977). Indeed, this belief is present not only in the scientific literature but also in popular culture, albeit only slightly confirmed by empirical data.

Only recently have researchers sought to answer the question experimentally for longer distances. In 
analyzing the trajectories in large spaces both outdoors (Souman, Frissen, Sreenivasa, \& Ernst, 2009) and indoors (Bestaven, Guillaud, \& Cazalets, 2012), empirical evidence indicates that blindfolded subjects walk in circles, though rarely in a systematic direction.

The first goal of the present study was to identify and quantify the pattern of the observed trajectories during a walking task for which the subjects did not have visual or auditory cues over distances of $30.00,41.60,57.69$, and $80.00 \mathrm{~m}$ using a global positioning system (GPS) receiver to record the subjects' movements. We found that four different patterns could be recognized: (1) straight trajectory, (2) circular trajectory, (3) straight-circular trajectory, and (4) alternate trajectory. To understand the circular trajectory, a mathematical model was proposed to determine the geometrical quantities of this trajectory (mean radius and origin) based on physical quantities (linear speed and angular speed). This mathematical model was validated by measuring the error between the actual and predicted trajectories. Finally, we compared individual performance while walking a circular trajectory as a function of different target distances $(30.00,41.60,57.69$, and $80.00 \mathrm{~m})$.

Given that past studies on blind navigation showed that direction error varies as a function of the distance walked, we hypothesized that the increase in the target distance may lead the subject to lose directional orientation and increase the risk of expanding their angular deviations. In the particular case of the circular trajectory, an increase in angular velocities and decrease in the radius of the trajectory, indicating a worse trajectory, would be observed.

\section{Methods \\ Participants}

Fifteen volunteers (five male, 10 female), without any known impairment in the sensorial or musculoskeletal system, aged $18-30$ years $($ mean $=23.83$ years; $S D=$ 5.91 years), and never having previously participated in large-scale sports, participated in this study. All of the participants were right-handed and right-footed according to the Edinburgh inventory (Oldfield, 1971) and the Porac-Coren lateral preference foot questionnaire (Porac \& Coren, 1981). All of the subjects gave written informed consent prior to participation, and the study was approved by the local Ethics Committee (Process CEP-FFCLRP ${ }^{\circ}$ 578/2011).

\section{Equipment}

The study was performed during the daytime on a level and natural grass soccer field $(90 \times 60 \mathrm{~m})$ at an educational institution between 4:00 $\mathrm{PM}$ and 6:00 PM to reduce sunlight cues. In this space, four egocentric distances were demarcated, defined by the physical extension between the initial position and target location. These distances $(30.00,41.60,57.69$, and $80.00 \mathrm{~m})$ were measured using a tape-measure and discreetly marked with colored golf tees.

During the experiment, the subjects were blindfolded by wearing a mask that completely occluded central and peripheral vision and equipped with headphones that generated white noise to mask acoustic cues from the environment. The movements of the participants were recorded using a Juno Handheld AS GPS (Trimble) with Terrasync Standard software (Trimble).

\section{Walking task}

Each participant was guided to the experimental space, and the researcher gave explicit instructions prior to the experiment. The participant underwent a series of practice trials, without feedback, to get used to both the equipment and the task.

At the beginning of each trial, each participant was placed at the initial point and asked to observe and memorize for a few seconds the position of the target ahead (a traffic cone, $75 \mathrm{~cm}$ height) located at a previously defined distance $(30.00,41.60,57.69$, and $80.00 \mathrm{~m}$ ). Each participant walked each distance three times, with 12 trials per subject for a total of 180 trials. The participants then wore the blindfold and headphones and walked forward at a comfortable pace and stopped when they believed they had reached the location of the target. The traffic cone was removed by an assistant and placed beside the path during the trial to avoid collision.

During the walk, the experimenter walked alongside the blindfolded participant to record the complete route with a GPS receiver and provide a safe route for the subject. The experimenter was careful to maintain the same walking pace to not influence the subject's estimates. To prevent the subjects from knowing their navigational errors and correcting their performance from one trial to the next, they were instructed to keep their blindfold on after their walk and led back to the starting point via walking a large figure 8 . Once at the starting position, the participants were instructed to briefly remove the blindfold so they could see and memorize for a few seconds (approximately $5 \mathrm{~s}$ ) the new target location, which was randomly selected, before starting the next trial.

\section{Movement registration}

The walking data (distance in meters and elapsed time in seconds) for every trial were collected and recorded using a GPS receiver, whose data acquisition frequency is $f_{\text {gps }}=1 \mathrm{~Hz}$. To reduce the uncertainty of the distance, these data were extracted and post-processed using Path Finder Office software (Trimble) with differential correction and the appropriate data provided by the website of Rede Brasileira de Monitoramento Contínuo dos Sistemas GNSS, Instituto Brasileiro de Geografia e Estatística. As a result, the standard deviation of the distance measured was reduced from 2-5 $\mathrm{m}$ to 1-3 $\mathrm{m}$, values that satisfied our experimental requirements. 
After movement registration, the post-process of the data extracted from the GPS and coordinate transformation of all of the physical quantities could be calculated, namely, the subject velocity $\bar{v}$ (meters per second), angular deviation a (degrees), mean angular velocity $\dot{\psi}$ (radians per second), and radius of the theoretical circular trajectory $\boldsymbol{R}_{\mathrm{m}}$ (meters).

The subject velocity (1) was determined using the distance between two measures in each coordinate and the related time interval,

$$
\vec{v}(\mathrm{t}) \approx\left(\frac{\mathrm{x}(\mathrm{t})-\mathrm{x}(\mathrm{t}-\Delta \mathrm{t})}{\Delta \mathrm{t}}, \frac{\mathrm{y}(\mathrm{t})-\mathrm{y}(\mathrm{t}-\Delta \mathrm{t})}{\Delta \mathrm{t}}\right)
$$

The velocity (in meters/seconds) is calculated at the instant $\mathrm{t} . \mathrm{x}(\mathrm{t}-\Delta \mathrm{t})$ and $\mathrm{y}(\mathrm{t}-\Delta \mathrm{t})$ are the positions at instant $\mathrm{t}$. and are the positions in the previous instant $\mathrm{t}-\Delta \mathrm{t} . \quad \Delta \mathrm{t}=1 \mathrm{~s}$ is the sample time of the GPS.

To compare the subjects who had a path closer to the straight trajectory, the angular deviation was calculated according to Equation (2).

$$
\alpha=\operatorname{atan}\left(\frac{x_{c}}{y_{c}}\right)
$$

$x_{c}$ and $y_{c}$ are the local coordinates relative to the soccer field. The geometrical interpretation of this quantity is shown in Figure 1.

Lastly, we calculated both the angular velocity and mean radius of the theoretical circular path, supposing that the velocity and angular velocity of the subject are constant throughout the trajectory. In this condition, the body performs a circular trajectory. Thus, the mean radius is calculated using Equation (3).

$$
\mathrm{R}_{\mathrm{m}}=\frac{\mathrm{v}_{\mathrm{m}}}{\dot{\psi}_{\mathrm{m}}}(3)
$$

$\mathrm{v}_{\mathrm{m}}$ is the mean velocity $(\mathrm{m} / \mathrm{s}) . \quad \dot{\psi}_{\mathrm{m}}(\mathrm{rad} / \mathrm{s})$ is the angular velocity of the body.

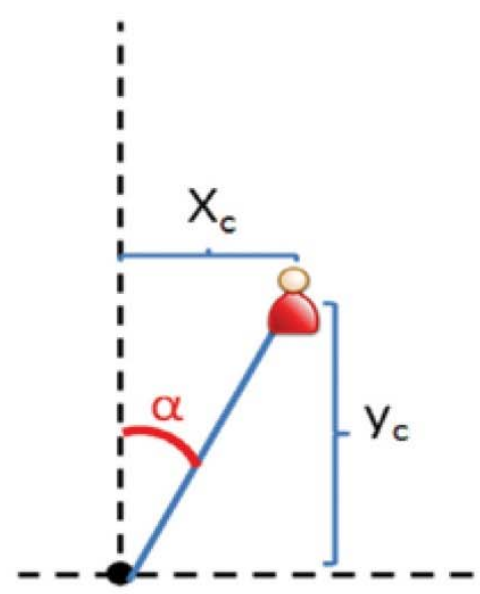

Figure 1. Geometric interpretation of an angular deviation of $\alpha$.
The circular trajectory can be described as a function of time using Equation (4).

$$
s(t)=\left(\frac{v}{\dot{\psi}}-\frac{v}{\dot{\psi}} \cos \dot{\psi} t, \frac{v}{\dot{\psi}} \sin \dot{\psi} t\right)
$$

Although the angular velocity $\dot{\psi}$ was not directly measured, its mean value $\dot{\psi}_{\mathrm{m}}$ was estimated by minimizing the functional error function $J$ between the theoretical $\left(\mathrm{x}_{\text {est }}, \mathrm{y}_{\mathrm{est}}\right)$ and observed trajectory given by Equation (5).

$J=\sum_{i=1}^{N}\left[x_{\text {est }}(\mathrm{i} . T)-x_{\text {obs }}(\text { i. T })\right]^{2}+\sum_{i=1}^{N}\left[y_{\text {est }}(\text { i. T })-y_{\text {obs }}(\text { i. T })\right]^{2}$

$\mathrm{N}$ is the total number of measured points of the trajectory. $T=1$ is the GPS sampling time.

\section{Coordinate transformation}

To describe the position of an object on the Earth's surface, one needs to use a specific coordinate system. This system is associated with the surface on which all of the calculations will be developed. The position of a body can be represented by coordinates in different ways, including on a spherical surface with denominated geodesic coordinates (such as a Geodetic System) or on a flat surface with a denominated Plane Coordinate System (such as Universal Transverse Mercator projections; Brys, 2005).

In the present study, the trajectory data were obtained by GPS and transformed into North East UP (NEU) coordinates to facilitate the analysis. Because the largest possible walking distance is less than $100 \mathrm{~m}$, the hypothesis of flat earth is satisfactory. The measurement uncertainty of each coordinate was directly obtained after post-processing, whereas the uncertainty of the calculated quantities such as velocity, total distance, and angular deviation was determined by the theory of error propagation.

Because the soccer field where the experiment was performed is not aligned with the local northeast system, the measured and post-processed coordinates were rotated through an angle of $\theta=12.73^{\circ}$ with regard to the right-hand rule applied to the vertical axis.

\section{Data calculation}

The results are presented as mean and standard deviation $( \pm \mathrm{SD})$. Nonparametric tests were also used to compare group means (Mann-Whitney test) and parameters across trials (Wilcox test). The results were considered statistically significant for $p \leq .05$.

\section{Results}

\section{Trajectory pattern}

Afterperforming the experiments for the four distances $(30.00,41.60,57.69$, and $80.00 \mathrm{~m})$ and calculating each trajectory according to the method presented in the last section above, we obtained the results for all of the 


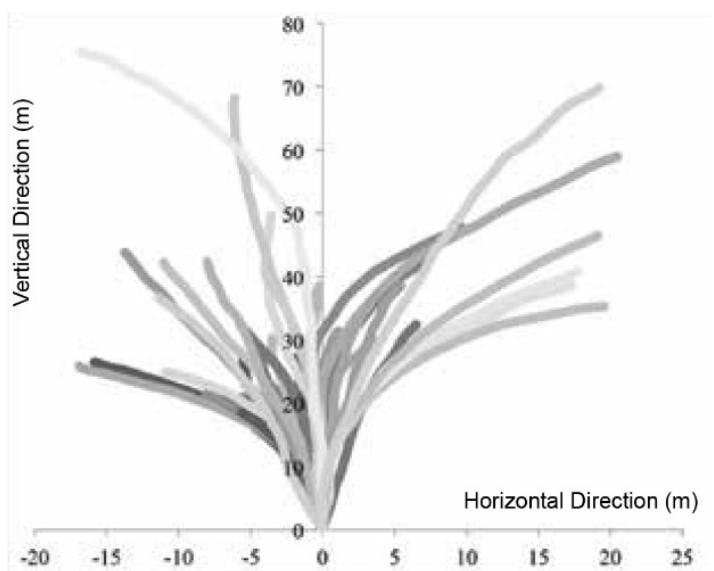

Figure 2. All trajectories during blindfolded walking to a $30.00 \mathrm{~m}$ target distance. In the frame of reference of this experiment, the horizontal direction is parallel to the field's goalposts and the vertical direction is perpendicular to them. The origin is located at the penalty spot.

subjects. Because of technical reasons, the data from one participant were excluded from the analysis. To illustrate these results, Figure 2 presents the trajectories walked relative to the target distance of $30.00 \mathrm{~m}$.

Motivated by the fact that most of the trajectories were arc of circumferences, the trajectories were classified into certain patterns. Thus, the trajectories were classified according to the following geometrical rules: (a) straight trajectory, in which the errors with respect to an ideal straight line were point-to-point less than $1.0 \mathrm{~m}$, (b) circular trajectory, in which the errors with respect to an ideal circular path were point to point less than $1.0 \mathrm{~m}$, (c) straight-circular trajectory, in which the errors with respect to an initial straight line and then a circular path were point-to-point less than $1.0 \mathrm{~m}$, and (d) alternate trajectory, in which the subject alternated between increasing and decreasing deviate trajectories. These patterns are shown in Figure 3.

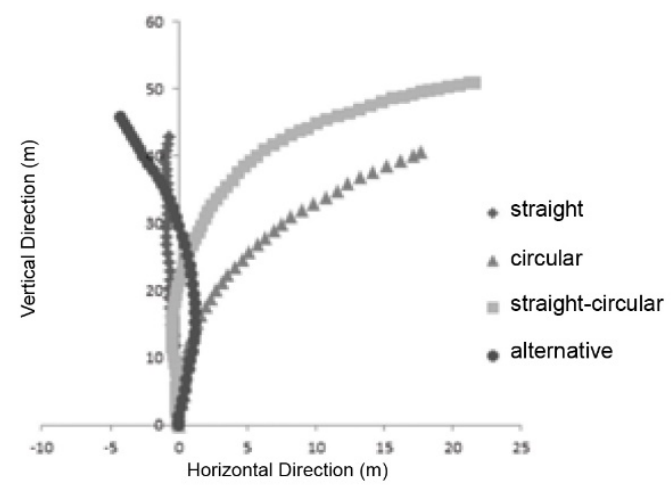

Figure 3. Example of the observed trials and their diverse classification. In the frame of reference of this experiment, the horizontal direction is parallel to the field's goalposts and the vertical direction is perpendicular to them. The origin is located at the penalty spot.
Table 1. Trajectory frequency during blind navigation (straight line, straight-circular, circular, and alternate) as a function of the target distance.

\begin{tabular}{lllll}
\hline $\begin{array}{l}\text { Target } \\
\text { distance } \\
(\mathbf{m})\end{array}$ & $\begin{array}{l}\text { Straight } \\
\text { line } \mathbf{( \% )}\end{array}$ & $\begin{array}{l}\text { Straight- } \\
\text { circular } \\
(\%)\end{array}$ & $\begin{array}{l}\text { Circular } \\
\mathbf{( \% )}\end{array}$ & $\begin{array}{l}\text { Alternate } \\
(\%)\end{array}$ \\
\hline 30.00 & 31 & 4 & 65 & 0 \\
41.60 & 7 & 14 & 71 & 7 \\
57.69 & 7 & 32 & 57 & 4 \\
80.00 & 21 & 48 & 28 & 3 \\
\hline
\end{tabular}

As shown in Table 4, for all of the distances, the most frequent pattern was the circular trajectory, and the least frequent pattern was the alternate trajectory. This assessment, based on the descriptive data, was corroborated by inferential analysis. The Mann-Whitney test for paired comparisons between the trajectory patterns indicated significant differences between the frequency of the circular pattern and the other patterns at all distances $(p<.05)$.

Table 1 also reveals some curiosities about the performance of the participants. The number of trajectories for the straight and circular patterns significantly increased with larger distances (i.e., 57.69 and $80 \mathrm{~m}$, respectively; $p<.05$ ). On average, the subjects veered later for more distant targets.

\section{Individual lateral preference}

To aid comparisons with previous and future studies that investigate veering, a score that reflects the preference in the lateral direction of deviation was established for the participants. Thus, in each trial, deviations to the right side of the body are indicated with a positive sign, and deviations to the left side of the body are indicated with a negative sign.

The majority of the participants deviated toward the left (Figure 3). The Wilcox test indicated significant lateral orientation preference to the left side $(69 \%)$ when considering the overall trials $(p<.05)$. Furthermore, more participants $(93 \%)$ changed their side of deviation between trials in one or the other direction.

\section{Circular trajectory analysis}

Visual inspection of every trial for each participant resulting from the movement of the subject while he or she was walking without being able to see the target revealed that all of the subjects deviated from the initial straight direction, performing as a general rule circular trajectories, such as circumference arcs (Figure 4).

To verify whether this directional pattern that was common among the subjects was true according to a more rigorous mathematical analysis, we attempted to fit a circle that best corresponded to the subject's trajectory. According to the explanation presented in ANNEX A, we calculated the velocity and estimated the 


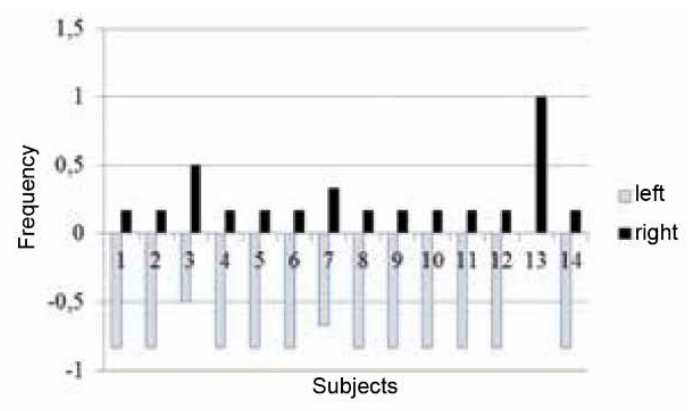

Figure 4. Veering score. Individual results are expressed in terms of the rate of deviation for all of the subjects $(n=14)$.

angular velocity and the mean radius of every trial for the four distances of the presented target. The results are summarized in Tables 1-3.

The data in Table 1 were used to verify whether the velocity and deviation varied as a function of target distance. The angular deviations were significantly greater with the large distance $(80.00 \mathrm{~m})$ compared with the shortest distance $(30.00 \mathrm{~m} ; p \leq .05)$ when considering alternate, straight, and straight-circular trajectories. No significant differences in linear velocity were found between distances $(p \geq .05)$.

When analyzing only the results of the circular trajectories shown in Table 2, we found that the average angular velocity values decreased as the target distance increased $(p \leq .05)$ and that the average radii for the target distances of 57.69 and $80.00 \mathrm{~m}$ were significantly greater than for the target distances of 30.00 and $41.60 \mathrm{~m}(p \leq .05)$. No significant differences in linear velocity or angular deviations were found between distances $(p \geq .05)$.

Interestingly, performance between trials could be assessed using the ratio. A straight trajectory has a $\frac{v}{4}$ ratio that tends toward infinity, whereas the worst trajectory has a $\frac{v}{\psi}$ ration that tends toward zero.

Notice that the hypotheses enumerated in the previous mathematical model are valid in this experiment. Subjects who walk on a soccer field have three degrees of freedom, given that his or her movement occurs on the plane and he or she always walks forward and not sideways. Although the hypothesis that linear speed is mainly constant during walking is not actually

Table 2. Subjects' mean (SD) velocity $\left(\mathrm{v}_{\mathrm{m}}\right)$ and angular deviation $\left(\alpha_{\mathrm{m}}\right)$ of the straight-line, straight-circular, and alternate trajectories in a blindfolded walking task as a function of the target distance.

\begin{tabular}{lllll}
\hline & \multicolumn{4}{c}{ Distance (m) } \\
\hline & 30.00 & 41.60 & 57.69 & 80.00 \\
\hline$v_{\mathrm{m}}(\mathrm{m} / \mathrm{s})$ & 1.088645 & 1.092807 & 1.080637 & 1.069234 \\
& $(.150423)$ & $(.152761)$ & $(.164306)$ & $(.130116)$ \\
\hline $\begin{array}{l}\text { Angular } \\
\text { deviation }\left({ }^{\circ}\right)\end{array}$ & 10.88359 & 14.43903 & 15.17768 & 16.53523 \\
& $(7.27021)$ & $(6.23411)$ & $(4.22301)$ & $(7.32321)$ \\
\hline
\end{tabular}

Table 3. Subjects' mean ( \pm SD) velocity $\left(v_{m}\right)$, angular deviation $\left(\alpha_{m}\right)$, angular velocity $\left(\dot{\psi}_{\mathrm{m}}\right)$, and radius $\left(\mathrm{R}_{\mathrm{m}}\right)$ for circular trajectories as a function of the target distance.

\begin{tabular}{|c|c|c|c|c|}
\hline & \multicolumn{4}{|c|}{ Distance (m) } \\
\hline & 30.00 & 41.60 & 57.69 & 80.00 \\
\hline \multirow{2}{*}{$\mathrm{v}_{m}(m / s)$} & 1.130971 & 1.117794 & 1.104549 & 1.034852 \\
\hline & (.140463) & $(.173785)$ & $(.175206)$ & (.120995) \\
\hline \multirow[t]{2}{*}{$\alpha_{m}\left({ }^{\circ}\right)$} & 16.05234 & 16.39701 & 14.64203 & 25.36245 \\
\hline & $(8.47061)$ & $(8.234028)$ & $(6.7311)$ & (9.6339) \\
\hline \multirow[t]{2}{*}{$\dot{\Psi}_{m}(\mathrm{rad} / \mathrm{s})$} & .022411 & .016922 & .015928 & .015392 \\
\hline & (.008613) & $(.006498)$ & (.005049) & $(.005021)$ \\
\hline \multirow[t]{2}{*}{$R_{m}(m)$} & 59.19046 & 71.44876 & 80.67353 & 84.57265 \\
\hline & (28.80093) & (28.27592) & (33.25417) & (25.71603) \\
\hline
\end{tabular}

Table 4. Mean error $\mu$ between the coordinates of the point of the theoretical circular trajectory and corresponding point of the actual trajectory and standard deviation $\sigma$ as a function of the target distance.

\begin{tabular}{ccc}
\hline Target distance $(\mathbf{m})$ & $\boldsymbol{\mu ( m )}$ & $\boldsymbol{\sigma}(\mathbf{m})$ \\
\hline 30.00 & .518 & .259 \\
41.60 & .587 & .348 \\
57.69 & .517 & .232 \\
80.00 & .595 & .299 \\
\hline
\end{tabular}

correct, the mean error between the theoretical and actual trajectories calculated by Equation (4) was $\mu=.554 \mathrm{~m}$, with a standard deviation of $\sigma=.285 \mathrm{~m}$ (see Table 3 ). The GPS uncertainty after post-processing was 1-3 m, and the circular equation is indeed a good model to fit these data. Importantly, the greatest deviances between the theoretical and actual trajectories occurred at the end of the walk when the subjects reduced their velocity when they realized that the trajectory approached the target location. An example of such behavior can be seen in Figure 5. Even with these limitations, one can

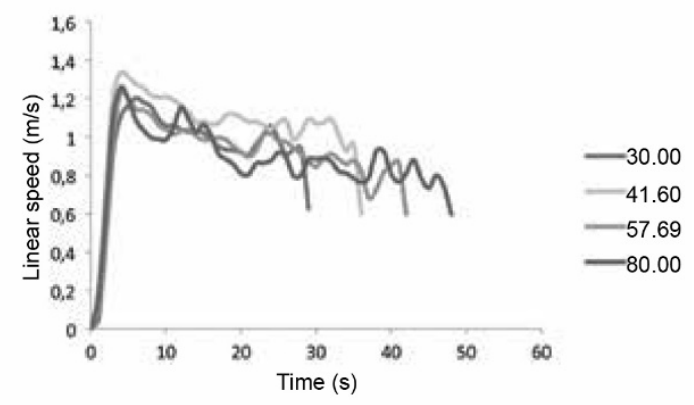

Figure 5. Examples of angular velocity plots and their observed trajectory: (a) circular, (b) straight line, (c) straightcircular, and (d) alternate. 
apply the mathematical model and eventually ascertain that some of the trajectories are approximately circular.

\section{Discussion}

\section{Angular velocity and trajectory patterns}

Although angular velocity was not directly measured, one can apply the mathematical model presented in ANNEX A along with the results of all of the experiments and intuitively predict angular velocity behavior associated with each trajectory pattern. In the discussion that follows, we assume that the subjects have considerable speed control, which was observed throughout all of the trials and is represented in Figure 5 , while their angular orientation system can freely vary as a function of time. This analysis does not seek to precisely determine the angular velocity pattern associated with a specific trajectory, but rather provide for future studies some insights into the expected behavior of angular velocity as a function of time using an intuitive approach. The results are presented in Figure 6 . Likewise, with linear velocity, one can argue that the angular velocity during the beginning and end of the trajectory can likely vary greatly, and this analysis does not provide any insights into the actual angular velocity behavior. However, we should consider that these stages of the trajectory are relatively brief when considering the entire movement.

In this paper we used mathematical models to account for and quantify the observed trajectory patterns during a blindfolded walking task in a large real environment. Although this model contains specific abstractions that may be a departure from actual walking behavior, it captures relevant aspects of veering behavior.

The results demonstrated that the circular trajectory was the most frequent pattern among all of the subjects and over all of the target distances. This finding corroborates the results of previous studies (Bestaven et al., 2012; Souman et al., 2009), even under different experimental conditions.

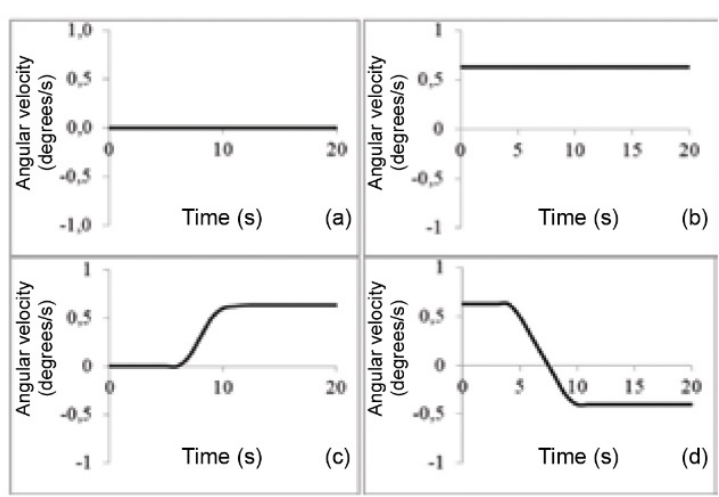

Figure 6. Speed and walking trajectories. One representative subject's performance shows linear velocity for one trial for each target distance during blind navigation.
Consequently, our results indicate that maintaining straight-ahead walking in the absence of visual and auditory information is almost impossible and that all subjects deviated toward one side or the other, unintentionally tending to walk in circles. Notice that the participants rarely corrected their trajectories during the tasks once they began. The absence of reliable sensory signals did not encourage any correction of the deviations by the subjects.

Both short and long distances require the same control of spatial orientation during navigational tasks and locomotion along the trajectory. However, if we compare individual performance when walking a circular trajectory as a function of different target distances $(30.00,41.60,57.69$, and $80.00 \mathrm{~m})$, better performance (i.e., lower angular velocity) was related to longer distances.

Given that the majority of the trajectories tended toward the left, we looked at the pattern of lateral preference as one possible reason for the individual tendency to deviate toward one side while walking. Few studies have reported that handedness or footedness is related to veering direction (Day \& Goins, 1999; Scharine \& McBeath, 2002). People who are rightfooted tend to deviate to the left side, and people who are left-footed tend to deviate to the right. Nonetheless, our results cannot support this idea when considering that our sample consisted of only right-handed individuals. Investigations of a larger group of subjects who are lefthanded and right-handed may help resolve this issue.

Because we cannot conclude that our results indicate that lateral preferences is a possible cause of this circling behavior, we should look for other possible factors, including lower to higher levels of proprioceptive and vestibular asymmetries.

A very famous theorem from geometry, Euler's rotation theorem, can provide some insights into the existence and origin of this circling behavior in the absence of vision. It states that, in a three-dimensional space, any rotation with a fixed point or a composition of rotations is identical to a singular movement around an axis. Considering that the subject walks on a flat surface, he or she can only rotate around an axis that goes approximately from his or her head to his or her feet. The rotation axis can be considered the spine, and this movement can be described by an angle. The mathematical model presented in this study considers this a viable hypothesis.

Given that any member connected to the spine can potentially have some influence on this rotational movement, slight changes in the natural head position may induce a deviation by modifying the center of locomotor activity at the spinal level (Toussaint, Do, \& Fagard, 2008).

To maintain equilibrium during locomotion, normal subjects try to stabilize their head (Pozzo, Berthoz, \& Lefort, 1990). Apparently, vision facilitates this equilibrium. Head stability most likely induces not only 
gaze stabilization but also a reference for organizing the movement of other segments (Pozzo, Levik, \& Berthoz, 1995). When vision is excluded, the vestibular system and proprioceptive information from the neck region act together to relate the trunk to space (Karnath, Sievering, \& Fetter, 1994).

Furthermore, proprioceptive input from the neck muscles and vestibular signals play an important role in building up and updating spatial representations, including the position, orientation, and movement of the body (Bottini et al., 2001). Evidence of the role of these sensory afferents comes from the specific effects of lateralized or direction-specific stimulation of peripheral sensory systems such as caloric vestibular stimulation and posterior neck muscle mechanical vibration. This stimulation can induce a distortion of egocentric coordinates, causing, for instance, unintentional deviation of the trajectory during walking (Bove, Diverio, Pozzo, \& Schieppati, 2001; Fitzpatrick, Wardman, \& Taylor, 1999) and body rotation during stepping-in-place in normal subjects (Bove, Courtine, \& Schieppati, 2002).

Therefore, the imbalance of multiple inputs that converge on the central networks that are responsible for the representation of the sagittal mid-plane would create the conditions for circling behavior (Bove et al., 2002). Although our results do not support a direct causal link between head rotation on the trunk and circling behavior, future studies should certainly elaborate on these correlations.

\section{Acknowledgements}

This work was supported by CAPES. The authors are grateful to Centro Universitário Moura Lacerda for providing the space for this study, engineer Jonas Ribeiro (Santiago e Cintra- GeoTecnologias) for help using the GPS receiver, and Maria Amélia Cesari (Universidade Federal de São João Del-Rei) for useful discussions.

\section{References}

Bestaven, E., Guillaud, E., \& Cazalets, J. R. (2012). Is "circling" behavior in humans related to postural asymmetry? PloS One, 7(9), e43861.

Bottini, G., Karnath, H. O., Vallar, G., Sterzi, R., Frith, C. D., Frackowiak, R. S., \& Paulesu, E. (2001). Cerebral representations for egocentric space: functional-anatomical evidence from caloric vestibular stimulation and neck vibration. Brain, 124(6), 11821196.

Bove, M., Courtine, G., \& Schieppati, M. (2002). Neck muscle vibration and spatial orientation during stepping in place in humans. Journal of Neurophysiology, 88(5), 2232-2241.
Bove, M., Diverio, M., Pozzo, T., \& Schieppati, M. (2001). Neck muscle vibration disrupts steering of locomotion. Journal of Applied Physiology, 91(2), 581-588.

Brys, L. M. (2005). Cálculos Geodésicos - Aplicações on-line. Universidade Federal do Rio Grande do Sul, Instituto de Geociências. Retrieved from http://www.ufrgs.br/engcart/Teste/ inicial.htm; accessed May 1, 2014

Day, H. D., \& Goins, V. J. (1997). Veering in women: inconsistency of forward and backward progression. Perceptual and Motor Skills, 85(2), 587-596.

Fitzpatrick, R. C., Wardman, D. L., \& Taylor, J. L. (1999). Effects of galvanic vestibular stimulation during human walking. Journal of Physiology, 517(3), 931-939.

Guldberg, F. O. (1897) Die Cirkularbewe ung als herische Grundbewegung ihre Ursache. Phinomenahtiit und Bedeutung. eitscfri l fur Biologie, 35, 419-458.

Howard, I. P., \& Templeton, W. B. (1966). Human spatial orientation. London: Wiley.

Kallie, C. S., Schrater, P. R., \& Legge, G. E. (2007). Variability in stepping direction explains the veering behavior of blind walkers. Journal of Experimental Psychology: Human Perception and Performance, 33(1), 183-200.

Karnath, H. O., Sievering, D., \& Fetter, M. (1994). The interactive contribution of neck muscle proprioception and vestibular stimulation to subjective "straight ahead" orientation in man. Experimental Brain Research, 101(1), 140-146.

Mach, E. (1959). The analysis of sensations, and the relation of the physical to the psychical. New York: Dover.

Millar, S. (1999). Veering re-visited: noise and posture cues in walking without sight. Perception, 28, 765-780.

Mohr, C., \& Lievesley, A. (2007). Test-retest stability of an experimental measure of human turning behaviour in right-handers, mixed-handers, and left-handers. Laterality, 12(2), 172-190.

Mohr, C., Brugger, P., Bracha, H. S., Landis, T., \& Viaud-Delmon, I. (2004). Human side preferences in three different whole-body movement tasks. Behavioural Brain Research, 151(1), 321-326.

Mohr, C., Landis, T., Bracha, H. S., Fathi, M., \& Brugger, P. (2003) Human locomotion: levodopa keeps you straight. Neuroscience Letters, 339(2), 115-118.

Oldfield, R. C. (1971). The assessment and analysis of handedness: the Edinburgh inventory. Neuropsychologia, 9(1), 97-113.

Porac, C., \& Coren, S. (1981). Lateral preferences and human behavior. New York: Springer-Verlag.

Pozzo, T., Berthoz, A., \& Lefort, L. (1990). Head stabilization during various locomotor tasks in humans: I. Normal subjects. Experimental Brain Research, 82(1), 97-106

Pozzo, T., Levik, Y., \& Berthoz, A. (1995). Head and trunk movements in the frontal plane during complex dynamic equilibrium tasks in humans. Experimental Brain Research, 106(2), 327-338.

Previc, F. H., \& Saucedo, J. C. (1992). The relationship between turning behavior and motoric dominance in humans. Perceptual and Motor Skills, 75, 935-944.

Schaeffer, A. A. (1928). Spiral movement in man. Journal of Morphology, 45(1), 293-398.

Scharine, A. A., \& McBeath, M. K. (2002). Right-handers and Americans favor turning to the right. Human Factors, 44(2), 248-256.

Souman, J. L., Frissen, I., Sreenivasa, M. N., \& Ernst, M. O. (2009). Walking straight into circles. Current Biology, 19(18), 1538-1542. Toussaint, Y., Do, M. C., \& Fagard, J. (2008). What are the factors responsible for the deviation in stepping on the spot? Neuroscience Letters, 435(1), 60-64.

Why lost people walk in circles. (1893, February 18). Scientific American. 


\section{Appendix: Mathematical model for the circular trajectories.}

One can prove that, when moving with constant speed $v$ and constant angular speed, a body walks in a circular trajectory. Consider that a body has three degrees of freedom and can move according to two spatial coordinates and rotate over its vertical axis. In Cartesian coordinates, considering that the body starts from the origin, its velocity is expressed by (A.1).

$$
\vec{v}=(v \sin \psi t, v \cos \psi t) \text { (A. } 1)
$$

The trajectory $s(t)$ is calculated by integrating the velocity over time (A.2).
Thus,

$$
s(t)=\int \vec{v} d t(A .2)
$$

$$
s(t)=\left(\frac{v}{\dot{\psi}}-\frac{v}{\dot{\psi}} \cos \dot{\psi} t, \frac{v}{\dot{\psi}} \sin \dot{\psi} t\right)
$$

The above equation (A.3) represents a circumference of radius $R=\frac{v}{\psi}$ and center in $\left(\frac{v}{0}, 0\right)$. Indeed, this can be proven using the definition of circumference in terms of its parametric equation (A.4).

$$
\left(x-\frac{v}{\dot{\psi}}\right)^{2}+(y)^{2}=R^{2}(\text { A. } 4)
$$




\title{
ANEXOS
}

\section{ANEXO A - Aprovação do Comitê de Ética da FFCLRP-USP}

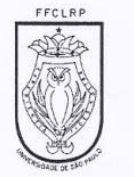

Universidade de São Paulo

Faculdade de Filosofia, Ciências e Letras de Ribeirão Preto

"Campus" de Ribeirão Preto

Of.CEtP/FFCLRP-USP/103/-jsI

Ribeirão Preto, 29 de agosto de 2011.

Prezada Pesquisadora,

Comunicamos a V. Sa. que o trabalho intitulado "PeRcursos DE DISTÂNCIAS E ORIENTAÇŌES ESPACIAIS AO CAMINHAR COM VISÄO OCLUIDA EM CAMPO ABERTO" foi reanalisado pelo Comitê de Ética em Pesquisa da FFCLRP-USP, em sua 99a Reunião, realizada em 25.08.11, e enquadrado na categoria: APROVADO, de acordo com o Processo CEP-FFCLRP n 578/2011 - 2011.1.1288.59.0.

Atenciosamente,

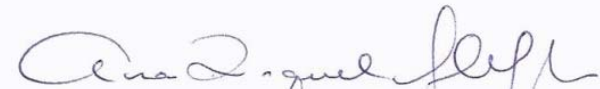

Prof. ${ }^{a}$ Dr. ${ }^{\text {a }}$ ANA RAQUEL LUCATO CIANFLONE

Coordenadora

\author{
À Senhora \\ Patrícia Consolo \\ Doutoranda do Programa de'Pós-Graduação em Psicobiologia da FFCLRP - USP \\ Com cópia para o orientador: \\ Prof. Dr. Sérgio Sheiji Fukusima \\ Docente do Departamento de Psicologia da FFCLRP - USP


ANEXO B - Inventário de Dominância Lateral de Edimburgo

Nome:

Data de Nascimento:

Sexo:

Por favor, indique sua preferência no uso das mãos nas seguintes atividades colocando o sinal + na coluna apropriada. Onde a preferência é tão forte que você nunca usaria a outra mão a menos que fosse forçado a usá-la, coloque ++ . Se em algum caso a mão utilizada é realmente indiferente, coloque + em ambas as colunas.

Algumas das atividades requerem as duas mãos. Nestes casos a parte da tarefa, ou objeto, para a qual a preferência manual é solicitada é indicada entre parênteses.

Por favor, tente responder todas as questões, e somente deixe em branco se você não tiver qualquer experiência com o objeto ou tarefa.

Você já teve alguma tendência a ser canhoto? Sim Não

\begin{tabular}{|l|l|l|l|}
\hline \multicolumn{2}{|l|}{} & Esquerda & Direita \\
\hline 1 & Escrever & & \\
\hline 2 & Desenhar & & \\
\hline 3 & Arremessar & & \\
\hline 4 & Uso de tesouras & & \\
\hline 5 & Escovar os dentes & & \\
\hline 6 & Uso de faca (sem garfo) & & \\
\hline 7 & Uso de colher & & \\
\hline 8 & Uso de vassoura (mão superior) & & \\
\hline 9 & Acender um fósforo (mão do fósforo) & & \\
\hline 10 & Abrir uma caixa (mão da tampa) & & \\
\hline 11 & Uso de pente & & \\
\hline 12 & Uso de martelo & & \\
\hline 13 & Uso de chave de fenda & & \\
\hline 14 & Uso de faca (com garfo) & & \\
\hline 15 & Distribuir cartas (carta sendo distribuída) & \\
\hline 16 & $\begin{array}{l}\text { Colocar linha no buraco da agulha (linha ou agulha de } \\
\text { acordo com qual delas é movimentada) }\end{array}$ & & \\
\hline 17 & Qual olho você usa quando está usando apenas um? & & \\
\hline
\end{tabular}


ANEXO C - Questionário de preferência lateral podal

Nome:

Data de Nascimento:

Sexo:

Instruções: Por favor, indique a sua preferência no uso dos pés nas atividades abaixo, circulando a resposta adequada. Atenção, não circule imediatamente uma resposta para as perguntas, mas imagine-se na realização de cada atividade, e somente depois marque a resposta apropriada. Se necessário, faça uma mímica da atividade. Tente responder todas as questões, e somente deixe em branco se você não tiver qualquer experiência com o objeto ou a tarefa.

\begin{tabular}{|l|c|c|c|}
\hline Pé & Esquerdo & Direito & Qualquer um deles \\
\hline $\begin{array}{l}\text { 1. Qual dos pés você } \\
\text { usa para saltar com } \\
\text { um pé só? }\end{array}$ & 0 & 1 & 2 \\
\hline $\begin{array}{l}\text { 2. Qual dos pés você } \\
\text { usa para chutar uma } \\
\text { bola? }\end{array}$ & 0 & 1 & 2 \\
\hline $\begin{array}{l}\text { 3. Qual dos pés você } \\
\text { usa para fazer um } \\
\text { desenho com o pé no } \\
\text { chão? }\end{array}$ & 0 & 1 & 2 \\
\hline $\begin{array}{l}\text { 4. Qual dos pés você } \\
\text { usa para subir para } \\
\text { um plano superior? }\end{array}$ & 0 & 1 & 2 \\
\hline $\begin{array}{l}\text { 5. Qual dos pés você } \\
\text { usa para pegar uma } \\
\text { pedrinha com os } \\
\text { dedos? }\end{array}$ & 0 & & 2 \\
\hline
\end{tabular}

